\title{
Advances in understanding and parameterization of small-scale physical processes in the marine Arctic climate system: a review
}

\author{
T. Vihma ${ }^{1,2}$, R. Pirazzini ${ }^{1}$, I. Fer ${ }^{3}$, I. A. Renfrew ${ }^{4}$, J. Sedlar ${ }^{5,6}$, M. Tjernström ${ }^{5,6}$, C. Lüpkes ${ }^{7}$, T. Nygård ${ }^{1}$, D. Notz ${ }^{8}$,

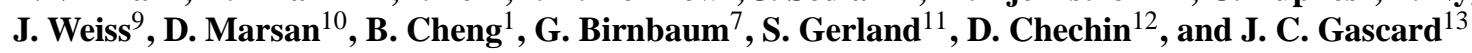 \\ ${ }^{1}$ Finnish Meteorological Institute, Helsinki, Finland \\ ${ }^{2}$ The University Centre in Svalbard, Longyearbyen, Norway \\ ${ }^{3}$ University of Bergen, Bergen, Norway \\ ${ }^{4}$ University of East Anglia, Norwich, UK \\ ${ }^{5}$ Bert Bolin Center for Climate Research, Stockholm, Sweden \\ ${ }^{6}$ Department of Meteorology, Stockholm University, Stockholm, Sweden \\ ${ }^{7}$ Alfred-Wegener-Institut Helmholtz-Zentrum für Polar- und Meeresforschung, Bremerhaven, Germany \\ ${ }^{8}$ Max Planck Institute for Meteorology, Hamburg, Germany \\ ${ }^{9}$ LGGE, Université de Grenoble, CNRS, Grenoble, France \\ ${ }^{10}$ ISTerre, Université de Savoie, CNRS, Le Bourget-du-Lac, France \\ ${ }^{11}$ Norwegian Polar Institute, Troms $\emptyset$, Norway \\ ${ }^{12}$ A. M. Obukhov Institute of Atmospheric Physics, Russian Academy of Sciences, Moscow, Russia \\ ${ }^{13}$ Université Pierre et Marie Curie, Paris, France
}

Correspondence to: T. Vihma (timo.vihma@fmi.fi)

Received: 13 November 2013 - Published in Atmos. Chem. Phys. Discuss.: 13 December 2013

Revised: 16 July 2014 - Accepted: 21 July 2014 - Published: 10 September 2014

\begin{abstract}
The Arctic climate system includes numerous highly interactive small-scale physical processes in the atmosphere, sea ice, and ocean. During and since the International Polar Year 2007-2009, significant advances have been made in understanding these processes. Here, these recent advances are reviewed, synthesized, and discussed. In atmospheric physics, the primary advances have been in cloud physics, radiative transfer, mesoscale cyclones, coastal, and fjordic processes as well as in boundary layer processes and surface fluxes. In sea ice and its snow cover, advances have been made in understanding of the surface albedo and its relationships with snow properties, the internal structure of sea ice, the heat and salt transfer in ice, the formation of superimposed ice and snow ice, and the small-scale dynamics of sea ice. For the ocean, significant advances have been related to exchange processes at the ice-ocean interface, diapycnal mixing, double-diffusive convection, tidal currents and diurnal resonance. Despite this recent progress, some of these small-scale physical processes are still not sufficiently understood: these include wave-turbulence interactions in the
\end{abstract}

atmosphere and ocean, the exchange of heat and salt at the ice-ocean interface, and the mechanical weakening of sea ice. Many other processes are reasonably well understood as stand-alone processes but the challenge is to understand their interactions with and impacts and feedbacks on other processes. Uncertainty in the parameterization of small-scale processes continues to be among the greatest challenges facing climate modelling, particularly in high latitudes. Further improvements in parameterization require new year-round field campaigns on the Arctic sea ice, closely combined with satellite remote sensing studies and numerical model experiments.

\section{Introduction}

Small-scale physical processes play an important role in the Arctic atmosphere-sea-ice-ocean system, in particular at the interfaces and within boundary layers. Here, we define small-scale processes as such processes that need to be 
parameterized in climate or meteorological/oceanographic forecast models, with their current horizontal resolutions typically of the order of 1 to $100 \mathrm{~km}$. These processes include (a) turbulent mixing in the atmosphere and ocean, (b) cloud and aerosol physics, (c) radiative transfer in the atmosphere, snow, ice, and ocean, (d) exchange of momentum, heat, and matter at air-sea, air-snow, air-ice, snow-ice, and ice-water interfaces, (e) small-scale mechanics in sea ice, (f) sea ice growth and melt, (g) formation of snow ice, superimposed ice, and frazil ice, and (h) topographic effects on the atmosphere and ocean in coastal and continental shelf regions.

Better understanding and modelling of the Arctic sea ice decline requires comprehensive, synthetic knowledge of small-scale processes in the atmosphere, snow, ice, and ocean. Such knowledge and related modelling capabilities are also prerequisites for a better understanding of the Arctic amplification of climate warming (Serreze and Barry, 2011), for which several processes have been proposed. Among them, the snow/ice albedo feedback has received most attention (e.g. Flanner et al., 2011; Hudson, 2011); in addition to its direct effect, it enhances the Arctic amplification by strengthening the water vapour and cloud radiative feedbacks (Graversen and Wang, 2009). Further, feedbacks related to the shape of the temperature profile (Pithan and Mauritsen, 2014), the small heat capacity of the shallow stably stratified boundary layer (Esau and Zilitinkevich, 2010) and increased autumn-winter energy loss from the ocean (Overland et al., 2008; Screen and Simmonds, 2010a) tend to amplify Arctic warming as do the effects of aerosols. It has been suggested that black carbon aerosols reduce the surface albedo (e.g. Hadley and Kirchstetter, 2012) and warm the atmosphere (e.g. Quinn et al., 2008), while other aerosols affect the optical properties of the clouds and precipitation processes (e.g. Fridlind et al., 2012; Solomon et al., 2011). In addition to the above-mentioned small-scale processes, an increase in the advection of heat and moisture from lower latitudes also contributes to the Arctic amplification (Graversen et al., 2008; Kapsch et al., 2013). The relative importance of the above-mentioned processes in the Arctic is not well understood.

Small-scale processes are most active and important in a layer that starts from the base of the ocean pycnocline and extends up to the top of the boundary layer capping inversion in the atmosphere, as schematically illustrated in Fig. 1. This layer extends down $300 \mathrm{~m}$ into the ocean (Dmitrenko et al., 2008) and typically up 100-1000 $\mathrm{m}$ in the atmosphere (Tjernström and Graversen, 2009), but seasonal and regional variations are large. This layer includes large vertical gradients in temperature, salinity, air humidity, and wind/current speed; these gradients are generated by a complex interaction of large-scale circulation and small-scale processes. The large gradients are the driving force for turbulent and conductive exchange processes in a vertical direction. Further, the layer bounded by the ocean pycnocline and air temperature inversion includes major variations in radiative transfer.

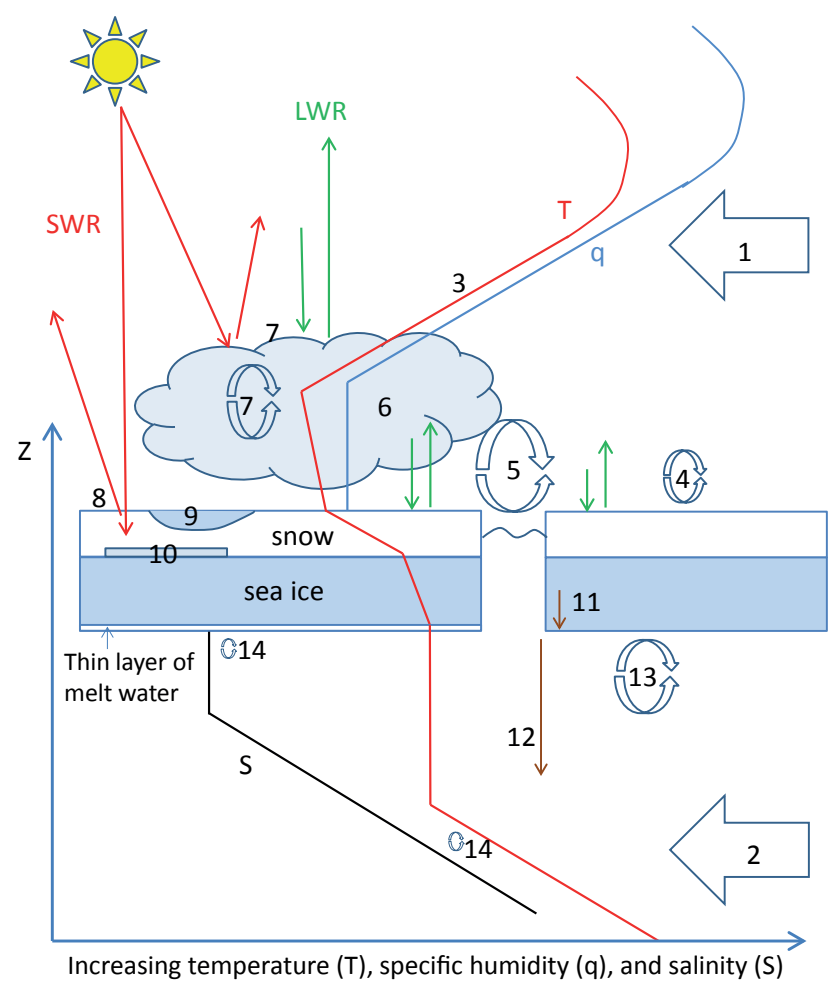

Figure 1. Simplified presentation of physical processes and vertical profiles of temperature $(T)$, air humidity $(q)$, and ocean salinity (S) in the marine Arctic climate system. In reality, the shape of the profiles varies in time and space. The numbers indicate the following processes: 1 - atmospheric advection of heat and moisture to the Arctic; 2 - oceanic advection of heat and salt to the Arctic; 3 generation of temperature and humidity inversions; 4 - turbulence in stable boundary layer; 5 - convection over leads and polynyas; 6 - cloud microphysics; 7 - cloud-radiation-turbulence interactions; 8 - reflection and penetration of solar radiation in snow/ice; 9 - surface melt and pond formation; 10 - formation of superimposed ice and snow ice; 11 - gravity drainage of salt in sea ice; 12 - brine formation; 13 - turbulent exchange of momentum, heat and salt during ice growth; and 14 - double-diffusive convection. More detailed illustration of small-scale processes is given in Figs. 2-12.

Compared to a dry atmosphere, the ocean, sea ice, snow, and clouds have a much higher long-wave emissivity and a much lower shortwave transmissivity (Perovich et al., 2007a, b).

Over the central Arctic Ocean, small-scale processes are somewhat more tractable than near the coasts and continental shelves. In the latter regions, processes have a more profound three-dimensional structure, including orographic influences on the air flow (Renfrew et al., 2008) and, likewise, influences of the bottom topography and river discharge on local stratification and circulation in fjords and coastal waters (Cottier et al., 2007). In all regions, small-scale processes (e.g. radiative transfer, cloud physics, and turbulent mixing) naturally include three-dimensional structures, but their net effect is mostly related to fluxes in the vertical direction; 
except for sea ice dynamics where many important smallscale processes act horizontally.

Processes on different scales are strongly interactive. On one hand, large-scale circulation and related lateral advection of heat and water vapour/freshwater in the atmosphere (Graversen et al., 2011; Sedlar and Devasthale, 2012; Kapsch et al., 2013) and ocean (Mauldin et al., 2010; Lique and Steele, 2012) strongly affect the boundary conditions for small-scale processes in the Arctic. On the other hand, small-scale processes modify the large-scale circulation via a number of interactive processes. For example, frictional convergence in the atmospheric boundary layer (ABL; see Table A1 for acronyms) affects the evolution of cyclones while brine release from sea ice affects deep convection and vertical stratification in the ocean and, hence, the global thermohaline circulation. From the point of view of climate and operational modelling, the wide spatial and temporal range of important processes is a major restriction. The important scales range from micrometres (e.g. cloud physics) to thousands of kilometres (planetary waves). As models cannot resolve all scales of motion, many fundamentally important processes need to be parameterized using simplified physics and empirical relationships to resolved grid-scale variables. Variability on the "mesoscale" (approximately 5-500 km in scale) is at the boundary of what is resolved and what must be parameterized in global numerical weather prediction and climate models. In the Arctic, this includes polar mesoscale cyclones, fronts, and orographic flows while there are also a wide range of oceanographic processes at these scales.

In sub-grid-scale parameterizations, the small-scale processes are presented as functions of those variables that can be resolved by the model grid. Sub-grid-scale parameterization is one of the issues in climate models that are most prone to uncertainties and errors. This is for several reasons: (a) processes are often so complicated that it is not possible to accurately describe them solely on the basis of resolved variables, (b) models have errors in the resolved variables, (c) the resolved variables represent a large volume (grid cell) but there are large variations in the sub-grid-scale processes inside the grid cell, (d) the physics of small-scale processes is often not sufficiently well understood, (e) parameterizations require experimental data to constrain closure assumptions and the amount of such data may not be sufficient (in volume or in range), and (f) parameterizations are often tuned to make the overall performance of models better, according to Steeneveld et al. (2010), even when this makes the description of the particular small-scale process worse. The latter is a source of compensating errors and further inhibits model development, since improvements in one particular process via tuning often results in degradation in the overall model performance.

Present-day climate and numerical weather prediction (NWP) models and atmospheric reanalyses include large errors in small-scale processes. For example, in a validation of six regional climate models against year-round observa- tions at the drifting ice station of the Surface Heat Budget of the Arctic Ocean (SHEBA), Tjernström et al. (2005) observed that the turbulent heat fluxes were mostly unreliable with insignificant correlations with observed fluxes and annual accumulated values an order of magnitude larger than observed. The downward shortwave and long-wave radiation in the six models were systematically biased negative. Tjernström et al. (2008) showed that the radiation errors were strongly related to errors in cloud occurrence, heights, and properties (such as water and ice content and their vertical distribution). In an evaluation of the latest atmospheric reanalyses against independent tethersonde sounding data from the central Arctic sea ice, Jakobson et al. (2012) showed that all five reanalyses included in the evaluation had large systematic errors. Even the best one (ERA-Interim of the ECMWF, 2012; Dee et al., 2011) suffered from a warm bias of up to $2{ }^{\circ} \mathrm{C}$ in the lowermost $400 \mathrm{~m}$ layer and a significant moist bias throughout the lowermost $900 \mathrm{~m}$. The observed biases in temperature, humidity, and wind speed were in many cases comparable to or even larger than the climatological trends during the latest decades. This represents a major challenge for investigations of the recent Arctic warming, which are often based on atmospheric reanalyses. If the errors are solely systematic, then reanalyses may still yield useful information on trends, but for many variables and regions, we lack the observations to determine if the errors are systematic or not.

The above-mentioned evaluation studies have addressed reanalyses and climate models, but little is known about the quality of operational weather forecasts in the central Arctic. Nordeng et al. (2007) reviewed the challenges in the field, and Jung and Leutbecher (2007) evaluated the ECMWF forecasting system, but quantitative comparisons between operational forecasts and observations taken at ice stations, research vessels, and aircraft in the central Arctic have been very limited (Birch et al., 2009). More studies have been carried out for the Arctic marginal seas and coastal areas (Hines and Bromwich, 2008, Lammert et al., 2010; Renfrew et al., 2009 b). Forecasting of polar lows and other mesoscale cyclones is discussed in Sect. 2.3.2.

The most essential sources of information available from the Arctic Ocean are in situ field observations, ice/ship-based or satellite remote sensing observations, operational analyses from NWP models, reanalyses, and results from model experiments dedicated to studies of small-scale processes. However, all these sources of information include uncertainties. Observations and data analyses focusing particularly on the Arctic are essential for an improved representation of processes within the Arctic, since the understanding obtained from lower latitudes may often not be valid for the Arctic. It should be noted that both atmospheric and ocean models apply parameterizations that are developed mostly on the basis of observations from low- and mid-latitudes. For example, stable stratification in the Arctic winter ABL is often long-lived, in contrast to the nocturnal stable ABL at lower 
latitudes; the latter is separated from the free atmosphere by the residual layer (Zilitinkevich and Esau, 2005). This makes the Arctic ABL more liable to the effects of propagating internal gravity waves. Also, the common presence of mixedphase clouds in the Arctic marks a drastic difference from lower latitudes; observations of liquid water present in clouds at temperatures down to $-34^{\circ} \mathrm{C}$ during SHEBA (Beesley et al., 2000; Intrieri et al., 2002) demonstrated the need to develop better parameterization schemes for the ice and liquid water fractions (Gorodetskaya et al., 2008). In the past, forecast centres running global climate or NWP models have not paid enough attention to problems in physical parameterizations in the Arctic, but the situation is improving with the Arctic coming more into focus, driven by the worldwide attention to Arctic climate change and the increasing need for operational weather and marine forecasting services in the Arctic.

During the International Polar Year 2007-2009 (IPY), a large effort was made for new field observations, data analyses, and model experiments addressing small-scale processes in the Arctic atmosphere-sea-ice-ocean system. One of the major efforts was the European project "Developing Arctic Modeling and Observing Capabilities for Long-term Environmental Studies" (DAMOCLES, in 2005-2009), for which this special issue is dedicated. The project included an extensive amount of in situ observations in the Arctic, supported by remote sensing, data analyses, and model experiments. During DAMOCLES, the drifting ice station Tara was a platform for oceanographic, sea ice, and meteorological research (Gascard et al., 2008). In addition, oceanographic and sea ice observations were carried out by several ships, meteorological research was conducted on ships, including short drift stations, by research aircraft, and at coastal sites. Furthermore, drifting buoys, underwater gliders, and moorings collected extensive sets of oceanographic, sea ice, and meteorological observations. A DAMOCLES synthesis paper on the large-scale state and change of the Arctic climate system is presented in Döscher et al. (2014), while our focus is on small-scale processes. Small-scale physical processes in the Arctic Ocean were reviewed by Padman (1995), and other reviews on certain aspects on small-scale processes in high latitudes have been published more recently. Bourassa et al. (2013) focused on radiative and turbulent surface fluxes and remote sensing observations, and Heygster et al. (2012) addressed the DAMOCLES advances in sea ice remote sensing, which is related to micro-scale processes in snow and ice. Hunke et al. (2011) and Notz (2012) focused on sea ice physics and modelling, and Meier et al. (2014) reviewed the recent changes in Arctic sea ice and their impacts on biology and human activity. Rudels et al. (2013) reviewed the ocean circulation and water mass properties in the Eurasian Basin of the Arctic Ocean.

In this review we focus on the advances in research on small-scale processes in the Arctic since the start of the IPY, addressing physical processes only and defining small-scale processes as those that need to be parameterized in climate models. Due to the above-mentioned recent papers, we will not address issues related to remote sensing of the ocean surface and sea ice. This review is organized in separate sections for small-scale processes in the atmosphere (Sect. 2), sea ice and snow (Sect. 3), and ocean (Sect. 4), with a crossdisciplinary synthesis, discussion, conclusions, and outlook in Sects. 5 and 6. A reader not interested in specifics of all fields can skip some of Sects. 2, 3, or 4.

\section{Atmosphere}

\subsection{Vertical structure and boundary layer processes}

Many of the small-scale processes in the Arctic atmosphere closely interact with the vertical structure of the atmosphere, modifying it and being constrained by it. The vertical structure of the Arctic atmosphere is characterized by an ABL capped by temperature and specific humidity inversions (hereafter "humidity inversions"), The inversions are generated by the combined effects of the negative radiation balance of the sea ice surface, the direct radiative cooling of the air, and the horizontal advection from lower latitudes (Fig. 1). The temperature inversion layer has a strong stable stratification, whereas the ABL stratification is typically stable or near-neutral; the latter stage is most often due to wind shear but, in conditions of large downward radiation, also due to surface heating. Above the ABL, mixed layers can also occur inside and below clouds (Sect. 2.2).

\subsubsection{Temperature and humidity inversions}

In the vertical, temperature and humidity inversion layers are considered to be small-scale features although their spatial and temporal coverage can be extensive. Before the IPY, the knowledge of temperature inversion statistics over the Arctic Ocean was mostly based on radiosonde sounding data from coastal stations and the Russian drifting stations whose tracks were mostly in the sector of $120-240^{\circ} \mathrm{E}$. The main findings were that surface-based inversions prevail during winter, extending to a height of typically $1200 \mathrm{~m}$, with a typical temperature increase of 10-12 K (Kahl, 1990; Serreze et al., 1992). More recent ship and aircraft data show that in winter and early spring, especially during low temperatures, strong surface-based inversions exist also in the Atlantic sector of the Arctic Ocean (Lüpkes et al., 2012b). In summer, a slightly stable or near-neutral ABL prevails over sea ice with a capping inversion of variable depth. Tjernström et al. (2012) analysed soundings from four summer expeditions in the central Arctic, including SHEBA, and found a very persistent picture of near-neutral boundary layer conditions with the layer depths ranging from $\sim 200$ to $\sim 400 \mathrm{~m}$. Tjernström and Graversen (2009) analysed all the soundings from SHEBA and concluded that virtually all temperature inversions fall into either surface-based inversions or elevated 
inversions capping a near-neutral ABL, with no intermediary state. In winter, shifts between the two states are rapid, presumably depending on the presence of stratocumulus clouds, in which radiative processes and in-cloud turbulent dynamics together cause the shift of the inversion base from the surface to the air (Tjernström and Graversen, 2009). There is also a pronounced annual cycle; in SHEBA, data surfacebased inversions were most common in winter and autumn, accounting for roughly $50 \%$ of the cases whereas in summer practically all inversions were elevated ones on top of a near-neutral ABL. Since SHEBA, however, the occurrence of surface-based inversions in autumn has most probably decreased due to the sea ice decline.

Using the Atmospheric Infrared Sounder data, Devasthale et al. (2010) estimated that the area-averaged $\left(70\right.$ to $\left.90^{\circ} \mathrm{N}\right)$ clear-sky temperature inversion frequency is $70-90 \%$ for summer and approximately $90 \%$ for winter. Raddatz et al. (2011) found similar temperature inversion frequencies for a Canadian polynya region, whereas Tjernström and Graversen (2009) reported, based on SHEBA, that inversions, either surface-based or elevated, are practically always present in the central Arctic. The spatial distribution of temperature inversions is inhomogeneous and strongly controlled by the surface type, the prevailing large-scale circulation conditions and by coastal topography (Pavelsky et al., 2011; Wetzel and Brummer, 2011; Kilpeläinen et al., 2012).

The strongest temperature inversions are most often found in the lowermost kilometre whereas the subsequent weaker inversions are nearly randomly distributed in the lowest $3 \mathrm{~km}$ (Tjernström and Graversen, 2009). The frequency, depth, and strength of temperature inversions have been found to correlate positively with each other, both spatially and temporally, and correlate negatively with surface temperature (Devasthale et al., 2010; Zhang et al., 2011). However, the negative correlation between the inversion strength and surface temperature is noticeably weaker in summer (Fig. 2), presumably due to a different formation mechanism: the summer inversion formation is probably dominated by warm air advection from lower latitudes while in winter the inversions are often generated due to radiation loss at the surface (Devasthale et al., 2010). Vihma et al. (2011) reported that temperature inversions on the coast of Svalbard are strongly affected by the synoptic-scale weather conditions such as $850 \mathrm{hPa}$ geopotential, temperature, and humidity. In addition, during winter temperature inversion strength over the ocean has a negative correlation with sea ice concentration (Pavelsky et al., 2011).

A particular feature in the Arctic atmosphere that rarely, if ever, occurs at lower latitudes is that specific humidity very often increases across the ABL capping inversion, even for cases where the relative humidity in fact drops in the vertical (Tjernström et al., 2004). Importantly, this causes the entrainment of free troposphere air into the ABL to be a source of moisture, rather than a sink which is the case practically everywhere else on Earth. This contributes to the very moist
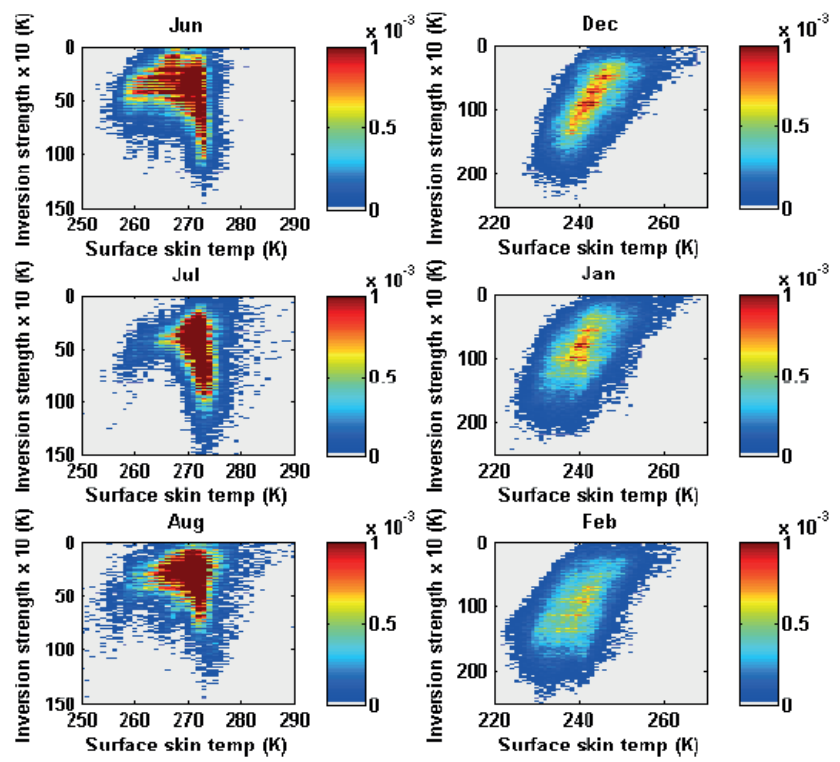

Figure 2. Histograms of inversion strength and surface temperature for summer (left column) and winter (right column) months in the Arctic, based on Atmospheric Infrared Sounder data. Note that the $x$ and $y$ axes are different for summer and winter months and inversion strength is multiplied by 10 . Each temperature-temperature bin is normalized by the total number of observations in the entire histogram. Reproduced with permission from Devasthale et al. (2010).

conditions prevailing in the Arctic ABL. The frequency of specific humidity inversions has been found to be more than $80 \%$ throughout the year in the coastal Arctic, excluding the slightly lower summer frequencies on the Russian coast (Nygård et al., 2014). Vihma et al. (2011), for example, found humidity inversions to be present in all their tethersonde profiles taken in spring on the coast of Svalbard. Although summertime humidity inversions are slightly less frequent, they are stronger than in winter due to higher summer temperatures (Devasthale et al., 2011; Nygård et al., 2014). Humidity inversion climatologies based on radio sounding data (Nygård et al., 2014) and satellite observations (Devasthale et al., 2011) differ notably, especially in the seasonal cycle of inversion properties, due to differences in the vertical resolution and methodology. Humidity inversions are nearly always found at multiple levels (Devasthale et al., 2011; Nygård et al., 2014). Vihma et al. (2011) reported that, compared to temperature inversions, humidity inversions were on average thicker and had their base at a higher level. They concluded that this was mostly due to the role of the snow and sea ice surface as a sink for heat but not commonly for humidity (see also Persson et al., 2002). In other studies, however, humidity inversions have been found to usually coincide with temperature inversions (Sedlar et al., 2012; Tjernström et al., 2012). Differences in the observations may at least partly originate from different seasons (early spring in Vihma et al., (2011) and late summer in Tjernström et al., 2012) while Sedlar et 
al. (2012) include SHEBA and several years of data from Barrow, hence possibly indicating that there may also be regional differences. A nonlinear relationship between humidity and temperature inversion strength is clearly found in all seasons except during summer (Devasthale et al., 2011).

Temperature and humidity inversions also have notable implications for the long-wave radiation. Bintanja et al. (2011) and Pithan and Mauritsen (2014) demonstrated that atmospheric near-surface cooling efficiency decreases markedly with temperature inversion strength, as the inversion layer damps the infrared cooling to space, and Boé et al. (2009) obtained analogous results for the role of air temperature inversion in reducing the radiative cooling of the ocean surface. Humidity inversions, in turn, can contribute up to $50 \%$ of the total amount of condensed water vapour in a relatively dry atmosphere in winter and spring, which can significantly influence the long-wave radiative characteristics of the atmosphere (Devasthale et al., 2011), and they are presumably vital for the formation and maintenance of Arctic clouds (Sect. 2.2.1).

Inversions are a robust metric to evaluate the reproducibility of ABL processes in numerical models (Devasthale et al., 2011). Currently, Arctic temperature and humidity inversions are not realistically captured with respect to strength, depth, and base height by operational weather forecasting models (Lammert et al., 2010), climate models (Medeiros et al., 2011), high-resolution mesoscale models (Kilpeläinen et al., 2012), or even reanalyses (Lüpkes et al., 2010; Jakobson et al., 2012; Serreze et al., 2012). In particular, it is the nature of the Arctic atmosphere to contain multiple inversion layers and this is not reproduced in the models (Kilpeläinen et al., 2012). The errors in temperature inversion characteristics are related to deficits in the simulation of stable boundary layer (SBL) turbulence, clouds, radiative transfer, and surface energy budget (Lammert et al., 2010; Kilpeläinen et al., 2012) but are also sensitive to vertical resolution in models.

\subsubsection{Stable boundary layer}

Over sea ice in the central Arctic, the ABL is typically stably stratified during 6 winter months and is near-neutral or weakly stable during the other months (Persson et al., 2002; Sect. 2.1.1). Although cases of near-neutral stratification occur throughout the year, from the point of view of understanding and parameterization of the ABL over sea ice, the main challenges are related to stable stratification and this will be our focus here. The inner part of the Arctic Ocean, where the ice concentration is high and the surface is relatively flat and homogeneous, is ideal for SBL studies (e.g. Heinemann, 2008). Research on the Arctic SBL is strongly motivated by the major problems that climate models and reanalyses have in stably stratified conditions. Further, there are important feedback mechanisms related to temperature inversion (Sect. 5.3).
A large part of the recent advance in research is still based on analyses of data from the SHEBA experiment. Important issues addressed in recent research include (a) scaling of SBL turbulence and (b) presence of turbulence under very stable stratification. Related to both (a) and (b), one of the main sources of uncertainty in SBL data analyses and modelling is the large scatter between experimental functions that describe the stability-dependent relationships between vertical gradients and fluxes. Until recently, these formulae have not been based on Arctic data, but Grachev et al. (2007a, b) derived new formulae for stable stratification on the basis of SHEBA data. Considering (a), the traditional scaling, based on the Monin-Obukhov similarity theory, is such that the flux-gradient relationships depend on the stability parameter $z$ / $L$, where the Obukhov length $L$ depends on the turbulent fluxes. Mauritsen and Svensson (2007) and Grachev et al. (2012) demonstrated that, for moderately and very stable conditions, a scaling simply based on the vertical gradients (expressed in terms of the gradient Richardson number, $R i$ ) is better, because in such conditions the vertical gradients are large and their errors are relatively small. Further, there is no self-correlation between fluxes and $z / L$.

Considering (b), on the basis of SHEBA and mid-latitude data, Sorbjan and Grachev (2010) concluded that the necessary condition for the presence of continuous turbulence is that $R i<0.7$, which is a much larger value than expected on the basis of older studies. Intermittent turbulence is, however, present in the atmosphere even under very stable stratification with $R i \gg 1$. This is related to the anisotropy of turbulence, which allows enhanced horizontal mixing, and to internal waves, which preserve vertical momentum mixing (Galperin et al., 2007; Mauritsen and Svensson, 2007). The energy of internal waves is associated with the turbulent potential energy (TPE), the importance of which has recently been better understood (Mauritsen et al., 2007; Zilitinkevich et al., 2013), in addition to the well-known importance of the turbulent kinetic energy, TKE. If TPE is taken into account, it follows that there is no critical Ri and turbulence can survive in the very stable boundary layer. Another approach to treat the very stable stratification is based on the quasi-normal-scale elimination (QNSE) theory, which also takes into account waves and the turbulence anisotropy (Sukoriansky et al., 2005). This is enabled by the spectral nature of QNSE, based on ensemble averaging over infinitesimally thin spectral shells. Implemented in the NWP model HIRLAM, the QNSE approach yielded promising results for the Arctic compared against SHEBA data (Sukoriansky et al., 2005).

Related to the division between weakly stable and strongly stable ABL, Lüpkes et al. (2008a) found that during SHEBA the lowest near-surface temperatures did not occur under calm conditions, but at a wind speed of about $4 \mathrm{~m} \mathrm{~s}^{-1}$. Based on the results of a column (atmosphere and sea ice) model, they found that this value can be considered as a lower threshold to generate sufficient mixing maintaining a close 
a

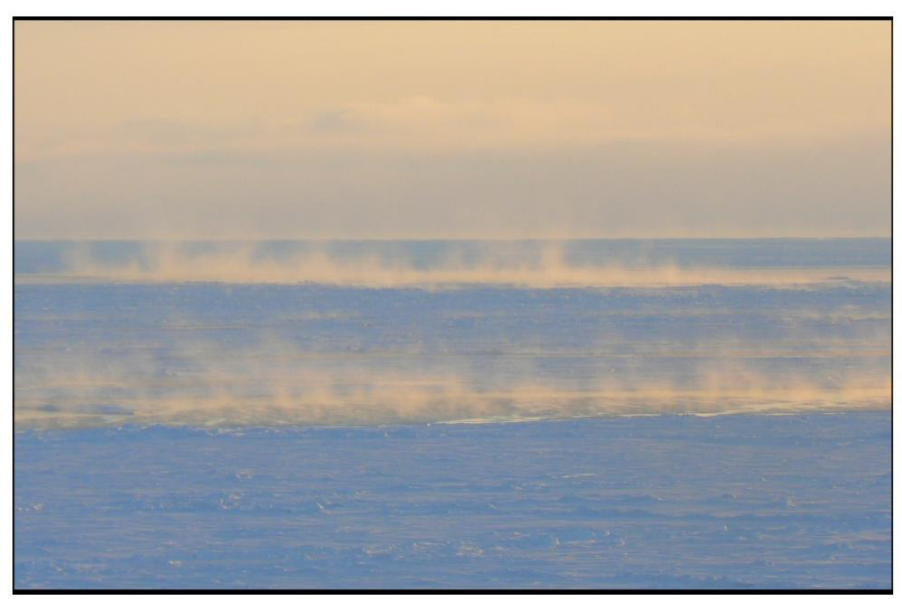

b

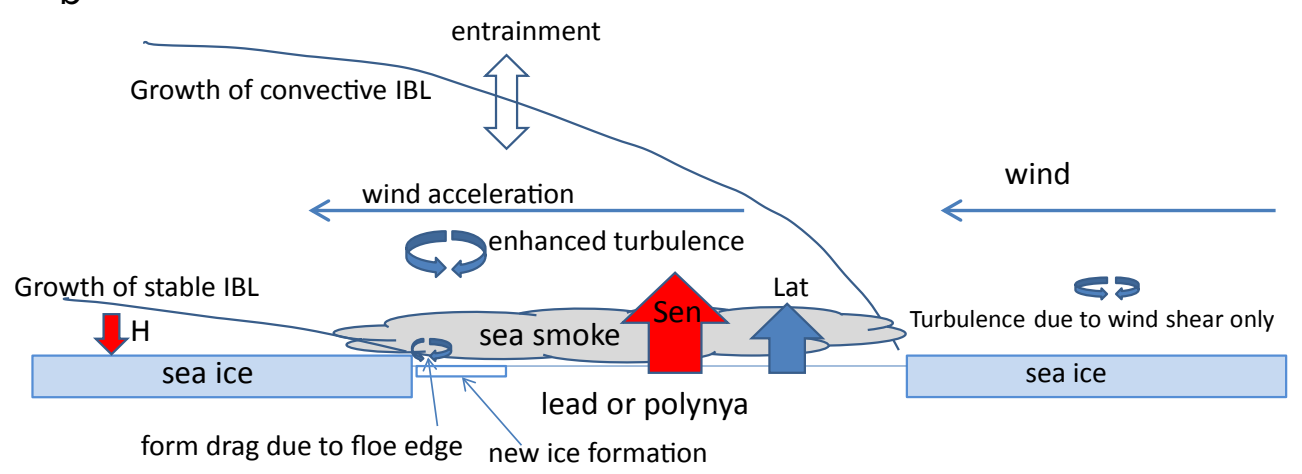

Figure 3. Convection over leads and polynyas: (a) sea smoke originating from leads in the Fram Strait on 7 March 2013 (photo: C. Lüpkes), (b) schematic presentation of ABL processes over a lead/polynya. Sen and Lat are the turbulent fluxes of sensible and latent heat, respectively.

thermal coupling between the snow surface and near-surface air. Also, Sterk et al. (2013) simulated the lowest near-surface temperatures in conditions of non-zero wind speed.

A low-level jet (LLJ) is a distinctive feature of the SBL; it is often generated by inertial oscillations related to the establishment of stable stratification, and it affects the SBL turbulence via top-down mixing due to the large wind shear below the jet core. An analytical model for an LLJ was presented by Thorpe and Guymer (1977). Recently, ReVelle and Nilsson (2008) improved the description of frictional effects in such a model and obtained promising results for the Arctic Ocean. New observations of LLJs over the Arctic Ocean include the work of Jakobson et al. (2013) based on tethered soundings at Tara. In their data, baroclinicity related to transient cyclones was the most important forcing mechanism for LLJs. On average, the baroclinic jets were strong and warm, occurring at lower altitudes than other jets, related among others to inertial oscillations and gusts.

Considering ABL modelling, it is well understood that the ABL schemes commonly applied in climate models and NWP yield excessive heat and momentum fluxes in the SBL (Cuxart et al., 2006; Tjernström et al., 2005), typically re- sulting in a warm bias near the surface (Atlaskin and Vihma, 2012). In the Arctic, Byrkjedal et al. (2007) demonstrated the importance of a high vertical resolution: not surprisingly, model experiments with 90 levels in the vertical yielded much better results than those with 31 levels, the latter being typical for climate models contributing to the IPCC AR4. The high-resolution simulations significantly reduced the warm bias and the excessive turbulent fluxes of heat and momentum that were present in the coarse resolution results over the Arctic Ocean.

A major challenge in ABL modelling is to better understand the interaction of turbulence, radiation, cloud physics, and thermodynamics of sea ice and snow. The work of Sterk et al. (2013), applying a single column version of the Polar Weather Research and Forecasting (Polar WRF), has yielded methodological advance in this respect. They used so-called process diagrams to indicate how the variations in parameter values in the schemes for various physical processes were related to differences in the model output. 


\subsubsection{Convection over leads, polynyas, and the open ocean}

Although the Arctic ABL has a predominantly stable or near-neutral stratification, convection occurs as well. This is mostly due to the coexistence of ice and open water surfaces causing strong gradients in the surface temperatures. The influence of open water on the atmosphere strongly depends on the season, being largest in winter and smallest in summer (Bromwich et al., 2009; Kay et al., 2011). Convection may appear over leads, polynyas, and over the open ocean during cold air outbreaks. Thus, there is a large variability in the involved spatial scales, and different parameterizations of turbulence are required. Convection over leads and polynyas (Fig. 3) has been studied since the 1970s (e.g. Andreas et al., 1979). As summarized by Lüpkes et al. (2012b) progress has been made during recent decades mainly with respect to the parameterization of energy fluxes at the lead surface. For example, the Andreas and Cash (1999) parameterization states that the transport of sensible heat is more efficient over small leads than over large leads due to the combined effect of forced and free convection. Recently, based on the lead distribution as analysed from a SPOT satellite image, Marcq and Weiss (2012) found that this dependence can increase heat fluxes over a large region of the Arctic by up to $55 \%$ since the small leads are dominating. Also, Overland et al. (2000) (observations) and Lüpkes et al. (2008a) (one-dimensional air-ice modelling) point to the strong potential impact of atmospheric convection over leads on the surface energy budget. Both found that the net heat flux over an ice-covered region in the inner Arctic was close to zero due to a balance of downward fluxes during slightly stable near-surface stratification and upward fluxes from leads.

Although the effect of a single lead on the temperature is small, the integral effect of convection over leads can be very large: according to the model simulations by Lüpkes et al. (2008a), during polar night under clear skies, a $1 \%$ decrease in sea ice concentration results in up to a $3.5 \mathrm{~K}$ increase of the near-surface air temperature, if the air mass flows over the sea ice long enough ( $48 \mathrm{~h})$. Polar WRF experiments by Bromwich et al. (2009) revealed that in winter over a region with an ice concentration of about $60 \%$, the gridaveraged surface temperature increased by $14 \mathrm{~K}$ compared to an experiment with $100 \%$ ice concentration. For Antarctic winter, Valkonen et al. (2008) obtained a maximum of $13 \mathrm{~K}$ sensitivity of the $2 \mathrm{~m}$ air temperature to the sea ice concentration data set applied (all based on passive microwave observations). A related modelling challenge is the formation of new ice in leads and polynyas (Fig. 3; Sect. 4.1), which strongly affects the surface temperature, the release of latent and sensible heat, and further the evolution of the ABL (Tisler et al., 2008). In particular, the modelling of thin ice growth is difficult due to the required resolution, but also the relation between the transfer coefficients of momentum and heat/humidity still requires future work (Fiedler et al., 2010).
The height reached by convective plumes strongly depends on the width of the lead/polynya, wind speed, surface air temperature difference, and the background stratification against which the convection has to work (e.g. Liu et al., 2006). On the basis of airborne observations and high-resolution modelling, Lüpkes et al. (2008b, 2012b) concluded that convection over 1-2 km wide leads reached altitudes of 50-300 m depending on the boundary layer structure on the upstream side of leads. On the basis of aircraft in situ, drop sonde, and lidar observations, Lampert et al. (2012) observed that over areas with many leads, the potential temperature decreased with height in the lowermost $50 \mathrm{~m}$ and then was nearly constant due to convective mixing up to the height of 100-200 m. When the leads were frozen and their fraction was small, however, an SBL extended up to a height of 200-300 m.

Ebner et al. (2011) showed in a modelling study that convective plumes generated over the Laptev Sea polynya influence atmospheric turbulence even $500 \mathrm{~km}$ downstream of the polynya, and Hebbinghaus et al. (2006) found that cyclonic vortices can be generated or intensified over polynyas due to convective processes. Such processes over large polynyas may be important with respect to the drastic changes in sea ice cover observed in recent years.

In models, difficulties arise in the treatment of plumes generated over leads, which interact with the stable or nearneutral environment when the convective internal boundary layer is growing (Fig. 3). Only first attempts have been made to account for the nonlocal character of turbulent fluxes in the plume regions at higher ABL levels (Lüpkes et al., 2008b). Processes in the upper ABL need to be investigated in future also with the help of Large Eddy Simulation (LES). For example, Esau (2007) found that the structure of turbulent regimes over leads can be extremely complicated under light winds as often found in Arctic regions. This finding forms a challenge for future improved parameterizations of energy transport.

Compared to the conditions over leads and polynyas, deeper convection in the Arctic atmosphere takes place in cold air outbreaks (CAOs) over the open ocean. Due to Arctic warming, the atmospheric boundary layer temperatures during CAOs have increased (Serreze et al., 2011), but Vavrus et al. (2006) found by a modelling study that the number of CAOs will increase during the 21 st century in several regions as, for example, over the Atlantic Ocean. On the basis of reanalysis data, Kolstad et al. (2009) concluded that seasonal and interannual variability of CAOs is mostly governed by the variability of the $700 \mathrm{hPa}$ air temperature, T700, rather than by the sea surface temperature. Using a rough measure of CAO occurrence based, for example, on T700, Kolstad and Bracegirdle (2008) concluded that climate models broadly capture the observed climatology of CAOs, but differences from observations occur in areas where models have excessive sea ice cover. As energy fluxes are very large in CAOs and extensive ocean regions are affected, small differences in the $\mathrm{CAO}$ occurrence and properties may have a large effect 
on the regional ocean-atmosphere heat flux. Furthermore, strong off-ice winds, typical for CAOs, have a large impact on the drift of sea ice in the marginal ice zone (MIZ), which in turn affects the CAO development. Thus, it is important to investigate small-scale physical processes in CAOs such as ABL turbulence in strong convective regimes as well as cloud physics.

Lüpkes et al. (2012b) determined that the simplest possibility for successfully parameterizing turbulent transport in a strong convective regime is to use closures allowing countergradient transport of heat. Applying a mesoscale model with different grid sizes, Chechin et al. (2013) found for idealized cases that the strength of the ice breeze developing in CAOs over open water downstream of the MIZ was strongly affected by the grid sizes: models with grid sizes larger than $20 \mathrm{~km}$ tend to underestimate the wind speed close to the ice edge. This finding confirms earlier results by Renfrew et al. (2009a, b) and Haine et al. (2009). Since the ice breeze occurring in a region of roughly $100 \mathrm{~km}$ width along the polar ice edges influences the energy fluxes, there might be a systematic underestimation of surface energy fluxes in largescale models.

One of the most striking small-scale features during CAOs is the occurrence of roll convection, which has been extensively studied in the last decades (Liu et al., 2006). There are, however, still fundamental questions under discussion. Gryschka et al. (2008) found in an LES study that in case of strong surface heating and weak wind shear, surface inhomogeneity in the MIZ is an important factor for the generation of convection rolls. This finding also stresses the importance of a close-to-reality treatment of the MIZ processes including the near-surface-fluxes (see Sect. 2.1.4).

\subsubsection{Surface roughness and momentum flux}

The drift speed of Arctic sea ice has increased during recent decades (Rampal et al., 2009; Spreen et al., 2011). Increased wind speeds have contributed to the drift acceleration between 1950 and 2006 (Häkkinen et al., 2008), but not between 1989 and 2009 (Vihma et al., 2012). Instead, the recent increasing trend in drift speeds is mostly due to ice becoming thinner and mechanically weaker (Sect. 3.3.1). To reliably model the ice drift velocity field and ice export out of the Arctic, it is essential to accurately parameterize the transport of momentum from the atmosphere to the sea ice. Moreover, the friction at the surface determines the atmospheric crossisobaric mass flux, sometimes called Ekman transport, that is very important for the proper simulation of the lifetime of synoptic-scale weather systems.

The momentum flux depends on the wind velocity, thermal stratification in the ABL, and aerodynamic roughness of ice/snow surface, which can be expressed as a roughness length $\left(z_{0}\right)$ or drag coefficient $\left(\mathrm{C}_{\mathrm{D} 10 \mathrm{~N}}\right.$ referring to that at $10 \mathrm{~m}$ height under neutral stratification). In addition to the skin friction over smooth ice/snow surface, the aerodynamic roughness of sea ice is affected by factors generating form drag: ridges, floe edges, and sastrugi (Andreas et al., 2010a, b; Andreas, 2011; Lüpkes et al., 2012a, 2013). This generates a challenge for operational modelling: the above-mentioned characteristics of sea ice surface vary rapidly in time and often over small spatial scales, but they are difficult to observe by remote sensing. Over broken sea ice cover, however, the form drag is mostly caused by floe edges, whose occurrence is related to the sea ice concentration, which can be observed by remote sensing.

$z_{0}$ of sea ice can be calculated on the basis of tower or aircraft observations. However, the results are not directly comparable as tower observations are not necessarily representative of the wider surroundings where the occurrence of ice ridges, floe edges, and sastrugi may differ from that in the footprint area of the tower. New results for the Arctic sea ice, based on the tower observations from SHEBA, include those by Andreas et al. (2010a, b). A significant advance has been the better understanding of the differences between $z_{0}$ in winter and summer. For winter conditions, Andreas et al. (2010a) propose a constant $z_{0}$ for a large range of friction velocities, and argue that the former stronger dependence on friction velocity found by Brunke et al. (2006) might have occurred due to a fictitious self-correlation. Andreas et al. (2010b) addressed the Arctic summer, when open water is present due to melt ponds and leads, and proposed $\mathrm{C}_{\mathrm{D} 10 \mathrm{~N}}$ with a dependence on the sea ice concentration. Lüpkes et al. (2012a) revised this dependence by including a drag partitioning concept distinguishing between skin drag over sea ice and open water in melt ponds and leads and form drag caused by the edges of ponds and leads. They proposed a hierarchy of drag parameterizations whose complexity depends on the background model used (e.g. stand-alone atmosphere or coupled ocean-sea-ice-atmosphere model). Compared to pre-IPY results, the role of melt ponds in the parameterizations by Andreas et al. (2010) and Lüpkes et al. (2012a) is a new aspect. Lüpkes et al. (2013) showed on the basis of sea ice concentration and melt pond fraction data obtained by MODIS (Rösel et al., 2012) that the inclusion of the melt pond effect on roughness has a significant impact on the drag coefficients to be used in climate models.

It should be noted that NWP and climate models often apply $z_{0}$ values over sea ice that are much larger than those suggested as mean values by field observations. Further, to avoid decoupling, models often apply some threshold values, e.g., a lower limit for the friction velocity. In general, a high $z_{0}$ and other means to enhance turbulent mixing yield more Ekman pumping and a better evolution of synoptic-scale systems (Beare, 2007; Svensson and Holtslag, 2009). Few studies exist where the momentum flux in climate models is systematically evaluated. Tjernström et al. (2005) concluded that the momentum flux is systematically overestimated for five evaluated regional models. This overestimation leads to an enhanced mixing and is a root cause for many other systematic problems in NWP and climate models. 
Compared to the large number of studies related to aerodynamic roughness, only few studies have addressed the effect of stratification on the wind stress over Arctic sea ice. Considering differences between sea ice and open water, the effects of stratification and roughness usually tend to compensate each other. At least for low wind speeds, open water (leads, polynyas, and the open ocean) usually has a lower $z_{0}$ than sea ice but for most of the year the stratification over open water is unstable, which enhances the vertical transport of momentum. Demonstrating the dominating effect of stratification, a larger momentum flux over open water than sea ice has been observed (Brümmer and Thiemann, 2002) and obtained in modelling studies (Tisler et al., 2008; Kilpeläinen et al., 2011). At a global scale, advances have also been made in studies of momentum flux over the open ocean (see Bourassa et al. (2013) for a review).

The surface momentum flux also affects drifting/blowing snow. Most of the recent research advances originate from Antarctica and Greenland, but the issue is relevant also for the Arctic sea ice: via redistributing the snow thickness, drifting/blowing snow further affects the locations of melt pond formation (Sect. 3.1). Andreas et al. (2010a) showed that, under wind speeds strong enough for the occurrence of drifting snow, the $z_{0}$ of snow-covered sea ice is independent of the friction velocity (see above), which is in contrast to many commonly applied parameterizations.

\subsection{Clouds and radiation}

\subsubsection{Cloud physics}

Clouds are ubiquitous in the Arctic. As mentioned in Sect. 2.1, clouds interact with the temperature and humidity inversions and affect the ABL stratification (Figs. 1 and 4), and fog (sea smoke) is often formed over leads and polynyas (Fig. 3). The cloud fraction has an annual cycle with a maximum in early autumn and minimum during late winter (e.g. Curry et al., 1996; Shupe et al., 2011). This has been observed since the beginning of the satellite era (Liu et al., 2012), yet atmospheric models continue to struggle with even this first-order cloud property. An ensemble average of stateof-the-art CMIP3 climate models generally agree with satellite observations of the Arctic cloud fraction annual cycle. Individually, however, models display a substantial inter-model spread, largest during winter and smallest in summer, which dramatically biases their ability to capture the correct annual cycle amplitude and some models even have an inverse annual cycle with less clouds in summer and more in winter (Karlsson and Svensson, 2011). Summer clouds also posed problems for the Community Atmospheric Model version 4 (CAM4) (Kay et al., 2011), and simulation of clouds was one of the main problems in testing of the Polar WRF model against SHEBA data (Bromwich et al., 2009) and recently against the Arctic Summer Cloud-Ocean Study (ASCOS) data (Wesslen et al., 2014) as part of the Arctic System Re-

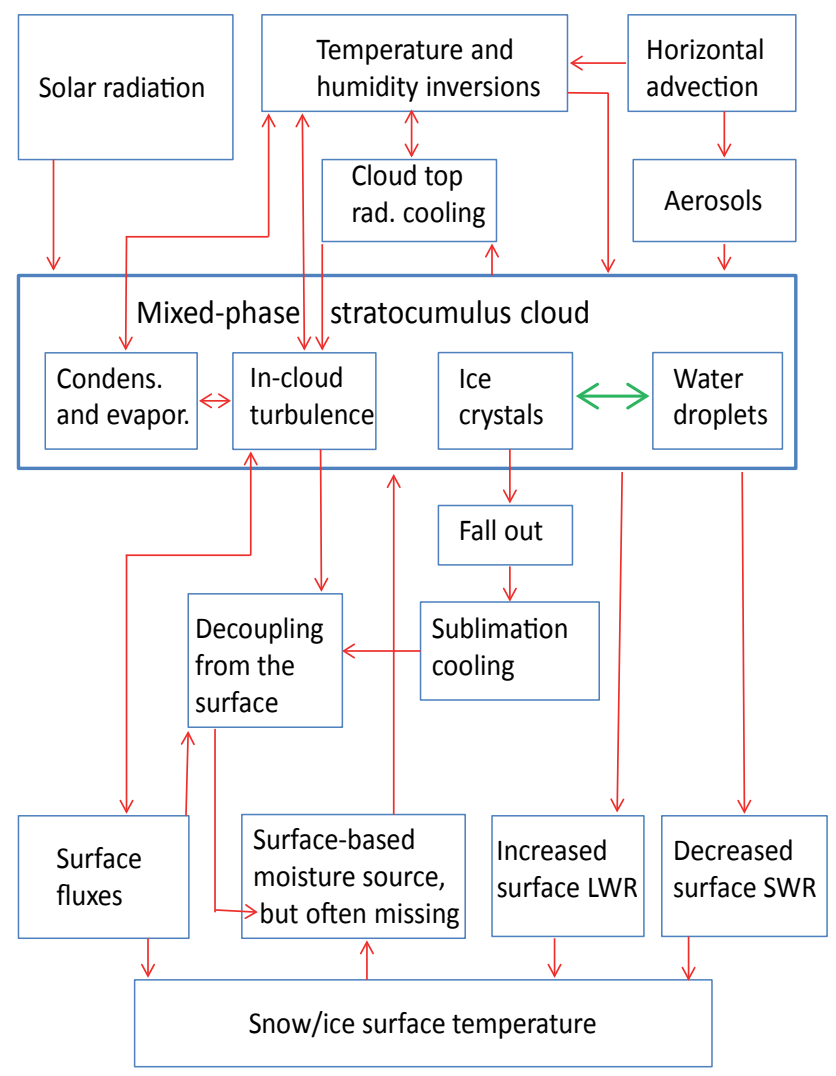

Figure 4. Schematic diagram on the effects and interactions related to mixed-phase stratocumulus clouds and radiative transfer. Macroand microphysical processes and interactions are shown as arrows, the green arrow representing numerous microphysical processes related to aerosols, nucleation, evaporation, depositional ice growth, cloud layer glaciation, and effects of saturation vapour pressure differences of liquid and ice (see e.g. Morrison et al., 2012).

analysis effort. Models also have difficulties in representing the correct amount and vertical distribution of cloud hydrometeor phase partitioning over polar regions, under a wide range of annual temperatures. These biases lead to direct consequences for the surface radiation budget, near-surface temperature, and the lower ABL thermal stability and turbulent structure (Tjernström et al., 2008; Birch et al., 2009; Karlsson and Svensson, 2011; Kay et al., 2011; Cesana et al., 2012; Liu et al., 2012).

The difficulties in modelling clouds over the Arctic are related to the numerous interactive processes, schematically illustrated in Fig. 4 for mixed-phase stratocumulus (MPS) clouds. Even though cloud fraction is relatively high yearround, Shupe (2011) has clearly shown that seasonally dependent, vertical cloud phase preferences exist. Liquid-only clouds rarely exist above $2 \mathrm{~km}$ above ground level, and occur predominantly during the sunlit portions of the year. Unlike the rest of the globe, MPS clouds tend to be the most common in the lower Arctic troposphere, except during winter and early spring when ice-only clouds are somewhat 
more frequent. The MPS clouds have a profound impact on the surface energy balance, since liquid water generates significantly more long-wave radiation to the surface than do ice clouds (Tjernström et al., 2008; Sedlar et al., 2011; Wesslen et al., 2014), and hence on the surface melt and freeze (Fig. 4). Therefore, MPS clouds will be a focus here.

An obvious connection between cloud phase and atmospheric temperature is present. MPS clouds are often the preferential cloud class when temperatures range between -15 to near $0{ }^{\circ} \mathrm{C}$ (Shupe, 2011; de Boer et al., 2009), but liquid water has been observed in clouds at temperatures as low as below $-34^{\circ} \mathrm{C}$ (Intrieri et al., 2002). Complicating the matter, the presence of liquid droplets and ice crystals together forms an unstable equilibrium due to the saturation vapour pressure differences of ice and liquid, the WegenerBergeron-Findeisen (WBF) process (c.f. Morrison et al., 2012). Despite this instability, liquid-topped clouds with ice and/or drizzle precipitating from this layer are the norm within the lower Arctic troposphere from spring through autumn (Tjernström et al., 2004; de Boer et al., 2009; Shupe, 2011; Sedlar et al., 2011). Shupe et al. (2011) observed mean duration times of the order of $10 \mathrm{~h}$ for these cloud systems, but they may also occur as quasi-stationary systems persisting for days (Shupe et al., 2008; Sedlar et al., 2011; Shupe, 2011).

The generally long lifetime of MPS clouds suggests that relative humidity with respect to liquid $\left(\mathrm{RH}_{\text {liq }}\right)$ is kept high within and near the cloud layer. If $\mathrm{RH}_{\text {liq }}$ becomes subsaturated in the presence of ice crystals, liquid droplets must evaporate following the WBF process, and hence would cause a rapid depositional ice growth and cloud layer glaciation. Instead, Shupe (2011) has shown that in-cloud $\mathrm{RH}_{\text {liq }}$ and temperature distributions at a number of Arctic stations are in fact surprisingly similar, lending support for a system that is both conditioned for, and dependent upon, mixedphase clouds. In general, stratiform clouds do not need largescale updrafts, e.g. convection, to sustain them. Instead, these clouds rely on cloud-driven (in-cloud production of) vertical motion where the small-scale dynamics (turbulence) depends on the presence of liquid, through the cloud-top cooling, but also supplies the moisture that sustain that liquid layer.

Cloud top radiative cooling is typically very efficient as near-adiabatic liquid water content (LWC) profiles are common in the Arctic (Curry, 1986; Shupe et al., 2008). Arctic MPS droplet radii generally also increase with height (e.g. Curry, 1986) and droplet effective radii often range between 4 to $15 \mu \mathrm{m}$. Typical LWC in MPS peaks between 0.1 and $0.2 \mathrm{~g} \mathrm{~m}^{-3}$ (McFarquhar et al., 2007) and together with relatively thin liquid layers (Shupe et al., 2008; Shupe 2011), cloud liquid water path (LWP) is often below $100 \mathrm{~g} \mathrm{~m}^{-2}$ (de Boer et al., 2009; Sedlar et al., 2011; Shupe et al., 2011). In-cloud ice water contents (IWC) are generally largest between cloud mid-level and base, decreasing upwards towards cloud top where they are initially formed (Shupe et al., 2008). Recent campaigns report a wide spectrum of ice crystal ef- fective diameters, ranging from $20-60 \mu \mathrm{m}$ (McFarquhar et al., 2007; Shupe et al., 2008) and upwards of $100 \mu \mathrm{m}$ when falling through the sub-cloud layer (de Boer et al., 2009).

The ratio of LWC to total water content is often larger than 0.8 (McFarquhar et al., 2007; Shupe et al., 2008) indicating the resilience of cloud liquid despite near-constant drizzle and ice precipitation. In fact, de Boer et al. (2011) found evidence that liquid saturation occurs prior to ice crystal development even in a supersaturated environment with respect to ice. The authors suggest that ice nucleation mechanisms in the Arctic MPS thus tend to be controlled by processes that rely on the presence of liquid condensate, further emphasising the importance of cloud motions in controlling the resilience of MPS.

In contrast to subtropical stratocumulus where decoupling between the surface and the cloud layer occurs during daytime as a part of a diurnal cycle, the Arctic ABL and subcloud thermodynamic structure often feature a persistent decoupling between the surface and the cloud layers (Shupe et al., 2013), and the mechanisms are different. This decoupling appears to be most common during the cold, dark months but also occurs during the transition and summer seasons (Kahl, 1990; Tjernström et al., 2004, 2012; Sedlar et al., 2011, 2012; Solomon et al., 2011; Shupe et al., 2013). Thus, the surface-based moisture source for Arctic MPS is often missing (Fig. 4). Sedlar and Tjernström (2009) and Sedlar et al. (2012) identified a common, persistent Arctic MPS cloud regime over the Arctic where the cloud layer is decoupled from the surface, a liquid cloud top extending above the stably stratified temperature inversion base, and ice crystals precipitating from the cloud. They hypothesize that the presence of specific humidity inversions, a common Arctic phenomenon (see Sect. 2.1.1), are vital to Arctic MPS survival. Surface turbulent heat and moisture fluxes are generally small over sea ice (Persson et al., 2002; Tjernström et al., 2005, 2012), and ice crystals falling from the cloud into the sub-saturated sub-cloud layer will further enhance decoupling due to cooling from ice crystal sublimation (Fig. 4; Harrington et al., 1999). Thus, instead of moisture originating from the surface, the increased humidity within the inversion structure may be the moisture source which sustains the cloud system (Solomon et al., 2011; Sedlar et al., 2012).

Turbulent kinetic energy is generated near cloud top (Shupe et al., 2012, 2013) due to parcel buoyancy differences initiated by radiative cloud-top cooling, causing topdown overturning circulations and vertically turbulent motions. Within these turbulent eddies, condensation and evaporation compete (Fig. 4), often with condensation (evaporation) occurring in turbulent updrafts (downdrafts) near cloud top (Shupe et al., 2008). These mechanisms also occur within, and sustain, warm subtropical stratocumulus. The key difference in the Arctic is the presence of liquid and ice simultaneously. Shupe et al. (2008) show that ice production is generally limited to cloud-generated updrafts that increase the supersaturation with respect to ice. When downdrafts 
were observed, ice production generally ceased and fewer ice crystals grew to large sizes and fell from the still-present, yet slightly more tenuous, liquid layer. Hence the coexistence of liquid and ice is intimately linked to cloud-scale motions, which in turn depends on the presence of liquid water.

Tjernström (2007) suggested that most of the boundary layer turbulence in the Arctic is in fact generated by boundary layer clouds, at least in summer. If the in-cloud turbulence production is strong and stratification below the cloud layer is weak, the cloud-induced turbulent eddies may penetrate to the surface, hence affecting the surface fluxes of momentum, heat, and moisture (Fig. 4). Cloud-generated mixing is found beneath cloud base, but the extent to which these turbulent motions reach the surface is often limited by a subcloud stable layer (Shupe et al., 2013; Sedlar and Shupe, 2014) and is also dependent on the distance from the cloud base to the surface and the sublimation of precipitation in the layer below the cloud base (Fig. 4). Hence the strongest but also most variable turbulence generation is due to buoyant cloud overturning due to cloud top cooling, which generates eddies that often persist below the cloud base. Mechanical generation of turbulence at the surface, on the other hand, is seldom very strong and intense buoyant mixing is essentially absent over sea ice (other than over winter leads/polynyas), and the ABL is therefore most often shallow. Coupling, or the lack thereof, of MPS clouds to the surface and surface fluxes are therefore more often dependent on if the cloud-generated turbulence can reach down to the ABL or not, rather than the other way around. This in turn is sensitive to the cloudgenerated turbulence but also to the cloud base height (Fig. 4; Tjernström et al., 2012; Shupe et al., 2013; Sotiropoulou et al., 2014).

Spectral analysis of in-cloud vertical velocities reveals only modest changes to the cloud-generated temporal frequencies and horizontal wavelengths of vertical velocity when the cloud layer transitions between a surface-cloud coupled and decoupled state (Sedlar and Shupe, 2014); the authors concluded that the surface-cloud coupling state is therefore a result of the cloud processes and not dependent on the turbulence generated near the surface. Analysis of winter soundings from SHEBA in Tjernström and Graversen (2009) additionally shows how the boundary layer structure changes are almost binary between a well-mixed state, similar to summer conditions when clouds containing liquid water are present, and a distinct surface inversion structure when clouds are either absent or optically thin.

In terms of temperature, the radiative cooling from the liquid cloud top (Harrington et al., 1999) dominates over other local processes and hence, in the absence of frontal passages or other large-scale controls, cloud droplets will continuously form to replace the water that precipitates out. Cloud droplets can persist as long as a moisture source is present. The presence of humidity inversions near cloud top provide such a source (Fig. 4), and Solomon et al. (2011) describe how cloud-generated vertical motions, and small but appreciable droplet condensation above the temperature inversion base, create the link between the cloud layer and the stable upper entrainment zone. This is a feature unique to the low-level Arctic thermodynamic structure, not observed in lower latitudes where large-scale subsidence generally prohibits humidity increases near cloud top. Furthermore, this situation is maintained by ice crystal formation and fallout (Shupe et al., 2008), effectively limiting the LWC near cloud top.

In addition to moisture, clouds need aerosol particles on which to condense and freeze (Fig. 4). These cloud condensation nuclei $(\mathrm{CCN})$ and ice nuclei largely determine the clouds' microphysical structure and hence their radiative properties. Over the Arctic, where local sources of pollution generally do not exist, transport in the region is considered a large contributor to the concentration and composition of CCN and ice nuclei (e.g. Shaw, 1975). In winter, when the ocean is ice covered, there is a substantial transport of aerosols and aerosol precursor gases into the Arctic (Barrie, 1986; Garrett and Zhao, 2006; Lubin and Vogelmann, 2006). In summer, the meridional transport is smaller and the formation of low clouds and fog at the MIZ, as sub-Arctic marine air adjusts to the frozen or melting surface, forms an effective filter for the transport of aerosols in the lower troposphere. Thus, in the summer boundary layer the aerosol concentrations are generally very low compared to further south (Tjernström et al., 2014) while transport of aerosols from lower latitudes may occur at higher elevations (Lance et al., 2011). While the ocean surface is more exposed in summer, local production of aerosols may be important (Tjernström et al., 2014). Low aerosol concentrations and low temperatures both contribute to a preference for optically thin clouds and also promote precipitation formation.

Historically, many models, especially weather forecast models, such as the ECMWF model, distinguish between cloud liquid and ice based only on temperature, often having failed to maintain liquid in very cold winter clouds (e.g. Beesley et al., 2000; Tjernström et al., 2008). Recently more advanced moist physics has made its way into stateof-the-art climate and weather forecast models (Meehl et al., 2013). However, while being more physically based, it has been difficult to properly tune such schemes to work well in all seasons and under all conditions. Tjernström et al. (2008) showed that models with more advanced cloud physics schemes generally did not perform better than those with simple temperature schemes. In an evaluation of ERAInterim and two versions of the Arctic System Reanalysis (ASR) against the ASCOS data, it was found that ERAInterim more faithfully retained the observed Arctic MPS in spite of its much simpler temperature dependent formulation, albeit not necessarily for the right reasons (Wesslén et al., 2014). 


\subsubsection{Cloud-radiation interaction}

The central Arctic imposes unique boundary conditions on both shortwave (solar) and long-wave (infrared) radiative transfer, controlled by the large seasonal variations in the incoming fluxes and a wide range of surface albedo conditions (Sect. 3.1.2). The presence of cloud cover impacts radiation reaching the surface in two competing ways. First, cloud hydrometeors absorb long-wave radiation, increasing the emissivity relative to a clear-sky atmosphere. This results in a net warming effect at the surface, especially over the Arctic where clear-sky effective emissivity is generally low, but simultaneously leads to cooling of the upper portion of the clouds. Conversely, clouds reflect incoming shortwave radiation to space resulting in a net surface cooling effect. Over the Arctic, the efficiency of shortwave cloud cooling is further limited by relatively large solar zenith angles (SZAs) and surface albedos; the latter is often as high as that of the overlying cloud. In fact, it still remains uncertain whether the net radiative effect of clouds in summer is to cool the surface over the large-scale Arctic Basin, even though observations from SHEBA suggest a net cloud cooling effect during June and July (Intrieri et al., 2002; Shupe and Intrieri, 2004). In an Arctic-wide sense, this net cloud effect is significantly connected to time of year, geographic location and surface albedo, notwithstanding the cloud physical properties.

The surface energy residuals, available for melting or freezing of the ice, are therefore strongly modified by the cloud radiative forcing. During ASCOS, surface energy budget analysis during the end of the 2008 melt season, towards the initiation of freeze-up, demonstrated the delicate interplay of clouds, radiation, turbulence, and heat conduction in snow and ice (Sedlar et al., 2011). A week-long delay of the autumn freeze-up was realized through the manifestation of a positive long-wave cloud radiative forcing of about $70 \mathrm{~W} \mathrm{~m}^{-2}$, while the shortwave radiative cooling was limited to about $-40 \mathrm{~W} \mathrm{~m}^{-2}$ by surface albedo and SZA constraints. Net surface energy residuals, however, were significantly reduced by redistribution of heat and moisture via near-surface turbulence and heat conduction in snow/ice. The increase of the surface albedo, that eventually put the energy balance beyond recovery, was not gradual but a result of heavy frost formation and melt pond freezing during a short colder period with new snowfall (Sedlar et al., 2011; Sirevaag et al., 2011; Tjernström et al., 2012). The onset of freeze-up was not realized until the low-level Arctic MPS became tenuous and cloud LWP decreased below $20 \mathrm{~g} \mathrm{~m}^{-2}$ - essentially diminishing the cloud greenhouse effect.

Comparing various climate models, the monthly averaged spread in LWP and ice water path (IWP) in the Arctic can be as large as a factor of 3 (Karlsson and Svensson, 2011). Such variability inherently results in differences in cloud fraction as well as in the cloud-radiation interaction (Karlsson and Svensson, 2011). Tjernström et al. (2008) identified significant biases in several regional climate model simulations of surface radiative fluxes during SHEBA. Both downwelling shortwave and long-wave radiation were negatively biased, while the bias magnitudes varied depending on the model. Tjernström et al. (2008) found a significant underestimation (overestimation) in cloud LWP above (below) $20 \mathrm{~g} \mathrm{~m}^{-2}$. Conversely, nearly all models underestimated the IWP and there were clear biases in the model simulations of liquid to total cloud water path. The authors speculated that the biases in downwelling long-wave radiation might be due to an absence of sufficient liquid water in winter and that the downwelling shortwave radiation bias was due to tooopaque clouds, i.e. too-high cloud albedo. However, even when the actual errors in LWP and IWP were cancelled in the analysis a bias remained. Thus, even if the distribution of ice and liquid were properly resolved, the modelled cloudradiation interaction tends to be misrepresented, and this error will propagate to surface radiation balance errors for the ice and the ocean in coupled Earth System Models. These results point at the importance of a proper handling of the aerosol/cloud/radiation feedback in resolving the proper radiation balance at the surface (Sect. 5.3).

\subsection{Partly resolved processes}

\subsubsection{Coastal and fjordic features}

Coastal regions and in particular coastal mountain ranges can have a pronounced impact on the mesoscale and boundary layer meteorology of the adjacent coastal waters. This impact arises from the combined effects of orography and spatial differences between the surface temperatures of snow/icecovered land, sea ice, and the open ocean. Considering orographic effects, when the wind is flowing towards a barrier it must either rise over it or be distorted by it, i.e. it turns to flow along the coast as a barrier wind or related feature, such as a tip jet (common near the southern tip of Greenland). On the downstream side of a barrier there is often some sort of orographic forcing mechanism leading to mesoscale features such as gap winds, katabatic winds, foehn winds or wake effects. The surface temperature differences affect the thermodynamics of the ABL and further the wind field, sometimes also generating mesoscale circulations. All of these mesoscale phenomena are only partially resolved in current climate models and global NWP models, although NWP models can adequately simulate these features if appropriate parameterizations are used and the grid size is sufficiently small.

Complex small-scale processes over Arctic coastal regions, including fjords, have received increasing attention, especially around Greenland and Svalbard. During the IPY, the Greenland Flow Distortion Experiment (GFDex) (Renfrew et al., 2008) and the Norwegian IPY-Thorpex Experiment (Kristjansson et al., 2011) both examined such coastal phenomena through aircraft observations and numerical simulations. The first comprehensive observations of barrier 
winds off southeastern Greenland are documented in Petersen et al. (2009). They found barrier-effect enhancements of up to $20 \mathrm{~m} \mathrm{~s}^{-1}$ and peak wind speeds of up to $40 \mathrm{~m} \mathrm{~s}^{-1}$. The structure of the barrier winds was strongly dependent on the synoptic-scale situation, often consisting of a cold barrier jet undercutting a warmer maritime air mass and generally with a significant ageostrophic component of the flow. A climatology of these barrier winds shows that they occur typically once a week, but with a large interannual variability determined primarily by the broader-scale situation (Harden et al., 2011). Off SE Greenland, there are two distinct areas of occurrence (Harden et al., 2011). Idealized numerical simulations (Harden and Renfrew, 2012) and reanalyses work (Moore, 2012) have shown that these two areas are related to two areas of steep topography, separated by a major fjord. In SE Greenland, barrier winds are known to play a key role in generating a fjordic ocean circulation leading to submarine melting and thus the rapid retreat of ice shelves that is now being seen there (Straneo et al., 2010).

The first in situ observations of a tip jet off Cape Farewell, Greenland documented near-surface winds of over $35 \mathrm{~m} \mathrm{~s}^{-1}$ and peak jet winds of almost $50 \mathrm{~m} \mathrm{~s}^{-1}$ (Renfrew et al., 2009a), while a dynamical analysis of these events showed their characteristic curve around the "tip" was associated with a collapse in the cross-jet pressure gradient as the barrier decreases in height (Outten et al., 2009, 2010). Tip jets are also found off Svalbard (e.g. Reeve and Kolstad, 2011), and over the Bering Sea (Moore and Pickart, 2012); while gap flows were observed by an instrumented aircraft in the Svalbard region during the Norwegian IPY-Thorpex experiment (Barstad and Adakudlu, 2011).

There are generally very high winds associated with all of these coastal jet features, so consequently there are elevated momentum fluxes and often elevated heat and moisture fluxes, depending on the source of the air, i.e. the air-sea temperature difference. Petersen and Renfrew (2009) provided observations from six GFDex flights into tip jets and barrier winds using the eddy covariance method and found fluxes up to $1.9 \mathrm{~N} \mathrm{~m}^{-2}$ (momentum), $300 \mathrm{~W} \mathrm{~m}^{-2}$ (sensible heat), and $300 \mathrm{~W} \mathrm{~m}^{-2}$ (latent heat). These are among the highest fluxes ever directly measured and certainly significant enough to lead to enhanced ocean mixing, water mass changes, and potentially circulation changes in the ocean (e.g. Våge et al., 2008; Haine et al., 2009, Sproson et al., 2010). Although large air-sea heat fluxes are not always the case; the heat fluxes associated with Greenland's easterly tip jets tend to be more moderate and are not associated with the deep open ocean convection events that tend to occur in the SE Labrador Sea (Sproson et al., 2008).

The spatial variability of atmospheric variables within a fjord may be very large (Fig. 5). For Svalbard fjords, Kilpeläinen et al. (2011) reported that variability can reach levels comparable to the synoptic-scale temporal variability. The contribution of surface type to the spatial variability of turbulent heat fluxes increases with increasing air-sea tem-

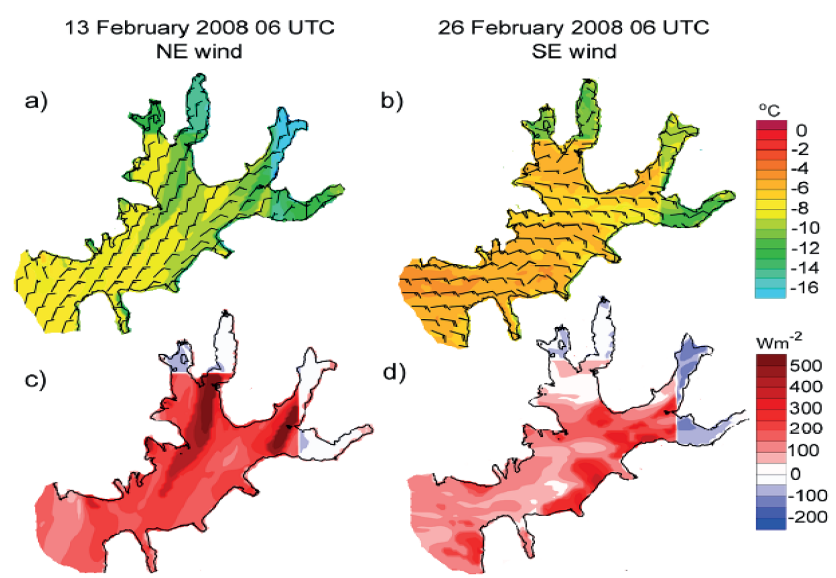

Figure 5. Examples demonstrating large spatial variations in air temperature and wind (a and b) and sensible heat flux (c and d) over a complex fjord (Isfjorden in Svalbard, length approximately $100 \mathrm{~km}$ ), as simulated applying a high-resolution atmospheric model. Redrawn with permission from Kilpeläinen (2011).

perature difference and typically dominates over topographic effects. On the other hand, the effect of topography dominates over surface type for the spatial variability of wind speed and momentum flux (Kilpeläinen et al., 2011). Realistic parameterization of turbulent fluxes in a fjord is a challenge as the Monin-Obukhov similarity theory has limitations in this environment. The combination of topographic effects and wave influence often causes significant crosswind momentum transfer and sometimes also upward momentum transfer, which invalidate conventional stability and scaling parameters (Kilpeläinen and Sjöblom, 2010; Kral et al., 2014). Monin-Obukhov similarity theory has, however, been found to be applicable during moderate or high wind speeds when the wind direction is along the fjord axis (Kilpeläinen and Sjöblom, 2010; Mäkiranta et al., 2011; Kral et al., 2014), which resembles results from valleys. The non-dimensional wind gradients in Arctic fjords have been found to be smaller than predicted by traditional empirical similarity functions, indicating a higher momentum flux than expected from the vertical wind shear in the surface layer (Kilpeläinen and Sjöblom, 2010; Mäkiranta et al., 2011; Kral et al., 2014). The non-dimensional temperature gradients, in turn, have generally higher values than suggested by the traditional empirical similarity functions in unstable conditions, indicating less efficient sensible heat transport over fjords (Kilpeläinen and Sjöblom, 2010; Kral et al., 2014). In stable conditions, however, more efficient mixing of sensible heat than predicted has been reported in a fjord environment by Mäkiranta et al. (2011). They suggest that in stable conditions the wind shear above the boundary layer provides a non-local source for the turbulence which enhances the mixing over the fjord. Their interpretation was supported by tethersonde observations of Vihma et al. (2011): LLJs were often lifted above the cold air pool on an ice-covered fjord (Kongsfjorden). The 
presence of sea ice cover was found as a very important factor for determining whether a katabatic flow can reach the fjord surface or be elevated above the stable boundary layer (Vihma et al., 2011). Effects of sea ice cover on spatial variations in the ABL over a Svalbard fjord were also detected by Láska et al. (2012).

Orographic effects are sometimes responsible for the genesis of polar mesoscale cyclones, e.g. in the case of lee cyclones southeast off Greenland. In most cases, however, polar mesoscale cyclones are not directly related to orographic forcing and are discussed in a separate section below.

\subsubsection{Mesoscale cyclones}

Polar mesoscale cyclones are vortices north of the main polar frontal zone, with the most intense ones (near-surface wind speeds more than $15 \mathrm{~m} \mathrm{~s}^{-1}$ ) being classified as polar lows. They are typically short-lived (12-48 h in duration) and generally occur over the subpolar seas. They fall broadly into two classes: those that are fundamentally convective, i.e. forced by large air-sea heat fluxes, and those that are fundamentally baroclinic, i.e. instabilities of a horizontal temperature gradient, often associated with Arctic fronts. In reality, most polar mesoscale cyclones have a mixture of these forcing mechanisms at different stages of their life cycle. Polar mesoscale cyclones tend to occur over the sub-polar seas, e.g. the Greenland, Norwegian, Iceland, Barents, Irminger, Labrador, and Bering seas, the Sea of Japan, and the Gulf of Alaska in the Northern Hemisphere. Further background can be found in, e.g. Renfrew (2003) and Rasmussen and Turner (2003).

In recent years there has been an upsurge of interest in polar lows. The IPY was a focal point for a number of field campaigns which observed polar lows, including GFDex (e.g. Renfrew et al., 2008) and the Norwegian IPY-Thorpex campaign (Kristjánsson et al., 2011). In the latter, arguably the most comprehensive set of observations of a polar low to date were obtained for a case over the northern Norwegian Sea, enabling studies of the structure, dynamics, lifecycle, simulation accuracy, and predictability of this event (e.g. Linders and Saetra, 2010; Føre et al., 2011; Føre and Nordeng, 2012; McInnes et al., 2011; Wagner et al., 2011; Irvine et al., 2011; Aspelien et al., 2011; Kristiansen et al., 2011). Finding, for example, that this case had critical upper-level forcing (Føre et al., 2011), and was more accurately simulated with a convection-permitting grid resolution of 4 or $1 \mathrm{~km}$ (McInnes et al., 2011). Operational weather forecasting systems have now reached the state where polar lows should be able to be predicted routinely. Numerical weather prediction grid sizes have been adequate for some time, but observing and data assimilation systems have not always been able to consistently provide suitable initial conditions; for example, in Irvine et al. (2011) there was strong sensitivity to the initial conditions. Regional high-resolution ensemble prediction systems (EPS) provide a realistic prospect of robust predic-

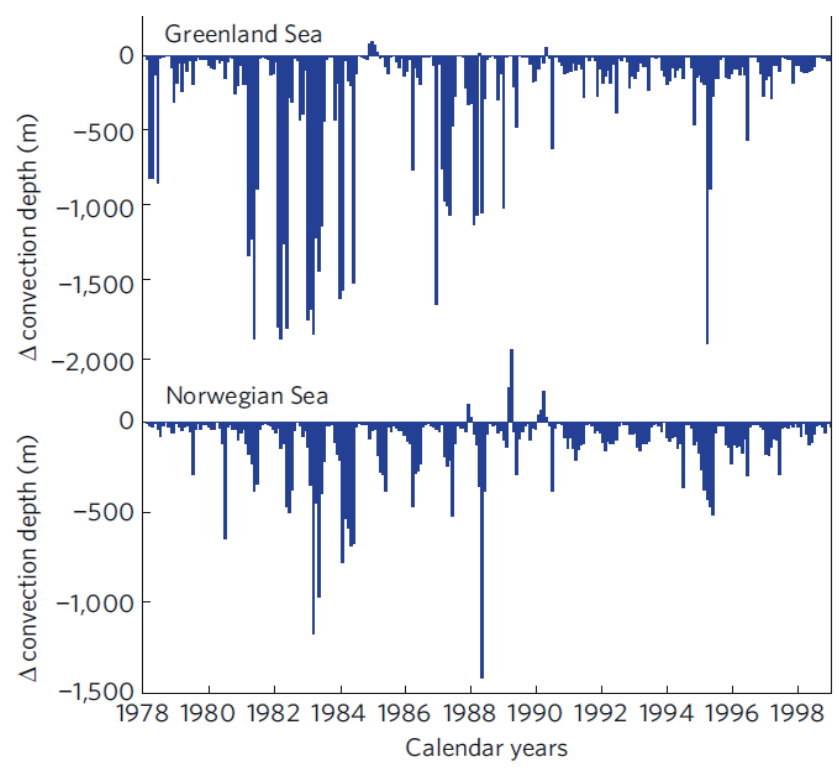

Figure 6. Differences in the monthly maximum depth of openocean convection in ocean model experiments with and without polar lows included in the atmospheric forcing (a) the Greenland Sea and (b) the Norwegian Sea. Reproduced with permission from Condron and Renfrew (2013).

tions at the mesoscale, tackling initial condition sensitivity for example. These regional EPS systems are still being developed and optimizing their setup for polar lows is a current challenge (Aspelien et al., 2011; Kristiansen et al., 2011). For example, Kristiansen et al. (2011) found a crucial dependence on EPS domain size and location, as well as on certain parameterization settings.

Polar mesoscale cyclones are not explicitly resolved by the current generation of global climate models. Due to their high impact, predictions of any changes in frequency or location of occurrence are important. A couple of recent studies address this: Kolstad and Bracegirdle (2008) use marine cold air outbreaks as a proxy for polar low activity; while Zahn and von Storch (2010) use dynamical downscaling to simulate polar mesoscale cyclones. In both studies a migration northwards is found, following the retreating sea ice pack, and consequently there is a decrease in the frequency of polar lows through the 21st century.

Polar lows are highly coupled phenomena. Large fluxes of heat, moisture, and momentum from the relatively warm ocean are usually crucial for their development. Hence they also provide a strong forcing for the ocean, e.g. deepening the mixed layer, thus bringing warmer waters to the surface (Saetra et al., 2008) and changing water mass properties and consequently the ocean circulation (Condron et al., 2008; Condron and Renfrew, 2013). In a set of high resolution ocean modelling experiments with and without polar lows, Condron and Renfrew (2013) found adding polar lows significantly increases the depth of deep convection (Fig. 6), spins 

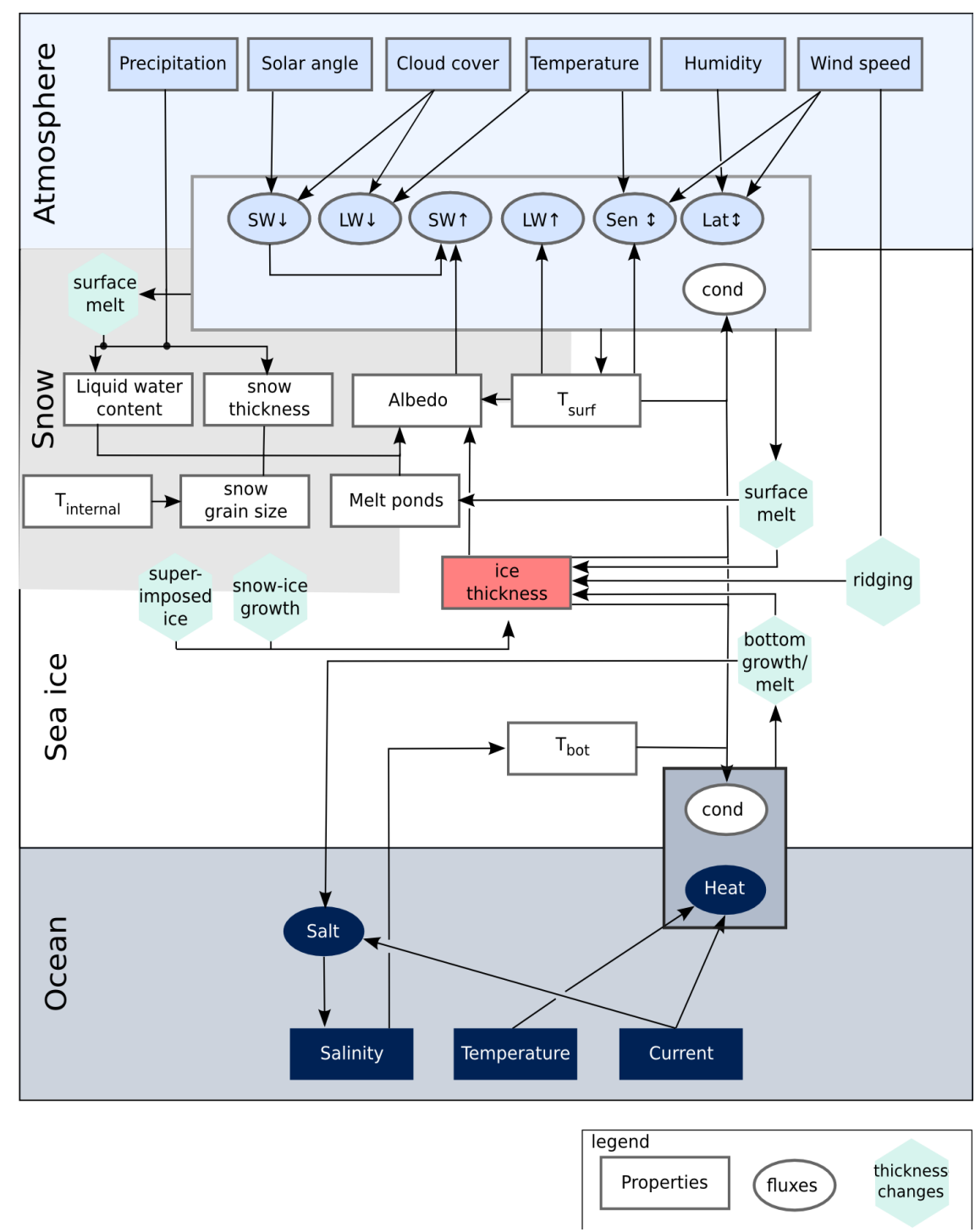

Figure 7. Schematic overview of some of the processes that influence and are influenced by the growth and melt of sea ice. Only the most important pathways of interaction are shown. SW is shortwave radiation, LW is long-wave radiation, Lat is latent heat flux, Sen is sensible heat flux, Cond is conductive heat flux in the ice, Heat is oceanic heat flux, Salt is oceanic salt flux, $T_{\text {bot }}$ is ice bottom temperature, and $T_{\text {surf }}$ is surface temperature.

up the Greenland Sea gyre, and increases the momentum and heat transported north in the North Atlantic subpolar gyre as well as the frequency of dense water flowing south out of the Nordic seas. The impact of polar lows on the coupled climate system is still uncertain: their occurrence is subject to changes in both the atmosphere and ocean, and any changes will potentially feedback on both the atmosphere and ocean.

\section{Sea ice and snow}

\subsection{Radiative processes and properties}

\subsubsection{Melt onset}

Based on the SHEBA data from the Beaufort Sea, Persson (2012) analysed the links between the spring onset of snow melt and free-tropospheric synoptic variables, clouds, precipitation, and in-ice temperatures. He found that the melt onset is primarily determined by large increases in downwelling long-wave radiation and modest decreases in the snow surface albedo. These changes in the radiative fluxes are related to synoptic events and seasonal warming of the free 
troposphere. The work of Persson (2012) benefited from detailed observations, but only addresses a single spring in a limited region. Maksimovich and Vihma (2012) utilized the ERA-Interim reanalysis, which are far less reliable than observations but allowed for the study of the interannual differences in the circumpolar Arctic. They found that the anomaly in net surface heat flux 1-7 days prior to the snow melt onset explains up to $65 \%$ of the interannual variance in the melt onset in the central Arctic. Among the terms of the net heat flux, the downward long-wave radiation most strongly controlled the variability of snow melt onset. Statistically, solar radiation by itself is not an important factor, but together with other fluxes it improves the explained variance of melt onset. In accordance with the above-mentioned results, the early melt onset in 2007 was preceded by an exceptionally warm spring (Vihma et al., 2008) with a large advection of warm, cloudy marine air masses from the Pacific sector (Graversen et al., 2011). After the melt onset, the evolution of the snow surface albedo and the transmissivity of the snow-ice system is crucial for the surface energy budget.

\subsubsection{Snow and ice albedo: observations and parameterizations}

A schematic illustration of snow and ice thermodynamic processes and interactions, with focus on the role of surface albedo, is provided in Fig. 7.

The detailed and complete data sets of snow/ice and atmospheric quantities that were collected during SHEBA have still been used during and after IPY to thoroughly evaluate and compare many snow and ice albedo schemes (Liu et al., 2007; Wyser et al., 2008; Pedersen et al., 2009). Several Arctic field campaigns carried out after SHEBA (including the Tara campaign of DAMOCLES) were crucial to monitor and deepen the understanding of the processes controlling the snow and ice albedo in a rapidly changing environment. Altogether, these observations have shown that the seasonal evolution of the Arctic sea ice albedo follows the surface metamorphism and change of phases, from dry snow to melting snow, pond formation, pond drainage, pond evolution, and autumn freeze-up (Perovich et al., 2009; Nicolaus et al., 2010a; Perovich and Polashenski, 2012). Seasonal ice has a lower albedo than multiyear ice, because (a) it has a thinner and therefore faster-melting snow layer, (b) the ice itself is thinner, containing a much lower fraction of scattering bubbles, and (c) melt ponds are more extensive due to less ice deformation and a smaller freeboard (Perovich and Polashenski, 2012). The area-averaged surface albedo results from a complex combination of the albedos of open water, melt ponds, snow-free sea ice, and snow-covered sea ice (Perovich et al., 2009).

As snow/ice albedo is the key factor affecting the surface energy budget over the polar areas, a large number of recent modelling studies have addressed the improvement of the snow and ice albedo representation, also with the goal of simulating the various climate feedback mechanisms affected by changes in snow/ice albedo. The climate models used in the IPCC AR4 systematically overestimated the sea ice albedo in summer, by as much as 0.05 (Wang et al., 2006), and failed to incorporate the recently observed rapid reduction of Arctic sea ice into their predicted ranges of variability. Small changes in the ice albedo scheme may lead to significant changes in the simulation of summer sea ice extent (e.g. Dorn et al., 2007, 2009). This result called for a reconsideration of the physical basis of the sea ice albedo models, which might explain in part why the rapid reduction of Arctic sea ice is better captured by the models used for the latest assessment report AR5 (Stroeve et al., 2012; Massonet et al., 2012).

An accurate albedo calculation requires a radiative transfer model in the atmosphere and in the snow/ice layer, coupled with a snow/ice model that represent the snow/ice crystals with their optical properties and the snow/ice layering (Peltoniemi, 2007; Kaempfer et al., 2007). The size and shape of the crystals determine their optical properties, thus the crystal metamorphism is the principal driver of the albedo evolution. However, in climate and NWP models albedo is usually expressed as a function of the bulk snow/ice/atmospheric properties that more or less directly affect the snow metamorphism (surface temperature, snow age) or are affected by it (snow and ice thickness, snow density), the form of the equation and the values of the included coefficients resulting from the best fit with observations or with detailed radiative transfer calculations (Gardner and Sharp, 2010). The degree of complexity varies a lot among these models; NWP models traditionally have much less detailed surface schemes than climate models. Prognostic snow and ice albedo parameterizations, which include a time-dependent albedo decay, gave the best results when their performance was compared with simpler temperature-dependent parameterizations (Essery et al., 2012; Wyser et al., 2008). Among the prognostic schemes, one of the most sophisticated is the model introduced by Dickinson et al. (1993), which accounts for the albedo dependence on spectral bands and direction of the illumination. It has been implemented in many climate models (Bitz et al., 2012; Goosse et al., 2009), and it has also been coupled to an explicit treatment of melt pond albedo (Pedersen et al., 2009).

Variations in the areal melt pond coverage are a major driver of albedo changes on melting Arctic sea ice. Considering observations of melt ponds, the drift of Tara in DAMOCLES offered a valuable opportunity to observe the temporal change of multiyear sea ice at very high latitudes. Sankelo et al. (2010) quantified the areal melt pond coverage at about $88^{\circ} \mathrm{N}$, which was higher than expected on the basis of previous observations, with maximum pond coverage of $32-42 \%$ in mid-August. Rösel et al. (2012) presented the first satellite-derived Arctic-wide, multi-annual melt pond data set. The study for the time period from 2000 to 2011 was based on Moderate Resolution Image Spectroradiometer 
(MODIS) data. Since there is an ongoing shift in the Arctic sea ice cover from multiyear ice to seasonal ice (Perovich and Polashenski, 2012), melt pond studies for first-year ice are becoming more and more important. Recent sophisticated field studies of melt ponds on seasonal sea ice were conducted on land-fast ice in the Chukchi Sea during the summer melt seasons of 2008, 2009, and 2010 (Polashenski et al., 2012). Ice surface topography and melt water balance are found to both play key roles in melt pond evolution.

Substantial efforts have already been made to formulate physically based models of melt pond formation and evolution to predict melt pond coverage (Scott and Feltham, 2010; Skyllingstad et al., 2009; Flocco and Feltham, 2007) and to incorporate explicit melt pond parameterizations/models into albedo calculations of global and regional sea ice and climate models (Holland et al., 2012; Flocco et al., 2010; Hunke and Lipscomb, 2010; Pedersen et al., 2009; Køltzow, 2007). The explicit consideration of melt pond effects has a huge impact on the simulated Arctic sea ice cover as shown, for example, by Flocco et al. (2012) who incorporated their pond model into the Los Alamos Community Ice CodE (CICE) sea ice model. Simulations for the period of 1990 to 2007 are in good agreement with satellite-based ice concentration. In comparison to simulations without ponds, the September ice volume is nearly $40 \%$ lower.

In the melt water accounting conceptualization, a melt pond can be represented as a volume of water determined by the balance of inflows and outflows, distributed in the lowest points of local topography (Polashenski et al., 2012). The general approach of the general circulation model (GCM) melt pond parameterizations by Holland et al. (2012), Hunke and Lipscomb (2010), and Pedersen et al. (2009) is based on this concept. ECHAM5 (Pedersen et al., 2009) and the Community Climate System Model (CCSM) CICE 4.0 (Holland et al., 2012; Hunke and Lipscomb, 2010) use functional relationships to relate pond depth to pond area fraction. CICE 4.0 uses a linear function, and the ECHAM5 version applied by Pedersen et al. (2009) used a more complex function. The linear function is based on SHEBA data. However, Polashenski et al. (2012) show that the relationship between melt pond depth and area fraction is not unique. Polashenski et al. (2012) suggest that a better solution to compute both quantities would be to relate components of the melt water balance to ice properties already calculated in the GCMs, and to collect data representing the topography of various ice types to better parameterize the areal distribution of melt water. The results of their field studies identify links between the temporal evolution of pond coverage and ice temperature, salinity, and thickness. Hence, measurement results provide new opportunities for realistically parameterizing ponds within sea ice models.

The simulation of surface albedo is also related to the representation of the thermal insulation of the snowpack, which is coupled to the modelling of snow mass and density. Compared to observations, more consistent results are obtained from those snow schemes that include a prognostic representation of snow density and take some account of the storage and refreezing of liquid water within the snow (Essery et al., 2012; Dutra et al., 2012). Presently, snow albedo schemes are more advanced over land than over sea ice. The reason is related to the complexity of the sea ice surface types, especially during melting conditions (Fig. 7). The Louvain-laNeuve sea ice model (LIM2), recently implemented into the ECMWF forecasting system (Molteni et al., 2011) has a sea ice albedo parameterization which includes several snow and ice categories, depends on snow and ice thickness and cloudiness, does not retain any melt water, and implicitly accounts for a constant melt pond fraction when the surface is melting. However, there is ongoing development of a more comprehensive snow model that includes a variable vertical resolution based on density stratification, the representation of melt ponds and superimposed ice formation. Also, in the case of CCSM, the land snow scheme (Community Land Model - CLM4, Lawrence et al., 2011) has a more advanced snow thermodynamic treatment than the latest version of the sea ice scheme (CICE4.0, Hunke and Lipscomb, 2010), which has fixed snow and ice density and thermal conductivity. This oversimplification was partly responsible for positive biases in snow thickness over the Arctic, and excessive late autumn and early winter snow density, with feedbacks on the albedo (Blazey et al., 2013).

The widely applied NWP and research model WRF is of ten used with an oversimplified snow albedo parameterization (a constant value of 0.8 ), which leads to large errors in summer shortwave radiative fluxes (Porter et al., 2011). To simulate Arctic atmospheric conditions during the SHEBA experiment, a simple idealized albedo model based on the SHEBA observations (Perovich et al., 2007a) and a satellite data set were used in Polar WRF (Bromwich et al., 2009). This albedo model was then applied to the entire Arctic Ocean to simulate the 1-year period from December 2006 to November 2007 (Wilson et al., 2011). Simulated annual mean temperatures had, however, a cold bias of -1 to $-2{ }^{\circ} \mathrm{C}$ (Wilson et al., 2011).

On some occasions, some of the most sophisticated prognostic albedo parameterizations in GCM and NWP models have been defined as "physically based" to distinguish them from even simpler albedo schemes (Essery et al., 2012), but in fact, they do not allow for coupling between penetration of solar radiation into the snow and ice layer, the micro-scale characteristics of the ice crystals, and the surface albedo. The gap between the snow albedo formulated in detailed radiative transfer and snow models and the albedo parameterizations applied in GCM and NWP models has recently been narrowed by the development of a prognostic parameterization of snow grain metamorphism, which links snowpack microphysics to albedo evolution (Flanner and Zender, 2006). In this SNow and ICe Aerosol Radiation (SNICAR) model, albedo is calculated from the inherent scattering-absorption properties of snow crystals and included absorbers. SNICAR 
has recently been implemented in sea ice models with detailed radiative transfer schemes and high vertical resolution (for instance the CCSM CICE4.0, Holland et al., 2012), contributing to a significant improvement in the simulation of Arctic albedo and sea ice concentration (Gent et al., 2011).

Many of the recently developed snow and ice albedo parameterizations have not yet been thoroughly evaluated against field observations. High quality, complete data sets of radiation and snow and ice properties are extremely rare and still their acquisition requires large efforts. Because of uncertainties in the forcing data and oversimplifications in representing many physical processes, increasing the complexity of the schemes may lead to severe simulation errors, and existing biases in the driving parameters will propagate to the processes that depend on them. Thus, even the simplest parameterizations can give equally good or bad results as the most complex ones (Essery et al., 2012; Brun et al., 2008). Recent advances in the remote sensing retrieval techniques of surface albedo over the Arctic allowed for the collection of a 28-year time series of albedo estimations in all sky conditions (Riihelä et al., 2013), offering a valuable reference data set to analyse spatial and temporal albedo variability.

The transfer of solar shortwave radiation under cloudy skies in the boundary zone of the open sea and snow/ice cover is a complex process that has not yet received much detailed attention. Pirazzini and Räisänen (2008) found that under overcast skies with multiple reflections between the cloud base and the snow/ice surface, the local value of downwelling solar radiation also depends on the albedo of the neighbouring surface type. They further derived a simple parameterization for the broadband effective albedo, defined as the albedo of a homogeneous surface that would result in the same downwelling irradiance as locally observed in the presence of a heterogeneous surface.

\subsubsection{Aerosol deposition on snow and ice}

Aerosol deposition on snow and ice is an issue that has witnessed substantial research recently. As black carbon (BC) effectively absorbs visible radiation, it causes acceleration in the growth of snow grains, and therefore an overall decrease in albedo. In particular, Hansen et al. (2005) suggested that the effect of BC on snow albedo contributes substantially to rapid warming and sea ice loss in the Arctic, although recent measurements (Forsström et al., 2009, 2013; Doherty et al., 2010) have shown substantially lower levels of BC than was observed in the 1980s (Clarke and Noon, 1985). In view of these findings, parameterizations of BC and soot concentration in snow have been recently developed (Flanner and Zender, 2006; Yasunari et al., 2011; Aoki et al., 2011). Evaluations of these parameterizations have revealed their capability to better reproduce the observed snow albedo and snow depth (Yasunari et al., 2011; Hadley and Kirchstetter, 2012). Moreover, it has been found that the $\mathrm{BC} /$ snow radiative forcing in the Arctic is at a maximum coincidentally at the time of snowmelt onset (Flanner et al., 2007), triggering strong snow albedo feedback in local springtime. For this reason, although the magnitude of the climate response from lightabsorbing particles on snow is much smaller than the impact of doubling $\mathrm{CO}_{2}$, the sensitivity of the atmosphere to the $\mathrm{BC} /$ snow forcing (i.e, the temperature change per unit of forcing) is three times larger than the sensitivity to the $\mathrm{CO}_{2}$ forcing (Goldenson et al., 2012; Flanner et al., 2007).

The Flanner et al. estimation of global annual mean $\mathrm{BC} /$ snow surface radiative forcings $\left(0.054\right.$ and $0.049 \mathrm{Wm}^{-2}$ during strong (1998) and weak (2001) boreal fire years) was in line with the IPCC AR4 estimation (IPCC, 2007) and was later confirmed by other studies (Wang et al., 2011; Goldenson et al., 2012). Over large areas of the Arctic Ocean and sub-Arctic seas, the autumn and winter near-surface warming resulting from this radiative forcing is $1-2{ }^{\circ} \mathrm{C}$ (Goldenson et al., 2012). Through 20 th century equilibrium climate experiments, Koch et al. (2009) obtained a $0.5^{\circ} \mathrm{C}$ mean Arctic surface warming due to the $\mathrm{BC} / \mathrm{snow}$ albedo effect. In equilibrium climate experiments, the effect of present-day aerosol deposition on sea ice thickness was estimated to be a thinning of about $30 \mathrm{~cm}$ (averaged over the year) compared to a scenario without aerosol deposition (Goldenson et al., 2012; Holland et al., 2012). Nevertheless, since the BC content in Arctic snow has decreased since the 1980s, it is improbable that the present aerosol load has contributed to the recently observed rapid decline of Arctic sea ice. Koch et al. (2011) attributed about 30-50\% of Arctic warming and ice melt that occurred in early 20 th century to the BC albedo effect, but determined that later in the century the reduction in Arctic BC contributed to Arctic cooling and increased snow/ice cover, so that on average, over the 20th century, only about $20 \%$ of Arctic warming and ice melting was attributable to the $\mathrm{BC}$ albedo effect.

Through idealized experiments, Flanner (2013) concluded that the current simulated distribution of Arctic atmospheric BC slightly cools the surface with a sensitivity of $-0.21 \pm 0.32 \mathrm{~K}\left(\mathrm{Wm}^{-2}\right)^{-1}$ supporting an earlier study (Shindell and Faluvegi, 2009), while the atmospheric and cryosphere-deposited BC originating from the Arctic (mostly Siberian forest fires) warms the Arctic with a sensitivity of $+0.5 \pm 0.4 \mathrm{~K}\left(\mathrm{Wm}^{-2}\right)^{-1}$. Flanner et al. (2009) argued that, in springtime, the radiative effect of the reduction of surface-incident solar energy (dimming) caused by atmospheric aerosols containing BC and organic matter has been smaller than the effect of the reduction of snow albedo caused by deposition of such aerosols (darkening), resulting in a warming. However, this is probably true only for the first half of the last century, as in more recent decades the dimming effect (causing atmospheric cooling) has likely dominated over darkening (Koch et al., 2011). 


\subsubsection{Transmittance of sea ice and snow}

Knowledge about the transmittance of sea ice for solar radiation is crucial when assessing the surface energy balance, and within that the contribution of atmospheric versus oceanic forcing to ice melt, and the radiation available for the ecosystem in and below the sea ice. Transmittance of the sea ice system depends on snow and ice properties, and on possible content of algae in the ice (e.g. Mundy et al., 2007). During recent years, spectral radiometer surveys have yielded substantial advances in resolving characteristics of transmittance of sea ice in time and space. Light et al. (2008) summarized SHEBA transmittance measurements under different ice types at different stages of the seasonal evolution of sea ice. Autonomous setups (Nicolaus et al., 2010b; Wang et al., 2014) have been installed on drifting ice floes, measuring transmittance continuously over periods covering the entire transition from freezing to melt and back to freezing conditions (Nicolaus et al., 2010a; Wang et al., 2014). With this, the nature, timing, and length of the period of increased transmittance during summer, related to snow metamorphism, snow melt, and ice properties, can be quantified. Such measurements are limited regarding information in space. Despite the fact that the ice floe with the autonomous setup is drifting, and thus covers a larger geographical area, the ice floe remains the same. New studies investigated the spatial variability of sea ice, and herein especially of first-year ice, the ice type that increases in relative portion over the Arctic as a whole at the cost of multiyear sea ice. Frey et al. (2011) studied an ice floe with a number of individual measurements under locations with different surface characteristics, and quantified the role of melt ponds for the radiation balance below the ice. By combining surface measurements from a sledge-based system (Hudson et al., 2012) with measurements carried out by divers beneath the ice, the complete radiation balance of the first-year sea ice system could be quantified, for a given case and stage (Hudson et al., 2013). Similar observations were also done over landfast ice near Barrow, Alaska, but with the under-ice radiation measured from a sledge that slides along the underside of the land-fast ice, pulled with a rope (Nicolaus et al., 2013).

On larger scales, models can help to estimate the amount of light penetrating the ice and its heating effect (e.g. Itoh et al., 2011). This requires, however, a good vertical resolution. Climate and NWP models have traditionally used a single snowpack layer, but a high vertical resolution in snow and ice models has been revealed to be important for correctly simulating light scattering coefficients (Light et al., 2008), surface albedo (Aoki et al., 2011), the onset of ice melt (Cheng et al., 2008b), sub-surface grain metamorphism and melt (Dadic et al., 2008; Cheng et al., 2008a, b), the vertical profile of thermal conductivity (Dadic et al., 2008), and deep snowpack conditions (Dutra et al., 2012). The increase in vertical resolution has yielded a fundamental improvement in the treatment of the penetration of shortwave radiation in snow and sea ice (Briegleb and Light, 2007; Light et al., 2008). By accounting for the ice layering, Light et al. (2008) concluded that much less radiation is absorbed in the uppermost highly scattering layer, and more light is predicted to penetrate deep into the ice and into the ocean than was previously accounted for. This modelling progress is parallel to the increased effort in simultaneous measurements of snow/ice spectral albedo and transmittance (Nicolaus et al., 2010a, b; Perovich, 2007; Ehn et al., 2008a, 2011), which have also revealed the impact of some biological processes on sea ice transmittance in the central Arctic (Nicolaus et al., 2010b) and on land-fast ice (Ehn et al., 2008a, b, 2011).

Radiative processes in sea ice and snow closely interact with sea ice structure and other processes, such as snow and ice melt, heat conduction, refreezing of melt water, and gravity drainage of salt (Fig. 7).

\subsection{Sea ice structure and non-radiative processes}

\subsubsection{Internal structure of sea ice: salinity and gravity drainage}

The internal structure of sea ice consists of a mixture of solid freshwater ice, liquid salty brine, and gas inclusions, whose interaction on the millimetre scale crucially affects the largescale behaviour of sea ice. This interaction defines the evolution of the solid fraction within sea ice, which in turn defines virtually all large-scale properties of sea ice; these include the heat capacity, heat conductivity, mechanical strength, and susceptibility to percolation of surface melt water to name but a few. In addition, the small-scale processes governing the interior structure of the ice define how efficiently brine can drain from the ice, which in turn contributes to shaping the large-scale circulation of the world ocean.

Most of our recent progress in modelling the small-scale structure of sea ice has come from the application of the socalled "mushy layer" theory (e.g. Feltham et al., 2006). This theory describes any multi-component, multi-phase reactive porous medium of which sea ice is but one example. This theory has in particular allowed us to better understand the temporal evolution of sea ice salinity (Notz and Worster, 2009). This understanding is crucial because the salt content and temperature of sea ice define, together with the amount of entrapped gas, the solid fraction of the ice as the most fundamental parameter for describing the state of a specific sea ice sample. We now know that, initially, all salt that is contained within sea water is also contained in newly formed sea ice. Much of this salt then rapidly drains out by convective overturning, which in the interior of the ice replaces dense, salty brine with less salty sea water (so-called gravity drainage). This leads to a rapid reduction of the salinity of sea ice and in turn increases the solid fraction of the ice. Additional loss of salt then occurs in summer through the slushing of fresh surface melt water that percolates through the ice. Measurements from warm first-year sea ice exposed 
to an increased oceanic flux show substantial desalination (Widell et al., 2006). Based on this understanding, models are starting to simulate in a physically consistent way the evolution of the bulk salinity of sea ice from its initial formation to its complete melt. Such models range from specialized models of gravity drainage (Wells et al., 2011; Rees Jones and Worster, 2013a, b) to more applied models that present simplified parameterizations of this major desalination process for the use in large-scale models (Turner et al., 2013; Griewank and Notz, 2013). Based on these models, a more realistic representation of the interaction between the smallscale structure of sea ice and the ocean and the atmosphere has now become possible.

For more details on this topic, we refer to the recent dedicated review article by Hunke et al. (2011).

\subsubsection{Formation of superimposed ice and snow ice}

Snow ice and superimposed ice are generated by refreezing of snow slush (Fig. 7). The slush layer is created by either ocean flooding or snow melting. In the case of ocean flooding, the product of refreezing is called snow ice, whereas in the case of snow melt and percolation of the melt water down to the snow-ice interface, the refreezing generates superimposed ice. Even long before the IPY, the generation of snow ice had already been taken into account in sea ice models (e.g. CICE, LIM) with a simplification of the Archimedes' principle, with more detailed modelling for seasonal sea ice presented in Cheng et al. (2006), for example.

The contribution of snow ice and superimposed ice to the total ice mass in the Arctic has, however, not received much attention so far. This is partly due to the fact that snow ice has been rarely formed in the Arctic, since the ratio of snow thickness to ice thickness has usually been low. Superimposed ice has been observed to occur in Arctic sea ice (e.g. Nicolaus et al., 2003; Wang et al., 2014), but it is usually rapidly deteriorated in the following melting season. Pre-IPY work in modelling of snow ice and superimposed ice mainly focused on sub-Arctic seas (Baltic Sea, Sea of Okhotsk) and to some extent on the Chukchi Sea (Cheng et al., 2008b). In Semmler et al. (2012) the modelled ice thickness on an Arctic lake showed a large improvement when snow ice and superimposed ice were taken into account.

The source term for snow ice and superimposed ice is the total precipitation available on ice. Accurate information on precipitation is critical for modelling, particularly in early winter. Detection of snow thickness in the Arctic is challenging because it is subject to large spatial and temporal variations, due to, for example, wind drift. The effects of wind also make in situ precipitation measurements liable to errors, which can be as large as $200 \%$ (Aleksandrov et al., 2005). Further, in situ measurements are rare, making NWP models the primary source of atmospheric forcing for snow and ice modelling. Cheng et al. (2013) introduced a simple snow parameterization scheme connected to precipitation from an
NWP model to account for snow accumulation in the early winter season.

Snowfall declines in the Arctic summer, which is mainly due to the change of precipitation from snowfall to rain with very little change in total precipitation (Screen and Simmonds, 2012). However, considering total annual precipitation, climate models project an increase (e.g. Overland et al., 2011). This together with the thinning of sea ice will likely result in a more extensive occurrence of snow ice and superimposed ice in the Arctic, with larger contributions to total ice mass (their contributions are already large, e.g. in the Baltic Sea and, for snow ice, in the Antarctic).

\subsubsection{Heat conduction}

The mass balance of sea ice and its snow cover largely depend on heat conduction through snow and ice (Fig. 7). Conductive heat flux contributes to the surface energy budget, and the melt/growth at the ice bottom is controlled by the difference between conductive heat flux and ice-water heat flux. Heat conduction is vitally important also for the consolidation of raft ice (Bailey et al., 2010). The thermal conductivity of snow is usually parameterized as a function of snow density, and that of sea ice, as a function of ice temperature and salinity (Maykut and Untersteiner, 1971). Pringle et al. (2007) presented a new parameterization for sea ice on the basis of amended data analysis; heat conductivity was higher than that based on Maykut and Untersteiner (1971): by 5$10 \%$ for multiyear ice and by $5-15 \%$ for first-year ice. For snow, a micro-tomographic study by Calonne et al. (2011) indicated that effective thermal conductivity increases with decreasing temperature, mostly following the temperature dependency of the thermal conductivity of ice. Accordingly, a temperature and density dependent heat conductivity of snow should be used in models (Lecomte et al., 2011).

The temperature dependence of snow and ice heat conductivity is a bulk effect, as indeed conductivity depends on the micro-structural and mechanical properties of the snow and ice texture, which change when subjected to temperature gradients. This became evident in temperature gradientsnow metamorphism experiments at a constant density: heat conductivity increased as much as twice its initial value in response to changes in structure and texture (Scheebeli and Sokratov, 2004), showing strong anisotropic behaviour (Shertzer and Adams, 2011). Moreover, Dominé et al. (2011) observed that the thermal conductivity of snow can be expressed as a function of snow density and shear strength alone.

In the Arctic, the spatial inhomogeneity of snow distribution has a major impact on regional heat conductivity, especially when snow depth is less than $0.4 \mathrm{~m}$. When snowpack is thin on average, bare ice is likely present because of the effect of wind in redistributing the snow thickness. Hence, effective snow heat conductivity would be a mixture of heat conductivity of snow and ice (Semmler et al., 2012). 


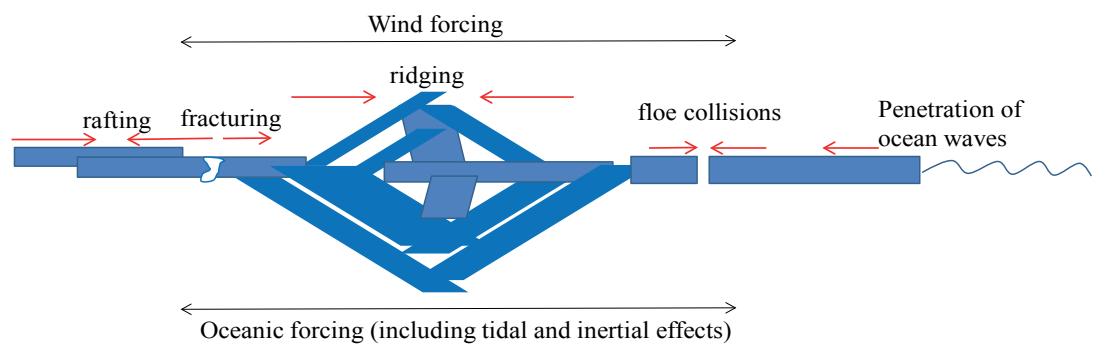

Figure 8. Processes generating mechanical waves travelling within sea ice.

\subsection{Small-scale dynamics of sea ice}

Sea ice dynamics are closely tied to the processes discussed above; they are forced by the air-ice momentum flux (Sect. 2.1.4) and affect the regional albedo (Sect. 3.1.2), heat fluxes from the ocean to the atmosphere via leads and polynyas (Sect. 2.1.3), and sea ice growth via rafting and ridging (Fig. 8), which further affects sea ice thermodynamics (Sects. 3.1 and 3.2).

\subsubsection{Sea ice deformation}

The much-faster-than-expected drift of the Tara in 20062007 along the Transpolar Drift was among the first signs of ongoing profound changes in Arctic sea ice mechanics and kinematics (Gascard et al., 2008). A systematic analysis covering 30 years of buoy drift data revealed a significant increase of both sea ice drift speeds and deformation rates over this period within the Arctic Basin (Rampal et al., 2009), with obvious consequences in terms of sea ice export, negative mass balance, and decline (Rampal et al., 2011). This accelerated kinematics does not simply result from sea ice shrinking and thinning but is also the consequence of a recent mechanical weakening of the Arctic sea ice cover in both winter and summer (Gimbert et al., 2012b). This mechanical weakening is likely related to an intensification of sea ice fracturing and fragmentation. This calls for a better understanding of these processes from local to regional scales. Indeed, through lead opening, sea ice fracturing partly controls energy fluxes between the ocean and the atmosphere (see Sect. 2.1.3), and to an extent momentum fluxes through a modification of surface roughness and drag coefficients (Sect. 2.1.4).

Mechanical waves travel within the Arctic sea ice cover, generated by ocean surface waves as well as sea ice fracturing, ridge build-up, and floe collisions (Fig. 8). While in situ stress measurements (Weiss et al., 2007) and aerial/satellite observations are essential to explore sea ice mechanics, a high frequency monitoring of sea ice fracturing and faulting, i.e. at the timescale of crack propagation, was not available until recently except for short-duration (week-long) experiments that only investigated high-frequency noise (e.g. Dudko et al., 1998). During the DAMOCLES field campaign in spring 2007 , a network of broadband $(100 \mathrm{~Hz}-60 \mathrm{~s})$ threecomponent seismometers was installed around Tara, recording signals dominated by ice swell (Marsan et al., 2011). Marsan et al. (2012) exploited the dispersion of this ubiquitous signal, i.e. the fact that the higher the frequency, the faster the wave propagation, and its dependence on the ice thickness, to invert the average thickness of Tara's floe. The results agreed well with electromagnetic measurements and drill hole profiles conducted on the same floe (Haas et al., 2011), thus validating the use of a classical concept (the dependence of wave propagation on ice thickness) to passively monitor sea ice thickness on a regular basis over horizontal scales from $10^{0}$ to $10^{2} \mathrm{~km}$.

These original seismic observations pave the way to more systematic recording and analysis of waves in ice over larger space and time scales in order to (i) monitor average ice thickness and its evolution at the regional scale and to (ii) complement satellite measurements of sea ice deformation by providing a much more detailed temporal sampling and therefore a better characterization of sea ice fracturing processes. This should help to constrain the parameterization of sea ice strength in sea ice models. Indeed, sea ice strength is still poorly constrained, both at the local or pan-Arctic scale, and an analysis of the response of sea ice to the Coriolis forcing is a way to estimate it.

\subsubsection{Relationships of inertial oscillations and sea ice rheology}

As mentioned in the previous section, the weaker the sea ice cover, the easier its fracturing and fragmentation. Consequently, when sea ice becomes more mobile, it is characterized by larger speeds and deformation rates. To measure such possible mechanical weakening at the global scale is difficult. This has been performed recently from the analysis of the response of sea ice to the well-defined Coriolis force, i.e. of inertial oscillations (Gimbert et al., 2012a, b).

In ice-covered waters, the amplitude of inertial oscillations depend on the ice state (thickness, concentration) as well as on ice rheology. For an ice cover consisting of a loose assembly of floes, such as south of Fram Strait (Lammert et al., 2009), we expect ice internal stresses to vanish, ice floes to move nearly in free drift, and therefore inertial oscillations to 

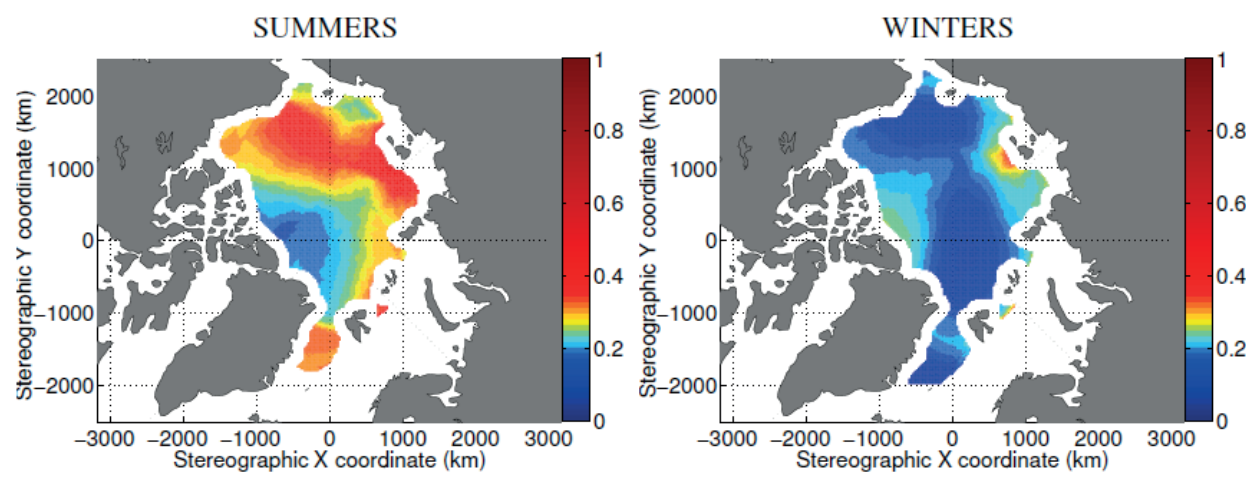

Figure 9. Spatial distribution of the magnitude of inertial oscillations in Arctic sea ice in summer in (a) 1979-2001 and (b) 2002-2008. The colour scale presents a non-dimensional parameter that Gimbert et al. (2012a) calculated to represent the magnitude of inertial oscillation. Reproduced with permission from Gimbert et al. (2012).

be strong. In contrast, in a compact ice cover, strong internal stresses immediately damp the oscillations, which become undetectable (Gimbert et al., 2012a). Therefore, the measurement of the average amplitude of these oscillations from ice drifter data can be used to estimate the amount of mechanical dissipation within the ice cover as well as its degree of cohesiveness and mechanical strength. Averaging must be done both in space, to mitigate sparse sampling, and in time, especially as inertial oscillations are particularly large after (episodic) strong winds.

Such quantitative analysis was performed by Gimbert et al. (2012a) on the basis of the buoy trajectory data set of the International Arctic Buoy Programme covering 30 years (1979-2008). It was found that (i) the amplitude of the inertial oscillations follows an annual cycle in agreement with the corresponding annual cycles of sea ice concentration, thickness, and kinematics, i.e. stronger oscillations in summer, (ii) oscillations are stronger in peripheral zones of the Arctic (the Beaufort Sea, eastern Arctic, and south of the Fram Strait) corresponding nowadays to first-year sea ice or to loose ice pack, and (iii) their average amplitude has significantly increased, especially in summer (Fig. 9). While the first two observations suggest that the use of inertial oscillations is relevant as a proxy for cohesion, and therefore for mechanical strength, the last observation points to a mechanical weakening over the latest 30 years at the global scale.

To discriminate the effects of the ice state (thickness, concentration) from those related to the sea ice mechanical behaviour per se, Gimbert et al. (2012b) built a coupled analytical ocean boundary layer-sea ice dynamical model and applied it to Arctic sea ice motion in the frequency domain around the inertial period. This model was able to explain the above-mentioned observations and trends obtained by Gimbert et al. (2012a). In particular, it was demonstrated that the strengthening of inertial oscillations in recent years was partly the result of a genuine mechanical weakening of ice cover, with a winter ice cover that nowadays mimics the mechanical behaviour of summer sea ice 20 to 30 years ago.
From the same model, a significant thinning of the Arctic Ocean boundary layer was also obtained, consistent with an enhanced stratification of the upper halocline triggered by sea ice melt or increasing river runoffs.

\section{Ocean}

\subsection{Ice-ocean interface: exchange of momentum, heat, and salt}

The exchanges of momentum, heat, and salt between sea ice and the underlying ocean are small-scale processes that must be parameterized in large-scale models. That these exchange processes depend on truly small-scale properties of the interface becomes particularly apparent for the exchange of heat and salt during sea ice melting. Here, early measurements showed that the melt rate of sea ice that drifts in comparably warm water is far less than would be expected from the turbulent exchange of heat and salt (McPhee et al., 1987). These small melt rates can be explained by the fact that during sea ice melting, a thin layer of meltwater with a very low salinity forms underneath the ice, which leads to a locally very stable stratification. Therefore, the far-field ocean cannot interact turbulently with the interface, but all transport is governed by diffusion across the thin sublayer underneath the retreating ice (Fig. 1; Notz et al., 2003).

Because water temperature is usually still below $0{ }^{\circ} \mathrm{C}$, the phase transition of the ice at the ice-ocean interface is not governed by a physical melt process, but rather by a dissolution process. Therefore, the double-diffusive transport of heat and salt (due to the lower molecular diffusivity of salt compared to heat) across the thin sublayer ultimately determines the ablation rate at the bottom of the ice. These processes can be parameterized for large-scale models based on a three-equation approach (Notz et al., 2003; McPhee, 2008), where three equations are solved that return the interfacial temperature, salinity, and ablation rate. A crucial parameter for these equations is the ratio of the exchange coefficients 
for heat and salt transfer across this interface. Here, recent measurements point towards a value of about 35 (Sirevaag, 2009; McPhee, 2008). The physical mechanisms that determine this value are, however, currently not well understood.

During freezing, the salty brine that is released from ice prevents the formation of a stable stratification. Hence, as long as ice is growing, the exchange of heat and salt is exclusively governed by turbulent exchange, and double-diffusive effects can be neglected (Fig. 1; McPhee, 2008). If the effect of the buoyancy flux is negligible, the main unknown then becomes the determination of the friction velocity, which in turn reduces primarily to a determination of the hydrodynamic roughness length $z_{0 \mathrm{~B}}$ at the ice-water interface. Only relatively few measurements of $z_{0 \mathrm{~B}}$ at the bottom of sea ice exist, and parameterizing $z_{0 \mathrm{~B}}$ as a function of ice type in large-scale models remains a major challenge. To our knowledge, most models prescribe a constant value and do not vary $z_{0 \mathrm{~B}}$ depending on the ice thickness distribution within a particular grid cell. This is despite the fact that $z_{0 \mathrm{~B}}$ ranges from $1 \mathrm{~mm}$ for undeformed sea ice (McPhee et al., 1999) to several centimetres for heavily deformed ice (Shaw et al., 2009) and ice in the MIZ.

The roughness length, stratification, and velocity of ice relative to the ocean together determine the exchange of momentum between the ocean and sea ice. Lu et al. (2011) found that for example in MIZ, most of the momentum transfer may occur through the form drag along the floe edge. In MIZ in the Barents Sea, Fer and Sundfjord (2007) observed dissipations rates in the upper ocean elevated above the levels expected from the wind-stress scaling, down to 2.5 times the keel depth, associated with the pressure-ridge keels. Hence, it is essential that the effects of form drag are accounted for, either via a larger value of $z_{0 \mathrm{~B}}$ or separately. This requires information or assumptions on the geometry of individual ice floes. The increasing availability of remotely sensed distribution of ice floes can, in the years to come, aid the inclusion of such distribution into large-scale models and allow for the parameterization of the related small-scale processes.

\subsection{Brine formation in the Arctic Ocean}

The salinity $(S)$ of sea ice depends on ice age and thickness (Notz and Worster, 2009) and rarely exceeds $S=15$, measured on the practical salinity scale, whereas the average salinity of polar surface water is about $S=30$. Accordingly, half of the salt contained in sea water is retained in sea ice and the other half is drained out (Sect. 3.2.1). The dense brines precipitate and convect through the surface mixed layer down to a certain depth depending on the vertical stratification and water depth. In Storfjorden, Svalbard, a major "brine factory" (Harpaintner et al., 2001), brines have two major effects depending on where they are formed. One effect is to increase salinity of the upper $100 \mathrm{~m}$ in Storfjorden in the deepest part of the fjord and the second effect is to form a benthic layer originating from the shallowest parts of the fjord and over- flowing at sill depth into the Barents Sea (Storfjordrenna). The first effect results from dilution into the underlying water masses provided that the water is deep enough to dilute the brines entirely before they reach the bottom of the fjord. The second effect results from the fact that brines precipitate to the bottom of the fjord because of shallow bottom depth. These two effects associated with brine formation may be related to the Arctic Ocean stratification.

Different processes contributing to the formation and evolution of the cold halocline layer (CHL) are described and discussed in Rudels et al. (1996). Salinization of cold water by brine rejection over shelves produces waters of varying salinities which can sink along the slope and interleave at their corresponding density levels (Aagaard et al., 1981). Depending on the density deficit, this process contributes partly to the formation and maintenance of the cold halocline or to the ventilation of the deeper waters. Middag et al. (2009) used dissolved aluminium concentrations in the Eurasian Basin that indicate deep reaching convection of shelf waters. Palaeoclimatologists (e.g. Dokken and Jansen, 1999) argued that this type of ventilation was predominant in the Arctic Ocean during the ice age in contrast with the warm period where ocean deep convection is the dominant ventilation factor for deep waters. Because of the strong upper layer stratification of the Arctic, brine rejection in the central Arctic (in leads, for example) cannot lead to deep reaching convection. This process, however, could contribute to the stratification in the upper CHL; an example from the Laptev Sea is given in Fig. 10. In the upper $100 \mathrm{~m}$, the characteristics structure of the CHL can be seen: the temperature is approximately uniform near the freezing point and salinity increases with depth. A distinguishing feature of this profile, however, is the temperature minimum between 50 and $100 \mathrm{dbar}$, where a local increase of salinity is observed. This subsurface layer of elevated salinity is at its freezing point (see the inset temperature-salinity diagram). This structure is a signature of local brine release, contributing to the variability in stratification in the CHL.

During the IPY, Bauch et al. (2011) collected an extensive data set on the oxygen isotope ratio $\delta^{18} \mathrm{O}$ in the Eurasian and Makarov basins that led them to identify layers of the CHL influenced by brine release in coastal polynyas and layers of the CHL influenced by sea ice formation over the open ocean where vertical convection is more dominant. Both processes are active in the present climate but it is not clear if one process dominates over the other.

Brine rejection occurs all over the Arctic Ocean but it is much more active in open water areas (polynyas) than in pack ice. In autumn and winter over polynyas, the sensible heat flux is usually the dominant part of the surface energy budget, with smaller contributions from the latent heat flux and net radiation (Lüpkes et al., 2012b). Consequently, the upward sensible heat flux is the main forcing term for frazil ice formation and brine release in polynyas. Due to the large Arctic sea ice retreat in summer, young sea ice expands very 


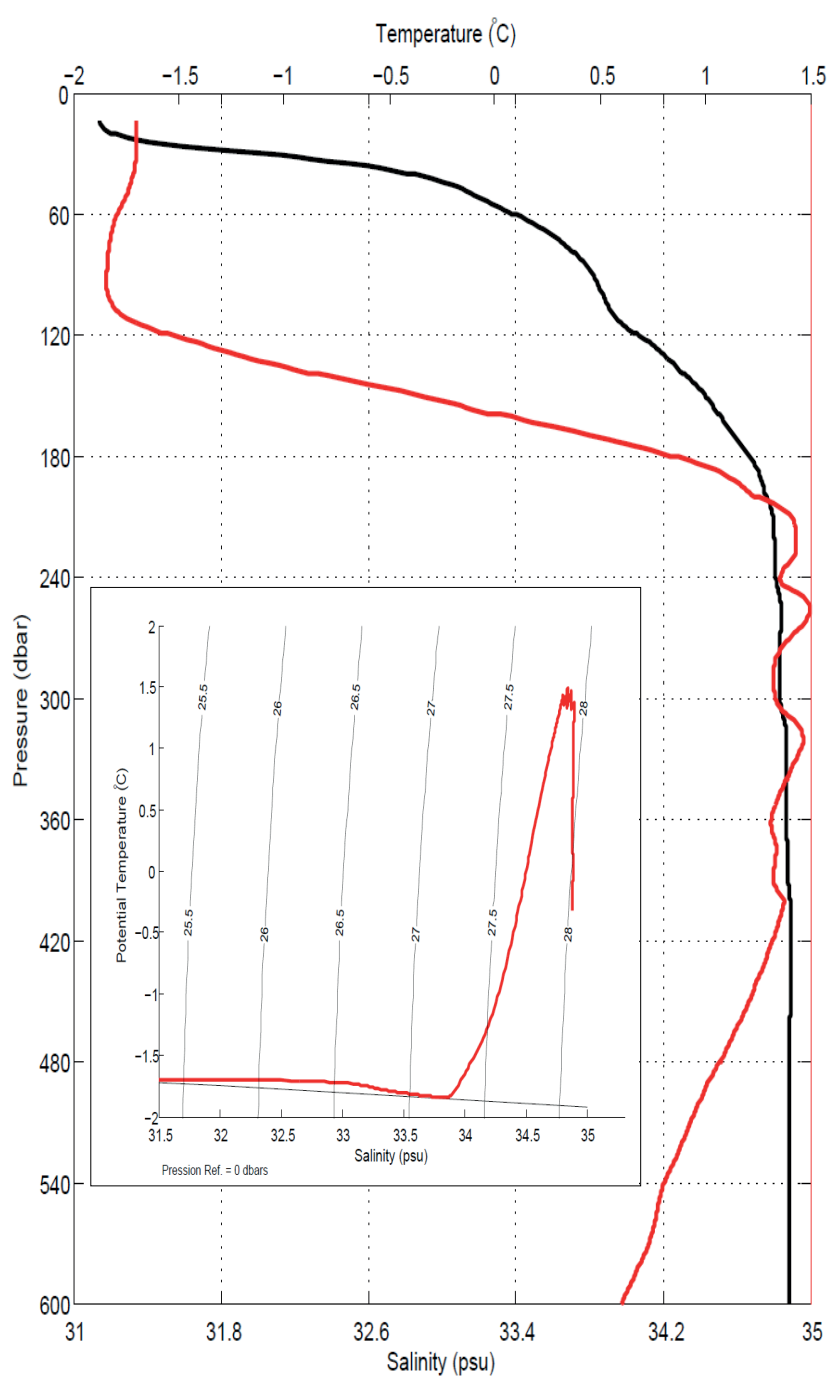

Figure 10. Temperature (red) and salinity (black, in practical salinity units) profile and temperature-salinity diagram (inner plot) of a sounding profile from 29 October 2006, close to the Laptev Sea. The isolines in the temperature-salinity diagram show the water density subtracted by $1000 \mathrm{~kg} \mathrm{~m}^{-3}$. Reproduced with permission from Bourgain and Gascard (2011).

fast in the Arctic Ocean and multiyear sea ice floes vanish. This tendency significantly enhances frazil ice formation and brine release in the Arctic Ocean, which can partly contribute to the CHL as described by Bourgain and Gascard (2011).

\subsection{Diapycnal mixing in the Arctic Ocean}

Subsurface layers with above zero temperatures in the Arctic Ocean, originating from the Atlantic and Pacific oceans, form a considerable heat reservoir. The inflow of warm Atlantic Water (AW) through the Fram Strait alone would be enough to melt $1 \mathrm{~m}$ ice per year if brought to the surface (Turner, 2010). Diapycnal mixing in the ocean is the main mechanism by which this interior oceanic heat can be fluxed

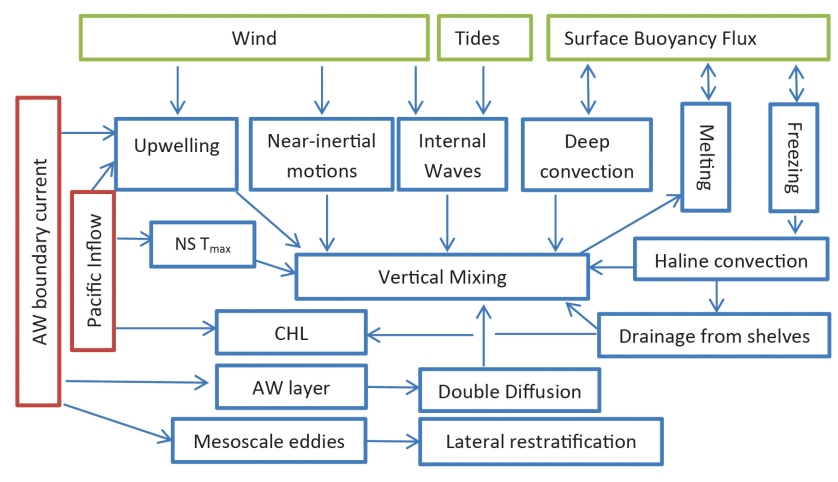

Figure 11. Main forcing (green), oceanic heat input (red), physical processes (blue), and their relations (arrows) in the Arctic Ocean. CHL is the cold halocline layer; AW is the Atlantic Water; and NS $T_{\max }$ is the near-surface temperature maximum.

to the surface, contributing to melting from the ice bottom. Mixing in the stratified interior ocean is related to internal wave energy, which tends to be low under the Arctic Ocean ice cover (Levine et al., 1985). Microstructure measurements conducted during the IPY show that the Arctic Ocean is a quiescent environment with background mixing rates close to molecular levels (Rainville and Winsor, 2008; Fer, 2009). Efficient vertical mixing and upward oceanic heat fluxes occur, however, along the continental rise and over topographic features where the warm boundary current is guided (Sirevaag and Fer, 2009; Fer et al., 2010).

An illustration of the main forcing mechanisms and physical processes leading to diapycnal mixing are summarized in Fig. 11. The reader is also referred to Fig. 2 of Padman (1995) and to Fig. 2 of Rainville et al. (2011) for sketches of the processes. Figure 2 of Rainville et al. (2011) also contrasts the dominant mixing processes for an Arctic Ocean with relatively small and large seasonal ice-free areas. In the central basins of the Arctic Ocean, the typical hydrography of the upper ocean is characterized by a $10-30 \mathrm{~m}$ thick mixed layer below the ice-ocean interface with temperature near the freezing point, overlaying a cold isothermal layer where salinity increases with depth (CHL), followed by the deeper pycnocline where both temperature and salinity increases to the relatively warm and saline core of AW. The core of AW gradually deepens as the water circulates along the margins and into the deep basins of the Arctic (Dmitrenko et al., 2008); in the Amundsen Basin, close to the North Pole, the core of the AW-derived water resides at around $300 \mathrm{~m}$ depth. Direct microstructure measurements in the Amundsen Basin, conducted during IPY show that the vertical mixing of heat is suppressed by the strong density stratification in CHL (Fer, 2009). In the central Canada Basin, subsurface temperature maxima due to intrusions of Pacific Summer Water are located at about $50 \mathrm{~m}$, i.e. closer to the ice. Utilizing the microstructure measurements made during the drift of the SHEBA ice camp, Shaw et al. (2009) reported that the 
strong stratification limited the thickness of mixing zone at the mixed-layer base. Observations made from ice-tethered profilers deployed during the IPY echo these findings (Toole et al., 2010). In addition, efficient lateral mixed-layer restratification also impedes mixed-layer deepening (Toole et al., 2010). Re-stratification as a result of sub-mesoscale (order of $1 \mathrm{~km}$ ) instabilities within the surface layer is reported using ice-tethered profiler measurements from the Canada Basin (Timmermans et al., 2012). Previous and subsequent estimates of vertical diffusivity and heat transport therefore suggest that the warm subsurface layers in the central basins cannot contribute to significant ice melt. Above the subsurface temperature and salinity maxima of AW, the stratification is favourable for double-diffusive convection (Sect. 4.4), which leads to diffusive fluxes up to an order of magnitude more efficient than molecular diffusion (Sirevaag and Fer, 2012). Given the quiescent interior and the large-scale lateral extent of diffusive staircases, the heat flux from doublediffusive convection can be significant for the average heat loss of the AW layer in the deep basins.

The competition between the role of diffusive mixing and the advection of the AW in the boundary current is decisive on the seasonality of the AW signal. The advective time scale for circum-Arctic transport of AW from the St Anna Trough to the southern Canada Basin, inferred from transient tracer data, is 7.5 years (Mauldin et al., 2010). The mixing rate between Barents Sea Branch Water in the boundary current and the interior of the Arctic is slow (5-10 years) allowing the advected inter-annually varying tracer signals to dominate over diffusion. At the Lomonosov Ridge where the boundary current bifurcates, however, the mixing rates are elevated, leading to gradual disappearance of the seasonal AW signal. Modelling results (Lique and Steele, 2012) support this; the seasonal AW signal survives over an order of $1000 \mathrm{~km}$ distance in the Nansen Basin along the continental slope whereas it is absent in the Canada and Makarov basins.

The oceanic heat is found to affect the sea ice growth and melt primarily in the MIZ (Polyakov et al., 2010; Steele et al., 2010). Heat accumulated in the upper ocean will largely be lost to the atmosphere, delaying the onset of the freezing season and sea ice growth, as well as affecting the heat and moisture fluxes. Numerical model results of Steele et al. (2010) show that approximately $80 \%$ of upper ocean warming in the Pacific sector arises from surface heat flux whereas the remaining warming originates from ocean lateral heat flux convergence. Melting as a result of upper warming induced by atmospheric fluxes, comprising of melting on the ice surface and also lateral and basal melting from local warming of the ocean surface, is responsible for about $60 \%$ of summertime melting; dynamical ocean processes, such as heat flux convergence and vertical mixing, account for the rest of the melting, with an increasing role of vertical diffusion (hence bottom melt) in late summer. In the Atlantic sector, positive temperature anomalies in the AW layer during 2007 coincided with a significant shoaling of this layer in the central
Arctic (Polyakov et al., 2010) and an estimated increase in the oceanic heat flux to the ocean surface, despite a coincident increase in stratification in the Makarov and Eurasian basins (Bourgain and Gascard, 2012). Observations from the drifting ice station ASCOS show a transition toward a more seasonal ice cover with a more pronounced freezing and melting cycle (Sirevaag et al., 2011). The heat and freshwater content in the mixed layer and upper cold halocline were significantly more and the winter mixed-layer salinity was significantly larger than those observed in the early 1990s. The ocean mixed layer was found to be heated from the top and heat was redistributed downwards by turbulent mixing.

Microstructure measurements made during IPY in the central Arctic Ocean show enhanced turbulence dissipation rates following a storm, correlated with near-inertial frequency band motions that appear in shear and strain in the upper ocean (Fer, 2014). The study emphasizes the importance of near-inertial internal wave energy and its role in mixing in the CHL and deeper Arctic stratification, primarily by modulating the Richardson number to favour shear production of turbulence kinetic energy. While the diapycnal mixing in the interior Arctic Ocean is quiescent, primarily due to weak internal wave field, recent studies have shown a correlation between the absence of sea ice and increased near-inertial shear and internal wave content (Rainville and Woodgate, 2009; Rainville et al., 2011). Retreating ice cover is thus suggested to lead to an increase in background mixing levels; the MIZ, in particular, can be a hot-spot of mixing with consequences for the ice extent. Recent studies show enhanced heat fluxes and turbulent mixing in the MIZ north of Svalbard (Fer and Sundfjord, 2007; Fer et al., 2010). In the wind-forced stratified Laptev Sea continental shelf, episodic intermittent diapycnal mixing was observed when baroclinic tides and inertial currents gave rise to a rotating shear vector in the pycnocline that is amplified on semidiurnal time scales (Lenn et al., 2011). The effect of decreasing ice cover on the internal wave energetics, however, is not well established. Comparisons of internal wave energy between modern and historical data, reanalysed in identical fashion, reveal no trend evident over the 30-year period in spite of drastic diminution of sea ice (Guthrie et al., 2013). The possible increase in internal wave forcing due to reduced sea ice cover may be offset by increased stratification by meltwater, which amplifies the dissipation of internal wave energy in the under-ice boundary layer.

The tidal mixing over topography controls the northward extension of temperate AW and thus sea ice cover variability (Holloway and Proshutinsky, 2007), and enhances dense water formation (Postlethwaite et al., 2011). Recent numerical model results show that there is significant internal tidal wave generation in the Arctic Ocean, with baroclinic tidal energy dissipation structures similar to but $2-3$ orders of magnitude less than that observed on mid-Atlantic and Hawaiian ridges (Kagan et al., 2011). The average coefficient of diapycnal diffusion is found to be less than the canonical value of 
the vertical eddy diffusivity in the deep ocean prescribed in models of global ocean circulation, but significant enough to influence the Arctic Ocean climate.

\subsection{Double diffusive convection in the Arctic Ocean}

The role of double diffusion at the ice-ocean interface is discussed in Sect. 4.1. Here we address double diffusion deeper in the ocean, far from the effects of the ice-ocean boundary layer (Fig. 1).

The Arctic Ocean is very quiescent (Sect. 4.3). The level of turbulent kinetic energy is very low, and this is a very favourable environment for double diffusion processes to occur. Double diffusion in the ocean is due to different molecular diffusivities of temperature and salinity (Kelley et al., 2003). There are two types of double diffusion in the ocean: Salt fingers occur when warm and salty water lies over a cold and fresh water. In contrast, a cold and fresh water laying above a warm and salty water as it occurs in the Arctic Ocean, is the preconditioning for the diffusive convection process. Steps like microstructures in the vertical distribution of temperature, salinity, and density are a manifestation of double diffusion. Mixed layers alternate with sharp interfaces both in temperature, salinity and density.

Measurements during IPY revealed the ubiquitous nature of double diffusive steps in the Canada Basin characterized by a surprisingly large spatial coherency of the steps over several hundred kilometres (Timmermans et al., 2008). The mixed layers interleaving with the sharp interfaces were described as small features of limited vertical extension (few metres) and related limited vertical heat fluxes ( 0.05 to $\left.0.3 \mathrm{~W} \mathrm{~m}^{-2}\right)$. Detailed microstructure measurements in the central Arctic show a persistent thermohaline staircase above the AW temperature maximum with an inferred average vertical heat flux of $0.6 \mathrm{~W} \mathrm{~m}^{-2}$ (Sirevaag and Fer, 2012). The lateral coherency seen in the Canada Basin was, however, absent in the Amundsen Basin (Sirevaag and Fer, 2012).

The main parameter characterizing double diffusion is the density ratio. This is the ratio between $\beta \delta S / \delta z$ and $\alpha \delta \theta / \delta z$, where $\beta$ is the haline contraction coefficient, $\alpha$ is the thermal expansion coefficient of sea water, and $\delta S / \delta z$ and $\delta \theta / \delta z$ are the vertical salinity and temperature gradients, respectively. The deepest part of the Arctic halocline was defined by Bourgain and Gascard (2011) as the depth where the density ratio is equal to 20 . At greater depth within the main thermocline, density ratios are typically between 1 and 10 . The most favourable conditions for double diffusion to occur correspond to density ratios approaching 1 . In such conditions, unstable temperature gradients develop through interfaces, leading to more active convection in the mixed layers (e.g. Kelley et al., 2003).

A structure of small steps in temperature and salinity profiles is also characteristic of double diffusion, as observed during IPY (Timmermans et al., 2008; Sirevaag and Fer, 2012); an example from the Amundsen Basin is shown
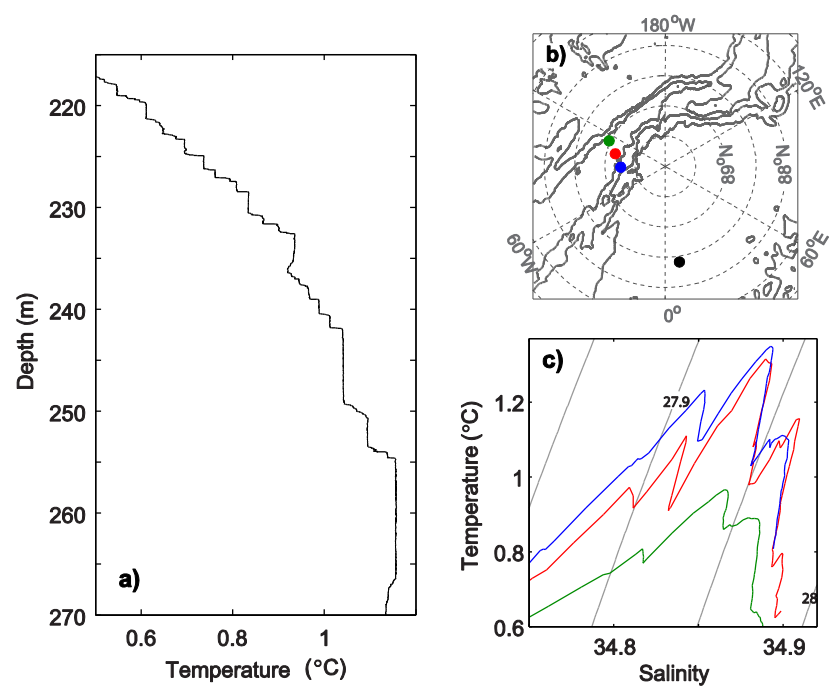

Figure 12. An example temperature profile (a), collected using a microstructure profiler, showing the staircase structure in the Amundsen Basin in the Arctic Ocean (station shown by black bullet point in (b)). Map showing the isobaths ( $1000 \mathrm{~m}$ contour interval) of the Lomonosov Ridge and station locations of (a) and (c) in corresponding colours (b). Temperature and salinity diagram from three profiles across the Lomonosov Ridge. The grey isolines show the water potential density subtracted by $1000 \mathrm{~kg} \mathrm{~m}^{-3}$ (c).

in Fig. 12a. On the continental slope of the Laptev Sea, Polyakov et al. (2012) observed profiles with larger steps, which were remarkably persistent in time despite internal waves, eddies and strong AW pulses significantly increasing the level of kinetic turbulent energy. This large step structure might be a result of a degenerative form of a double diffusion process, and it might not be correct to calculate the vertical heat fluxes associated with those large steps applying the double diffusion theory of Kelley et al. (2003). These large steps have not been observed in the past. The vertical scales of the steps that are much larger than the typical diffusive layer thicknesses, however, are comparable to the double diffusive, thermohaline intrusions frequently observed in the Arctic (Carmack et al., 1997, Rudels et al., 1999; Kuzmina et al., 2011). The intrusions are laterally coherent over thousands of kilometres, with nested temperature-salinity structure, and are proposed to be driven and organized by doublediffusive processes (Walsh and Carmack, 2003). The intrusions emanate from the core of the AW in the slope current, and spread into the interior basin propagating heat and salt over long distances. An example of the intrusive features at three stations taken across the Lomonosov Ridge is shown in Fig. 12c.

\subsection{Sub-mesoscale eddies, fronts, and other processes}

Sub-mesoscale processes, here defined as of the order of Rossby deformation radius, which is typically several 
kilometres in the upper Arctic water column, provide the link between mesoscale features (such as large frontal and current systems and large eddies, of the order of $100 \mathrm{~km}$ ) and fine- and small-scale processes that contribute to diapycnal mixing in the ocean (Sect. 4.3). Sub-mesoscale eddies, also referred to as sub-mesoscale coherent vortices (SCV), are frequently observed in the Arctic, particularly in the Canada Basin and along the ice edges and along the West Spitsbergen Current in Fram Strait (see Padman (1995) for a review). Using ice-tethered profilers covering as far north as $79^{\circ} \mathrm{N}$, Timmermans et al. (2008) analysed encounters of SCVs in the Canada Basin and found their formation mechanism consistent with the instability of a surface front. Arctic SCVs isolate and transport anomalous water properties, and have implications for transport and lateral dispersion in the Arctic. Furthermore, Timmermans et al. (2012) observe restratification in the upper layers that can be attributed to lateral processes associated with sub-mesoscale features. This has consequences for maintaining the insulating stratification of the CHL. The SCVs in ice-covered waters of the Arctic Ocean are relatively shallow (300-500 m) and differ from those involved in open ocean deep convection, e.g. in the Greenland Sea. Observations from drifting floats in the Greenland Sea revealed the existence of SCVs composed of very homogeneous newly formed Greenland Arctic Intermediate Water extending from near the surface down to $3000 \mathrm{~m}$ depth (Gascard et al., 2002). These SCVs had a $5 \mathrm{~km}$ diameter anticyclonic core with a time period of 2 to 3 days. They are transferring homogeneous oxygen rich waters from the shallow mixed layer deeper down through the main pycnocline to renew deep ocean layers and contribute to the largescale thermohaline circulation. These sub-mesoscale deep convective SCVs are among all the eddies, those having the longest lifetime (several years) and this is the reason why they are so-called SCV. They only exist where the ocean is deep enough (> $3000 \mathrm{~m}$ depth).

In pan-Arctic and global models, the SCVs are yet not resolved and must be parameterized. Their dynamics and resulting impact on vertical mixing are not properly understood or accounted for in the numerical models. Recent progress includes the promising implementation by Fox-Kemper et al. (2011), however, the application in the Arctic, under sea ice, merits further research.

More research is also needed for continental shelf waves trapped above the continental shelf break region all around the Arctic Ocean where resonance occurs during spring tides. This mechanism has great potential to trigger sea ice break up during springtime in MIZ and consequently to enhance sea ice melting and retreat.

\section{Discussion}

\subsection{Main advances and remaining challenges in individual research fields}

Considering research on $\mathrm{ABL}$ processes and the vertical structure of the lower troposphere, much of the advance has been based on field experiments. For the SBL, the SHEBA observations have still been the starting point for a major part of recent advances. This demonstrates the high quality and uniqueness of the data set but, due to the major changes in the lower boundary conditions for the ABL since SHEBA in 1997-1998 (decrease in sea ice concentration and thickness), it simultaneously urgently calls for new year-round drifting stations with sophisticated ABL observations. In SBL research, major challenges remain in understanding and modelling of conditions of very stable stratification, in particular the interaction of waves and turbulence. Considering convective ABL over leads and polynyas, part of recent advances have been based on the utilization of improved remote sensing products on ice concentration (e.g. Marcq and Weiss, 2012) and on coupled atmosphere-sea-ice-ocean modelling (e.g. Ebner et al., 2011). Challenges remain in the high sensitivity of winter air temperatures to sea ice concentration (Lüpkes et al., 2008a; Tetzlaff et al., 2013) in the representation of new, thin ice in atmospheric models (Tisler et al., 2008) and in the interaction of convective plumes with capping stable or near-neutral environments (Lüpkes et al., 2008b). In the dynamics of cold air outbreaks over the open ocean, the new results linking the occurrence of roll convection with surface inhomogeneities in upwind sea ice (Liu et al., 2006; Gryschka et al., 2008) are an interesting discovery, although the links are still under discussion. This work also demonstrates the need for close collaboration of atmospheric and sea ice scientists. Considering the occurrence and properties of temperature and humidity inversions, recent advances have been partly due to the availability of new remote sensing data (Devasthale et al., 2010, 2011) but also simply due to increased interest in the issue (Nygård et al., 2014). Improved estimates of large-scale moisture advection and surface evaporation (Boisvert et al., 2012, 2013) are a prerequisite for better understanding the processes controlling the vertical profile of air humidity.

Much of the advance in understanding and modelling Arctic clouds has been based on recent field data, above all from circum-Arctic coastal observatories (Shupe et al., 2011) and the I/B Oden expeditions in summer 2001 and 2008. The main advances have been related to the amounts of and partitioning between cloud liquid water and ice, radii of cloud droplets and ice crystals, decoupling between the surface and cloud layers, moisture sources from below and above the clouds, and production of turbulence in clouds. Challenges remain in improving our understanding of Arctic cloud physics (including the coupling of clouds, aerosols, radiative transfer, $\mathrm{ABL}$ turbulence, and cloud-generated turbulence) 
and even more in representing it in climate and NWP models. Limited horizontal and vertical resolution as well as a general lack of binned microphysical parameterizations mean that models will continue to rely on moist physics parameterizations based on more well-understood, lower latitude systems - which are likely not representative of Arctic conditions (e.g. Prenni et al., 2007). In the field of radiative transfer in the atmosphere, advances have taken place with respect to a better understanding of the interaction of radiation with cloud properties, condensation nuclei, surface albedo, near-surface turbulence, and heat conduction in snow and ice (Sedlar et al., 2011; Mauritsen et al., 2011). Comparisons against SHEBA data showed, however, that negative biases prevail in both shortwave and long-wave downward radiation in several regional climate models (Tjernström et al., 2008). A better handling of the aerosol/cloud/radiation feedback is a prerequisite for improving model results for radiation balance at the sea ice and open ocean surface.

Considering fjordic and coastal processes, the advance has been supported by new aircraft observations, tethersonde sounding campaigns, and model experiments. Recent studies include the first comprehensive observations on barrier winds off southeastern Greenland (Petersen et al., 2009) and the first in situ observations of a tip jet off Cape Farewell (Renfrew et al., 2009a), and investigations of the governing dynamics of these flows. The presence of sea ice in Svalbard fjords has been found to be important for the dynamics of katabatic winds. It is now well demonstrated that various coastal and fjordic features can be accurately simulated with a sufficient model resolution of the order of a kilometre, but it will take long before climate models can reach such a resolution.

The IPY was a focal point for extensive campaigns during which polar lows were observed. Operational weather forecasting systems have now reached the state where polar lows should be able to be predicted routinely. The recent development is above all related to better observing and data assimilation systems. Challenges remain, however, in the optimization of regional high-resolution ensemble prediction systems for polar lows (Kristiansen et al., 2011).

Recent studies have demonstrated the importance of downward long-wave radiation for the spring onset of snow melt on Arctic sea ice (Persson, 2012; Maksimovich and Vihma, 2012). After the onset, the amount of melt is primarily controlled by absorbed shortwave radiation. The albedo of snow evolves following the surface metamorphism and change of phases, from dry snow to melting snow, pond formation, pond drainage, pond evolution, and autumn freezeup (Perovich et al., 2009; Nicolaus et al., 2010a; Perovich and Polashenski, 2012). Numerous studies during and after IPY have addressed snow and sea ice albedo (more than 70 papers cited here), the actual research topics including the spectral differences, spatial variations between various surface types, and the effects of impurities such as black carbon. Further development of albedo parameterizations in climate and NWP models has been guided by the development of microscale models of snow metamorphism (Flanner and Zender, 2006), which allow the coupling between penetration of solar radiation into the snow and ice layer, the micro-scale characteristics of the ice crystals, and the surface albedo. A proper validation of these parameterizations is, however, still lacking. The development of new observation techniques for radiation (Nicolaus et al., 2010b; Hudson et al., 2012) and snow and ice properties (Arnaud et al., 2011; Gallet at al., 2009) has the potential to facilitate the future collection of high quality and complete data sets. There is also need for more realistic melt pond parameterizations, which, in addition to albedo, account for the latent heat, which has impact on the timing of autumn freeze-up. Further, more sophisticated snow aging parameterizations are needed based on the inherent snow microphysical properties and accounting for the effects of liquid melt water on optical and thermal snow properties.

New results on sea ice structure have been largely based on application of the mushy layer theory (Notz and Worster, 2009). This theory has proven particularly useful for better understanding the temporal evolution of sea ice salinity, in which the gravity drainage of salty brine and its replacement by less saline ocean water is essential. Process models work well for this desalination, and simplified parameterizations have been developed to describe it in large-scale models. Challenges remain in particular in realistically representing the fate of the draining brine in the oceanic boundary layer, and in realistically modelling the evolution of sea ice salinity during periods of melt water flushing in summer. Regarding the basic issue of heat conduction in snow and ice, the need to take into account the effects of temperature and density on snow heat conductivity is now better understood (Lecomte et al., 2011). Further, due to the spatial inhomogeneity of snow cover, the need to use an effective heat conductivity of snow is well demonstrated (Semmler et al., 2012). Future perspectives with thinner sea ice and increasing precipitation suggest an increasing contribution of snow ice and superimposed ice to the Arctic sea ice mass balance. The modelling of these granular ice types has much received attention, but snow/ice models suffer from considerable inaccuracy in precipitation forcing (Cheng et al., 2008b, 2013).

Considering the small-scale dynamics of sea ice, the first estimates of mechanical weakening of sea ice at the panArctic scale were made via analysis of the response of sea ice to the Coriolis force. On the basis of buoy data and model experiments, Gimbert et al. (2012a, b) demonstrated that the strengthening of inertial oscillations in recent years (Fig. 9) was partly a result of a genuine mechanical weakening of ice cover, with a winter ice cover that nowadays mimics the mechanical behaviour of summer sea ice 20 to 30 years ago. The mechanical weakening of the ice has contributed to accelerated drift. Seismometers installed on sea ice have allowed high-frequency monitoring of sea ice fracturing and faulting. The propagation speed of seismic waves has been found to 
depend on ice thickness, allowing a novel method to estimate the latter on a regional scale (Marsan et al., 2012). Seismic observations also allow for complementing satellite measurements by providing a much more detailed temporal sampling and therefore a better characterization of sea ice fracturing processes. Consequently, the next challenge is to extend the explorative DAMOCLES sea ice seismic survey to longer durations (at least a winter season) and to a broader-scale range, from the kilometre scale to the regional $(100 \mathrm{~km})$ scale. In addition, an analysis of seismic noise induced by ocean-wave energy and recorded by land-based seismic stations installed at the periphery of the Arctic Basin might be a way to monitor a proxy of the ice strength on a perennial basis (Tsai and McNamara, 2011).

The sea ice cover of the Arctic Ocean strongly reduces the energy input from the atmosphere, and thereby the mixing of the underlying water masses. Hence, mixing processes that do not play a large role elsewhere are often important in the Arctic. New results have demonstrated that above the subsurface temperature and salinity maxima of the Atlantic Water, the stratification is favourable for double-diffusive convection, which leads to vertical fluxes up to an order of magnitude larger than the molecular diffusion (Sirevaag and Fer, 2012). Apart from scarce direct microstructure measurements, our present quantification of double-diffusive fluxes depends on laboratory-based flux laws that may not be sufficiently accurate for geophysical environments. Recent observations following a storm event suggest that near-inertial response beneath the mixed layer can contribute significantly to vertical mixing within and below the CHL (Fer, 2014). The fraction of the near-inertial energy flux penetrating deep into the ocean and contributing to mixing, and particularly how it would change with ice cover, is uncertain. Challenges in understanding and modelling diapycnal mixing include the presence of large spatial variations: mixing is much more efficient along the continental rise and over topographic features, and the interplay between horizontal advection and diffusive mixing depends a lot on the location. Challenges also remain in the quantitative understanding of the role of the ocean heat that reaches the surface: how large a portion escapes to the atmosphere and how much is used to melt the sea ice? Important topics that have not received enough attention in recent years include deep ocean convection, continental shelf waves, and the role of near-inertial forcing. These processes should be considered in large-scale modelling of the Arctic Ocean by developing appropriate parameterizations.

\subsection{Cross-disciplinary analogies}

Small-scale processes in the Arctic atmosphere, snow, sea ice, and the ocean cover a broad range of research areas. In some fields addressed here, such as turbulence in the atmosphere and ocean, recent advances build on work that was started several decades ago, whereas some other issues, such as propagation of seismic signals in sea ice, represent very recently opened research fields. The older research fields of atmospheric and ocean turbulence have a lot of analogy in recent advances and challenges. The interaction of waves and turbulence is an important research topic both for the atmosphere and ocean. New evidence has been obtained demonstrating that turbulence prevails in the atmosphere even under very stable stratification, which is related to the anisotropy of turbulence and to internal waves, which preserve vertical momentum mixing (Galperin et al., 2007). In the Arctic Ocean, the weakness of the internal wave field is a primary cause of quiescent diapycnal mixing. Reduction of the sea ice cover is, however, expected to increase the background mixing levels (Rainville et al., 2011). Although the measurements in the MIZ are in support of this hypothesis (Fer et al., 2010), the effect of decreasing ice cover on the internal wave energetics is not yet well established (Guthrie et al., 2013).

During ice growth, the main uncertainty in modelling the turbulent exchange of heat and salt at the ice-water interface originates from the roughness length $z_{0 \mathrm{~B}}$. The observational values include a large scatter, and a major question is how to parameterize the role of form drag due to flow edges and keels. In the atmosphere, the new parameterizations for $z_{0}$ have dealt with the same issue: the role of ridges, flow edges, melt pond edges, and sastrugi in the generation of form drag (Andreas et al., 2010a, b; Andreas, 2011; Lüpkes et al., 2012a, 2013). The $z_{0}$ values applied in large-scale atmospheric models, however, sometimes strongly differ from the results of field experiments, because $z_{0}$ is used as a tuning parameter. In ocean models, the angle between the ice-ocean stress and ice drift vectors is often used similarly (Uotila et al., 2014).

Furthermore, the dominant vertical structures controlling stratification in the Arctic atmosphere and ocean, the temperature inversion and ocean halocline, are analogous in the sense that both are strongly affected by the horizontal advection (of heat and salt, respectively). Challenges remain in better quantifying these advective fluxes, their vertical profiles, and their interaction with small-scale processes. Differences between the atmosphere and ocean include double diffusion that only occurs in the ocean and the strong stabilizing role of melt water at the ice bottom. The latter makes double diffusion an important limiting factor in the ocean boundary layer during the melt season (in addition to its importance in the quiescent interior of the ocean).

\subsection{Feedback mechanisms}

Understanding the role of small-scale processes in the Arctic climate system is complicated by numerous feedback effects. Positive feedbacks are essential in explaining the observed Arctic amplification of the climate warming (Serreze and Barry, 2011; Pithan and Mauritsen, 2014; Döscher et al., 2014), and feedbacks related to small-scale processes are often interacting with changes in large-scale transport in the atmosphere (Langen et al., 2012) and ocean (Bitz et 
al., 2006). Here we focus on the feedbacks related to smallscale processes, which include the albedo, water vapour, aerosol/cloud/radiation, Planck, and lapse rate feedbacks. Several recent studies have stressed the close connections between these processes.

The surface albedo feedback (SAF) mechanism is reputed to have been an important contributor to the loss of Arctic sea ice over the last few decades (Screen and Simmonds, 2010b; Crook et al., 2011; Taylor et al., 2013). By synthesizing a variety of remote sensing and field measurements, both Flanner et al. (2011) and Hudson (2011) concluded that the change in the radiative impact of the Arctic sea ice at the top of the atmosphere in the period 1979-2008 has been a reduced cooling of about $0.1 \mathrm{Wm}^{-2}$. Combining this finding with the observed Northern Hemisphere warming, the Northern Hemisphere sea ice albedo feedback is between 0.17 and $0.54 \mathrm{~W} \mathrm{~m}^{-2} \mathrm{~K}^{-1}$ (or between 0.33 and $1.07 \mathrm{Wm}^{-2} \mathrm{~K}^{-1}$ if the effect of land-based snow is included) (Flanner et al., 2011). These values are substantially larger than comparable estimates obtained from 18 climate models of the CMIP3 data set (Flanner et al., 2011). Considering future climate projections of Arctic sea ice, Hudson (2011) estimated that in an ice-free summer scenario the radiative forcing caused by the albedo reduction would be about $0.3 \mathrm{Wm}^{-2}$, similar to the present-day anthropogenic forcing caused by tropospheric ozone pollution or by halocarbon emissions (Forster et al., 2007). Several studies have concluded that the Arctic climate system does not have an irreversible tipping point behaviour associated with the SAF (Stranne and Björk, 2011; Armour et al., 2011; Tietsche et al., 2011). However, Müller-Stoffels and Wackerbauer (2012) showed that the shape of the albedo parameterization near the melting temperature differentiates between reversible continuous sea ice decrease under atmospheric forcing and a hysteresis behaviour.

The SAF is strongly linked to the change in the phase of precipitation. The observed decline in summer snowfall and increase in rain over the Arctic Ocean and Canadian Archipelago has resulted in a substantial decrease in the surface albedo (Screen and Simmonds, 2012). Further, melt ponds enhance the SAF because of enhanced melt pond coverage in a warmer climate, while aerosol deposition on ice (when kept constant) reduces the SAF because of enhanced melt-out of aerosols in a warmer climate (Holland et al., 2012). Thus, the impact of particulate impurities on snow and sea ice is expected to decrease in a doubling $\mathrm{CO}_{2}$ scenario (Holland et al., 2012; Goldenson et al., 2012). Finally, the SAF can be enhanced by mechanical processes: a thinner, less concentrated sea ice cover is weaker (Gimbert et al., 2012b), which results in increasing fracturing and lead opening. These have an indirect effect on albedo, as splitting up of the ice field increases lateral melt and, hence, decreases the area-averaged albedo.

Although SAF has received the most attention, it is not certain if it is the strongest feedback in the Arctic climate system. One of the major problems in understanding SAF is its close interaction with cloud changes (Fig. 7). Sedlar et al. (2011) observed that sea ice albedo is a strong modulator of cloud shortwave radiative forcing (which decreases with increasing surface albedo) and of near-surface temperature. Graversen and Wang (2009) estimated that most of the polar amplification of the surface air temperature is not directly attributable to the SAF itself, but rather to the SAF strengthening of the water vapour and cloud feedbacks, which have a greenhouse effect that is larger in the Arctic than at lower latitudes. On the other hand, the presence of clouds over sea ice reduces the radiative forcing due to changes in sea ice concentration and albedo. Indeed, Hudson (2011) showed that the present-day cloud cover manages to mask approximately half of the clear-sky sea ice albedo feedback, while Mauritsen et al. (2013) found a dominating role of water vapour feedback. Generally, a reduction in sea ice extent is expected to cause an increase in cloud cover, but this relationship seems quite weak in summer (Eastman and Warren, 2010; Kay and Gettelman, 2009), when sea ice albedo feedback is most important.

In addition to albedo, cloud radiative forcing and related feedback are sensitive to the number of CCN available. During ASCOS, even at $100 \%$ relative humidity, Mauritsen et al. (2011) observed clouds optically thin enough to be undetectable by the eye: "tenuous clouds". Two regimes were found with an approximate division at $\mathrm{CCN}$ concentrations near $10 \mathrm{~cm}^{-3}$. When $\mathrm{CCN}$ was lower than this threshold, clouds would be "gray" in the infrared, and an increase in $\mathrm{CCN}$ would lead to an increase in downwelling radiation that far outweighed the simultaneous decrease in downwelling shortwave radiation; this gives rise to a warming effect at the surface. Conversely, when CCN concentrations were higher, further increases in $\mathrm{CCN}$ concentrations instead lead to reduced downwelling shortwave radiation causing a cooling effect at the surface while clouds are already black in the infrared resulting in little or no change in long-wave radiation. Perusing CCN observations from four expeditions to the summer Arctic, Mauritsen et al. (2011) speculated that the tenuous clouds regime may occur up to $30 \%$ of the time in summer; also see Tjernström et al. (2014).

The lapse rate feedback is related to the vertical structure of the warming. In the tropics, due to the deep convection and strong release of latent heat during cloud condensation throughout the troposphere, a small temperature increase is enough to compensate for a certain radiative imbalance at the top of the atmosphere. In the Arctic, however, due to the prevailing stable stratification, vertical mixing is limited and surface warming does not reach high altitudes. Hence, a larger near-surface temperature increase is needed to compensate for the same radiative imbalance as in the tropics (Bintanja et al., 2012; Pithan and Mauritsen, 2014). The often overlooked Planck feedback results from the fact that the long-wave radiation emitted by the Earth's surface and atmosphere is proportional to the fourth power of the absolute temperature. Hence, a certain increase in emitted long-wave 
radiation corresponds to a larger temperature increase in the Arctic than at lower latitudes (Pithan and Mauritsen, 2014). Even without any other feedback mechanisms, an increase in the greenhouse gas concentrations would cause small Arctic amplification. On the basis of CMIP5 climate model results, Pithan and Mauritsen (2014) argue that the largest contribution to Arctic amplification originates from the combined effects of the lapse rate and Planck feedbacks, the former being more important. Their net effect is that when the Earth surface warms, less energy is radiated back to space in the Arctic than at lower latitudes.

An issue not to be confused with the lapse rate feedback is the small heat capacity of a shallow ABL (typically SBL). A certain heat input results in a larger temperature increase in a shallow than in a deep ABL. As the ABL is typically shallow in the Arctic, this may have contributed to the Arctic amplification of climate warming (Esau and Zilitinkevich, 2010; Esau et al., 2012). It is, however, not a positive feedback, as heating of the ABL tends to increase its thickness.

The diapycnal mixing in the Arctic Ocean, in addition to double diffusion where favourable, is primarily driven by breaking internal waves that are forced by tides or wind. In an Arctic Ocean with a larger fraction of open water areas, the internal wave field is expected to be energized through more input of wind and near-inertial energy, which in turn leads to enhanced mixing. Increased amounts of oceanic heat from the AW layer can thus reach the under-ice boundary. Resulting increase in melting rates may lead to a positive feedback that needs to be studied. The implications may be more significant near the shelf break where the increased wind-driven energy can influence the AW boundary current dynamics and cross-slope exchange processes.

Feedbacks also occur at partly resolved scales, e.g. related to the occurrence of polar lows or ocean eddies. An accurate representation of feedbacks continues to be one of the major challenges in the modelling of the Arctic and global climate change. For example, the nature of sea ice loss - whether it will be reversible or not - is sensitive to the parameterization of feedbacks (Eisenman and Wettlaufer, 2009; MüllerStoffels and Wackerbauer, 2012). The present level of uncertainty is characterized by the fact that recent improvements in the ECMWF land snow scheme have resulted in a doubling of the snow-albedo feedback (Dutra et al., 2012). Further, the net effect of all the feedbacks taking place in the Arctic is difficult to assess because they operate on different spatial and temporal scales (Callaghan et al., 2012).

\subsection{Representativeness of results}

The results reviewed here are based on observations and model experiments, but the former are not uniformly distributed in space and time. The climatological representativeness of observations has been studied a lot (e.g. Bourassa et al., 2013). The representativeness of observations from the point of view of process understanding is, however, a dif- ferent issue. In some respect, spatial and temporal variations are less crucial for process understanding than for climatology; as soon as a process is physically understood, gaps in data are no longer a problem. However, it is often difficult to know if the state of sufficient physical understanding has been reached, or if the process is sensitive to changes in some boundary conditions that require further observations. This makes it difficult to quantify the representativeness of observations from the point of view of process understanding.

Various spatial and temporal scales are relevant here, but the most serious issue is the very limited amount of data available from winter and late autumn, when many smallscale processes are certainly different due to the lack of solar radiation. The only significant winter and late autumn in situ data sources originate from SHEBA, the Russian drifting stations, and coastal observatories, with the majority of literature relevant for this review based on SHEBA. When most results for winter processes are based on a single campaign, it raises the question of how sensitive the small-scale processes were to the conditions that happened to occur during that particular winter. Considering other seasons, it is not clear if the temporal unevenness in the amount of data has significantly affected the understanding and parameterization of processes, but the availability of data varies also between other seasons, often due to logistical reasons. Examples of these include easier access to sea ice by aircraft (including by helicopter) during spring than other seasons, and easier access to the northern parts of the Arctic Ocean by research vessels in late summer and early autumn than other seasons. It is clear that the observation method affects the representativeness and interpretation of the result (see Sect. 2.1.4 for sea ice roughness). In some respects, buoy observations build a bridge between research vessel and airborne surveys (Richter-Menge et al., 2006), but not for all variables that are needed in studies of small-scale processes.

In the coastal and archipelago areas, the representativeness of observations is naturally a major issue but even in the central Arctic, far from direct influence of land and sea floor orography, the boundary conditions for small-scale processes are affected by the large-scale flow in the ocean and atmosphere and related advection of heat, moisture, and salt. Hence, it is difficult to estimate how representative our observationally based knowledge of small-scale processes truly is, bearing in mind that a large portion of the best data sets have been gathered from rather limited regions, such as the Beaufort/Chukchi seas and the Atlantic sector of the Arctic. A new challenge is that observations may get less representative when the amount of thick ice is decreasing. In addition to sea ice and snow research, this is a problem also for meteorology and oceanography. For obvious safety reasons, manned ice stations and expensive automatic measurement devices are typically deployed on fairly thick sea ice. Not much information are available on the quantitative effects of these observational biases, but Inoue et al. (2009) have 
suggested that accuracy of reanalyses may decrease due to smaller sea ice areas available for buoy deployments.

Sea ice and snow thermodynamics is one of the processes most liable to small-scale spatial variations. Due to sastrugi, melt ponds, ice ridges and keels, rafted floes, cracks, and small leads, significant variations are present even on scales of less than a metre. In the case of measurements at manned ice stations, such variations can be mapped (e.g. Hudson et al., 2012), but in the case of buoys (e.g. ice mass-balance buoys) uncertainty often remains on the small-scale surroundings of the measurement site. Although buoys are typically deployed on sites as representative as possible (RichterMenge et al., 2006), these sites may gradually change to become less representative, especially during the melting season. It is therefore essential that studies on sea ice and snow thermodynamic processes are based on a large amount of in situ data, preferably supported by remote sensing data and model experiments.

\section{Conclusions and outlook}

We have reported advances in the development of parameterizations for the surface albedo, melt ponds, turbulent surface fluxes, desalination of sea ice, snow thermal conductivity, ablation rate at the ice bottom, double-diffusive transport, and sub-mesoscale coherent vortices. In cloud physics, radiative transfer in the atmosphere, sea ice small-scale dynamics, and diapycnal mixing in the ocean, the recent advance in physical understanding has not yet yielded remarkable improvements in parameterizations. Ideally, the advance in physical understanding and parameterization should progress hand in hand: large model errors may suggest that something is wrong or insufficient in the physical understanding, which generates a need for more process studies, which improve the physical understanding and further result in improved parameterizations. In practice, however, the improvement of largescale models often takes place after some delay. The reasons for this are manifold, including (a) limited computational power, (b) the need to prioritize among the large number of issues that need improvements in models, (c) too little communication between observationalists and large-scale modellers, (d) too little communication between disciplines, and (e) compensating errors in models, which stop balancing each other out. The development of parameterizations is further complicated by the lack of understanding of how much complexity is cost-effective.

A key difference between partially resolved processes (such as polar lows, orographic flows, and ocean mesoscale eddies) and processes that are only parameterized is that further increases in grid resolution will eventually enable good representation of the former in NWP and climate models. In the meantime (next decade or two), however, parameterizations of processes on both scales remain necessary. Hence, on both scales, we have to accept the fact that uncertainty and errors will remain in parameterizations. Future challenges include quantitatively understanding how much these errors are related to (a) the fact that many recent findings of smallscale physics have not yet been (fully) implemented in model parameterizations, (b) our lack of understanding of the processes, and (c) our inability to parameterize them using gridresolved variables. Further, accepting the fact that parameterizations will always have errors, more work is needed to develop and apply methods such as stochastic physics in ensemble prediction systems, as already done in some climate (Palmer and Williams, 2010) and NWP models (Krasnopolsky et al., 2013).

Considering climate modelling for this century, the sources of uncertainty can be roughly divided into three groups: (1) internal variability of the system, (2) model uncertainty, and (3) scenario uncertainty. According to Hawkins and Sutton (2009), the uncertainty related to internal variability dominates over the first decade of a model run, the model uncertainty dominates over the fourth decade, and the scenario uncertainty dominates over the ninth decade, except in high latitudes. There the model uncertainty is so large that it still dominates over the ninth decade. A major challenge for the Arctic research community is to reduce the dominating model uncertainty.

A concrete path towards better understanding and parameterization of small-scale physical processes in the Arctic is multifaceted. First, further advance can be made via more systematic and cross-disciplinary analyses of existing observations supported by model experiments devoted to improvement of parameterizations, applying both large-scale and process models (including LES). Large-scale operational and climate models are essential for evaluating how well the interaction of individual processes at different temporal and spatial scales is reproduced, preserving process relationships as diagnosed from observations. Attention should also be paid to the optimal utilization of new recent remote satellite sensing products, such as the SMOS (Soil Moisture and Ocean Salinity) data on thin ice thickness, new generation Radio Occultation instruments and sounders for atmospheric remote sensing, as well as fully exploiting the potential of MODIS, Calipso, Cloudsat, and EarthCARE data on (mixedphase) clouds. The WMO Polar Prediction Project (PPP) is expected to have a major role in the coordination of data analyses and modelling activities. The PPP will include an intensive phase: the Year of Polar Prediction (YOPP) in 20172019.

Second, after 16 years since the end of SHEBA, we desperately need more year-round field observations, including both in situ and ship/ice/aircraft-based remote sensing observations. It is essential that the observations are made in extensive, multi-disciplinary campaigns, so that the interaction of different variables and processes can be observed. Expectations for new process-level observations on the Arctic atmosphere-sea-ice-ocean system are laid at the doorstep of MOSAiC (Multidisciplinary drifting Observatory for Studies 
of Arctic Climate, described at www.mosaicobservatory. org/), a year-round field campaign planned for the time frame of 2017-2019. MOSAiC will overlap with YOPP, which will provide excellent possibilities for coordination of observations and model experiments. To improve the representativeness of observations (Sect. 5.4) a large spatial coverage of observations will be essential, so that observations at the main ice station will need to be supported by a network of autonomous ice-based stations, airborne observations (research aircraft, helicopters, unmanned aerial vehicles), underwater gliders, other research vessels, and intensive campaigns at coastal stations.

It is essential to develop novel observational methods focusing on the "New Arctic", characterized by, among others, larger areas of open water and thin ice, longer periods of snow and ice melt, and more rain instead of snow fall. Increasingly important processes to be studied include the autumn freeze-up, snow on sea ice, wave-ice interaction, and storm effects. Observations over thin ice will generate challenges for instrument deployment. Hence, further development of remote sensing methods is essential to obtain a good spatial and temporal coverage, and the role of unmanned aerial vehicles (e.g. Inoue et al., 2008; Reuder et al., 2012), dropsondes, controlled meteorological balloons (Voss et al., 2013), and autonomous underwater vehicles (e.g. Doble et al., 2009) is expected to increase. Underwater gliders have recently proven to be a suitable platform for ocean microstructure measurements (Fer et al., 2014). Coordinated planning of new observations is needed to maximize the utilization and mutual support of in situ and remote sensing data. Observational requirements need to be well defined and to be communicated to space agencies for future mission design. In some fields, such as snow and ice physics, field experiments could also be more systematically supported by laboratory experiments.
It is noteworthy to mention that a better understanding and modelling of small-scale processes in the Arctic is essential not only for the Arctic climate system but also for the mid-latitudes. Sea ice decline in the Arctic has had some, although mostly poorly understood, effects on the large-scale atmospheric circulation (see Vihma (2014) and Walsh (2014) for recent reviews). The effects reaching mid-latitudes originate from changes in small-scale processes in the Arctic, including interaction of convection and baroclinic processes (Petoukhov and Semenov, 2010), destruction of the low-level temperature inversion (Deser et al., 2010), a deepening of the ABL (Francis et al., 2009), and destabilization of the lower troposphere (Jaiser et al., 2012). Bearing in mind the large errors still present in reanalyses and climate models (see the Introduction), these findings call for more research on smallscale processes in the Arctic. 


\section{Appendix A}

Table A1. List of acronyms.

\begin{tabular}{|c|c|}
\hline Acronym & Definition \\
\hline $\mathrm{ABL}$ & atmospheric boundary layer \\
\hline ASCOS & Arctic Summer Cloud-Ocean Study \\
\hline ASR & Arctic System Reanalysis \\
\hline AW & Atlantic Water \\
\hline $\mathrm{BC}$ & black carbon \\
\hline CAM4 & Community Atmospheric Model version 4 \\
\hline $\mathrm{CAO}$ & cold air outbreak \\
\hline CHL & cold halocline layer \\
\hline CICE & The Los Alamos sea ice model \\
\hline CMIP3 & Coupled Model Intercomparison Project \\
\hline $\mathrm{CCN}$ & cloud condensation nuclei \\
\hline ECHAM5 & 5th generation of the ECHAM general circulation model \\
\hline ECMWF & European Centre for Medium-range Weather Forecasts \\
\hline EPS & ensemble prediction system \\
\hline ERA-Interim & an atmospheric reanalysis by the ECMWF \\
\hline GFDex & Greenland Flow Distortion Experiment \\
\hline HIRLAM & High-Resolution Limited Area Model \\
\hline IPCC AR4(5) & Intergovernmental Panel on Climate Change, Assessment Report 4(5) \\
\hline IPY & International Polar Year 2007-2009 \\
\hline IWC & ice water content \\
\hline IWP & ice water path \\
\hline LES & large eddy simulation \\
\hline LIM (2) & Louvain-la-Neuve Sea Ice Model (two-level version) \\
\hline LLJ & low-level jet \\
\hline LWC & liquid water content \\
\hline LWP & liquid water path \\
\hline MIZ & marginal ice zone \\
\hline MODIS & Moderate Resolution Imaging Spectroradiometer \\
\hline MOSAiC & Multidisciplinary Drifting Observatory for the Study of Arctic Climate \\
\hline MPS & mixed-phase stratocumulus \\
\hline NWP & numerical weather prediction \\
\hline PPP & Polar Prediction Project \\
\hline QNSE & Quasi-normal-scale elimination (method) \\
\hline $\mathrm{RH}_{\mathrm{liq}}$ & air relative humidity with respect to liquid water \\
\hline SAF & surface albedo feedback \\
\hline SBL & stable boundary layer \\
\hline SCV & sub-mesoscale coherent vortex \\
\hline SHEBA & Surface Heat Budget of the Arctic Ocean \\
\hline SMOS & Soil Moisture and Ocean Salinity (satellite) \\
\hline SNICAR & Snow and Ice Aerosol Radiation (model) \\
\hline SPOT & Satellite Pour l'Observation de la Terre (Satellite for Observation of the Earth) \\
\hline SZA & solar zenith angle \\
\hline TKE & turbulent kinetic energy \\
\hline TPE & turbulent potential energy \\
\hline WBF & Wegener-Bergeron-Findeisen (process in cloud physics) \\
\hline WMO & World Meteorological Organization \\
\hline WRF & Weather Research and Forecasting (model) \\
\hline YOPP & Year of Polar Prediction \\
\hline
\end{tabular}


Acknowledgements. Irina Gorodetskaya and two anonymous reviewers are acknowledged for their constructive comments. The DAMOCLES project (grant 18509) was funded by the 6th Framework Programme of the European Commission. The work has been additionally supported by the Academy of Finland (contract 259537), by the Deutsche Forschungsgemeinschaft (LU818/1-1, LU818/3-1), by the German Federal Ministry of Education and Science (project MiKlip, FKZ: 01LP1126A), the Research Council of Norway for IF (contract 178641/S30), and the UK's Natural Environment Research Council (NE/I028297/1).

Edited by: T. Garrett

\section{References}

Aagaard, K., Coachman, L. K., and Carmack, E.: On the halocline of the Arctic Ocean, Deep-Sea Research Part A, 28, 529-545, doi:10.1016/0198-0149(81)90115-1, 1981.

Aleksandrov, Y. I., Bryazgin, N. N., Førland, E. J., Radionov, V. F., and Svyashchennikov, P. N.: Seasonal, interannual and longterm variability of precipitation and snow depth in the region of the Barents and Kara seas. Polar Res., 24, 69-85, doi:10.1111/j.1751-8369.2005.tb00141.x, 2005.

Andreas, E. and Cash, B.: Convective heat transfer over wintertime leads and polynyas, J. Geophys. Res., 104, 25721-25734, 1999.

Andreas, E. L.: A relationship between the aerodynamic and physical roughness of winter sea ice, Q. J. Roy. Meteor. Soc., 137, 1581-1588, doi:10.1001/qj.842, 2011.

Andreas, E. L., Paulson, C. A., Williams, R. M., Lindsay, R. W., and Businger, J. A.: The turbulent heat flux from Arctic leads, Bound.-Layer Meteorol., 17, 57-91, 1979.

Andreas, E. L., Persson, P. O. G., Grachev, A. A., Jordan, R. E., Horst, T. W., Guest, P. S., and Fairall, C. W.: Parameterizing Turbulent Exchange over Sea Ice in Winter, J. Hydrometeorol., 11, 87-104, doi:10.1175/2009JHM1102.1, 2010a.

Andreas, E. L., Horst, T. W., Grachev, A. A., Persson, P. O. G., Fairall, C. W., Guest, P. S., and Jordan, R. E.: Parametrizing turbulent exchange over summer sea ice and the marginal ice zone, Q. J. Roy. Meteor. Soc., 138, 927-943, 2010b.

Aoki, T., Kuchiki, K., Niwano, M., Kodama, Y., Hosaka, M., and Tanaka, T.: Physically based snow albedo model for calculating broadband albedos and the solar heating profile in snowpack for general circulation models, J. Geophys. Res., 116, doi:10.1029/2010JD015507, 2011.

Armour, K. C., Eisenman, I., Blanchard-Wrigglesworth, E., McCusker, K. E., and Bitz, C. M.: The reversibility of sea ice loss in a state-of-the-art climate model, Geophys. Res. Lett., 38, L16705, doi:10.1029/2011GL048739, 2011.

Arnaud, L., Picard, G., Champollion, N., Domine, F., Gallet, J. C., Lefebvre, E., Fily, M., and Barnola, J. M.: Measurement of vertical profiles of snow specific surface area with a $1 \mathrm{~cm}$ resolution using infrared reflectance: instrument description and validation, J. Glaciol., 57, 17-29, 2011.

Aspelien, T., Iversen, T., Bremnes, J. B., and Frogner, I.-L.: Shortrange probabilistic forecasts from the Norwegian limited-area EPS: long-term validation and a polar low study, Tellus A, 63, 564-584, 2011.

Atlaskin, E. and Vihma T.: Evaluation of NWP results for wintertime nocturnal boundary-layer temperatures over Eu- rope and Finland, Q. J. Roy. Meteor. Soc., 138, 1440-1451, doi:10.1002/qj.1885, 2012.

Bailey, E., Feltham, D. L., and Sammonds, P. R.: A model for the consolidation of rafted sea ice, J. Geophys. Res., 115, C04015, doi:10.1029/2008JC005103, 2010.

Barrie, L. A.: Arctic air pollution: an overview of current knowledge, Atmos. Environ., 20, 643-663, 1986.

Barstad, I. and Adakudlu, M.: Observation and modelling of gap flow and wake formation on Svalbard, Q. J. Roy. Meteor. Soc., 137, 1731-1738, 2011.

Bauch, D., Rutgers van der Loeff, M., Andersen, N., TorresValdes, S., Bakker, K., and Povl Abrahamsen, E.: Origin of freshwater and polynya water in the Arctic Ocean halocline in summer 2007, Prog. Oceanogr., 91, 482-495, doi:10.1016/j.pocean.2011.07.017, 2011.

Beare, R. J.: Boundary layer mechanisms in extratropical cyclones, Q. J. Roy. Meteor. Soc., 133, 503-515, 2007.

Beesley, J. A., Bretherton, C. S., Jakob, C., Andreas, E. L, Intrieri, J. M., and Uttal, T. A.: A comparison of cloud and boundary layer variables in the ECMWF forecast model with observations at Surface Heat Budget of the Arctic Ocean (SHEBA) ice camp, J. Geophys. Res., 105, 12337-12349, 2000.

Bintanja, R., Graversen, R. G., and Hazeleger, W.: Arctic winter warming amplified by the thermal inversion and consequent low infrared cooling to space, Nature, 4, 758-761, doi:10.1038/ngeo1285, 2011.

Birch, C. E., Brooks, I. M., Tjernström, M., Milton, S. F., Earnshaw, P., Söderberg, S., and Persson, P. O. G.: The performance of a global and mesoscale model over the central Arctic Ocean during late summer, J. Geophys. Res., 114, D131104, doi:10.1029/2008JD010790, 2009.

Bitz, C. M., Gent, P. R., Woodgate, R. A., Holland, M. M., and Lindsay, R.: The Influence of Sea Ice on Ocean Heat Uptake in Response to Increasing CO2. J. Climate, 19, 2437-2450, doi:10.1175/JCLI3756.1, 2006.

Bitz, C. M., Ridley, J., Holland, M., and Cattle, H.: Global Climate Models and 20th and 21st Century Arctic Climate Change, in: Arctic Climate Change, edited by: Lemke, P., and Jacobi, H.W.: Atmospheric and Oceanographic Sciences Library, Springer Netherlands, 405-436, 2012.

Blazey, B. A., Holland, M. M., and Hunke, E. C.: Arctic Ocean sea ice snow depth evaluation and bias sensitivity in CCSM, The Cryosphere, 7, 1887-1900, doi:10.5194/tc-7-1887-2013, 2013.

Boé, J., Hall, A., and Qu, X.: Current GCMs' Unrealistic Negative Feedback in the Arctic, J. Clim., 22, 4682-4695, doi:10.1175/2009jcli2885.1, 2009.

Boisvert, L., Markus, T., and Vihma, T.: Moisture flux changes and trends for the entire Arctic in 2003-2011 derived from EOS Aqua data. J. Geophys. Res., 118, 5829-5843, doi:10.1002/jgrc.20414, 2013.

Boisvert, L. N., Markus, T., Parkinson, C. L., and Vihma, T.: Moisture fluxes derived from EOS aqua satellite data for the North Water Polynya over 2003-2009, J. Geophys. Res., 117, D06119, doi:10.1029/2011JD016949, 2012.

Bourassa, M. A., Gille, S., Bitz, C., Carlson, D., Cerovecki, I., Cronin, M., Drennan, W., Fairall, C., Hoffman, R., Magnusdottir, G., Pinker, R., Renfrew, I., Serreze, M., Speer, K., Talley, L., and Wick, G.: High-Latitude Ocean and Sea Ice Surface Fluxes: 
Challenges for Climate Research. B. Am. Meteor. Soc., 94, 403423, doi:10.1175/BAMS-D-11-00244.1, 2013.

Bourgain, P. and Gascard, J. C.: The Arctic Ocean halocline and its interannual variability from 1997 to 2008, Deep-Sea Res. I, 58, 745-756, 2011.

Bourgain, P. and Gascard, J. C.: The Atlantic and summer Pacific waters variability in the Arctic Ocean from 1997 to 2008, Geophys. Res. Lett., 39, L05603, doi:10.1029/2012GL051045, 2012.

Briegleb, B. P. and Light, B.: A Delta-Eddington Multiple Scattering Parameterization for Solar Radiation in the Sea Ice Component of the Community Climate System Model, NCAR Technical Note NCAR/TN-472 + STR, NCAR/TN-472+STR, National Center for Atmospheric Research, Boulder, CO, 2007.

Bromvich, D. H., Hines, K. M., and Bai, L.-S.: Development and testing of Polar Weather Research and Forecasting Model: 2. Arctic Ocean, J. Geophys. Res., 114, D08122, doi:10.1029/2008JD010300, 2009.

Brümmer, B. and Thiemann, S.: Arctic wintertime on-ice air flow. Bound.-Layer. Meteorol., 104, 53-72, 2002.

Brun, E., Yang, Z.-L., Essery, R., and Cohen, J.: Snow-cover parameterization and modeling, in Snow and Climate, in: Snow and Climate, edited by: Armstrong, R. L., and Brun, E., Cambridge University Press, Cambridge, UK, 125-180, 2008.

Brunke, M. A., Zhou, M., Zeng, X., and Andreas, E. L.: An intercomparison of bulk aerodynamic algorithms used over sea ice with data from the Surface Heat Budget for the Arctic Ocean (SHEBA) experiment, J. Geophys. Res., 111, C09001, doi:10.1029/2005JC002907, 2006.

Byrkjedal, Ø., Esau, I. N., and Kvamst $\varnothing$, N. G.: Sensitivity of simulated wintertime Arctic atmosphere to vertical resolution in the ARPEGE/IFS model, Clim. Dynam., 30, 687-701, doi:10.1007/s00382-007-0316-z, 2007.

Callaghan, T. V., Johansson, M. J., Key, J., Prowse, T., Ananicheva, M., and Klepikov, A.: Feedbacks and interactions: from the Arctic cryosphere to the climate system, Ambio, 40, 75-86, doi:10.1007/s13280-011-0215-8, 2012.

Calonne, N., Flin, F., Morin, S., Lesaffre, B., Rolland du Roscoat, S., and Geindreau, C.: Numerical and experimental investigations of the effective thermal conductivity of snow, Geophys. Res. Lett., 38, L23501, doi:10.1029/2011GL049234, 2011.

Cesana, G., Kay, J. E., Chepfer, H., English, J. M., and de Boer, G.: Ubiquitous low-level liquid-containing Arctic clouds: New observations and climate model constraints from CALIPSO-GOCCP, Geophys. Res. Lett., 39, L20804, doi:10.1029/2012GL053385, 2012.

Chechin, D. G., Lüpkes, C., Repina, I. A., and Gryanik, V. M.: Idealized dry quasi-2D mesoscale simulations of cold-air outbreaks over the marginal sea-ice zone with fine and coarse resolution, J. Geophys. Res., 118, 8787-8813, doi:10.1002/jgrd.50679, 2013.

Cheng, B., Vihma, T., Pirazzini, R., and Granskog, M.: Modeling of superimposed ice formation during spring snow-melt period in the Baltic Sea, Ann. Glaciol., 44, 139-146, 2006.

Cheng, B., Vihma, T., Zhang, Z., Li, Z., and Wu, H.: Snow and sea ice thermodynamics in the Arctic: Model validation and sensitivity study against SHEBA data, Chinese J. Polar Sci., 19, 108122, 2008a.

Cheng, B., Zhang, Z., Vihma, T., Johansson, M., Bian, L., Li, Z., and $\mathrm{Wu}, \mathrm{H} .:$ Model experiments on snow and ice thermodynamics in the Arctic Ocean with CHINARE2003 data, J. Geophys. Res., 113, C09020, doi:10.1029/2007JC004654, 2008b.

Cheng, B., Mäkynen, M., Similä, M., Rontu L., and Vihma, T.: Modelling snow and ice thickness in the coastal Kara Sea, Russian Arctic, Ann. Glaciol., 54, 105-113, doi:10.3189/2013AoG62A180, 2013.

Clarke, A. D. and Noone, K. J.: Soot in the arctic snowpack: A cause for perturbations in radiative transfer, Atmos. Environ., 19, 2045-2053, 1985.

Condron, A. and Renfrew, I. A.: The impact of polar mesoscale storms on northeast Atlantic Ocean circulation, Nature Geosci, 6, 34-37, doi:10.1038/ngeo1661, 2013.

Condron, A., Bigg, G. R., and Renfrew, I. A.: Modelling the impact of polar mesoscale cyclones on ocean circulation, J. Geophysical Res., 113, C10005, doi:10.1029/2007JC004599, 2008.

Cottier, F., Nilsen, F., Inall, M. E., Gerland, S., Tverberg, V., and Svendsen, H.: Wintertime warming of an Arctic shelf in response to large-scale atmospheric circulation, Geophys. Res. Lett., 34, L10607, doi:10.1029/2007GL029948, 2007.

Crook, J. A., Forster, P. M., and Stuber, N.: Spatial patterns of modeled climate feedback and contributions to temperature response and polar amplification, J. Clim. 24, 3575-3592, 2011.

Curry, J. A.: Interactions among Turbulence, Radiation and Microphysics in Arctic Stratus Clouds, J. Atmos. Sci., 43, 90-106, 1986.

Curry, J. A., Rossow, W. B., Randall, D., and Schramm, J. L.: Overview of Arctic Cloud and Radiation Characteristics, J. Clim., 9, 1731-1764, 1996.

Cuxart J., Holtslag, A. A. M., Beare, R., Beljaars, A., Cheng, A., Conangla, L., Ek, M., Freedman, F., Hamdi, R., Kerstein, A., Kitagawa, H., Lenderik, G., Lewellen. D., Mailhot, J., Mauritsen, T., Perov, V., Schayes, G., Steeneveld, G.-J., Svensson, G., Taylor, P., Wunsch, S., Weng, W., and Xu, K.-M.: Single-column intercomparison for a stably stratified atmospheric boundary layer, Bound. Layer Meteorol., 118, 273-303, 2006.

Dadic, R., Schneebeli, M., Lehning, M., Hutterli, M. A., and Ohmura, A.: Impact of the microstructure of snow on its temperature: A model validation with measurements from Summit, Greenland, J. Geophys. Res., 113, D14303, doi:10.1029/2007JD009562, 2008.

de Boer, G., Eloranta, E., and Shupe, M. D.: Arctic Mixed-Phase Stratiform Cloud Properties from Multiple Years of SurfaceBased Measurements at Two High-Latitude Locations, J. Atmos. Sci., 66, 2874-2887, doi:10.1175/2009JAS3029.1, 2009.

de Boer, G., Morrison, H., Shupe, M. D., and Hildner, R.: Evidence of liquid dependent ice nucleation in high-latitude stratiform clouds from surface remote sensors, Geophys. Res. Lett., 38, L01803, doi:10.1029/2010GL046016, 2011.

Dee, D. P., Uppala, S. M., Simmons, A. J., Berrisford, P., Poli, P., Kobayashi, S., Andrae, U., Balmaseda, M. A., Balsamo, G., Bauer, P., Bechtold, P., Beljaars, A. C. M., van de Berg, L., Bidlot, J., Bormann, N., Delsol, C., Dragani, R., Fuentes, M., Geer, A. J., Haimberger, L., Healy, S. B., Hersbach, H., Hólm, E. V., Isaksen, L., Kållberg, P., Köhler, M., Matricardi, M., McNally, A. P., Monge-Sanz, B. M., Morcrette, J. J., Park, B. K., Peubey, C., de Rosnay, P., Tavolato, C., Thépaut, J. N., and Vitart, F.: The ERA-Interim reanalysis: configuration and performance of the data assimilation system, Q. J. Roy. Meteor. Soc., 137, 553-597, 2011. 
Devasthale, A., Willen, U., Karlsson, G. K., and Jones, C. G.: Quantifying the clear-sky temperature inversion frequency and strength over the Arctic Ocean during summer and winter seasons from AIRS profiles, Atmos. Chem. Phys., 10, 5565-5572, doi:10.5194/acp-10-5565-2010, 2010.

Devasthale, A., Sedlar, J., and Tjernström, M.: Characteristics of water-vapour inversions observed over the Arctic by Atmospheric Infrared Sounder (AIRS) and radiosondes, Atmos. Chem. Phys., 11, 9813-9823, doi:10.5194/acp-11-9813-2011, 2011.

Deser, C., Tomas, R., Alexander, M., and Lawrence, D.: The seasonal atmospheric response to projected Arctic sea ice loss in the late twenty-first century, J. Climate, 23, 333-351, 2010.

Dickinson, R. E., Henderson-Sellers, A., and Kennedy, P. J.: Biosphere-Atmosphere Transfer Scheme (BATS) Version le as Coupled to the NCAR Community Climate Model, NCAR Technical Note NCAR/TN-387+STR, NCAR/TN-387+STR, National Center for Atmospheric Research, Boulder, CO, 1993.

Dmitrenko, I. A., Polyakov, I. V., Kirillov, S. A., Timokhov, L. A., Frolov, I. E., Sokolov, V. T., Simmons, H. L., Ivanov, V. V., and Walsh, D.: Toward a warmer Arctic Ocean: Spreading of the early 21st century Atlantic Water warm anomaly along the Eurasian Basin margins, J. Geophys. Res., 113, C05023, doi:10.1029/2007JC004158, 2008.

Doble, M. J., Forrest, A. L., Wadhams, P., and Laval, B. E.: Through-ice AUV deployment: Operational and technical experience from two seasons of Arctic fieldwork. Cold Reg. Sci. Technol., 56, 90-97. doi:10.1016/j.coldregions.2008.11.006, 2009.

Doherty, S. J., Warren, S. G., Grenfell, T. C., Clarke, A. D., and Brandt, R. E.: Light-absorbing impurities in Arctic snow, Atmos. Chem. Phys., 10, 11647-11680, doi:10.5194/acp-1011647-2010, 2010.

Dokken, T. and Jansen, E.: Rapid changes in the mechanism of ocean convection during the last glacial period, Nature, 401, 458-461, 1999.

Dominé, F., Bock, J., Morin, S., and Giraud, G.: Linking the effective thermal conductivity of snow to its shear strength and density, J. Geophys. Res., 116, F04027, doi:10.1029/2011JF002000, 2011.

Dorn, W., Dethloff, K., Rinke, A., Frickenhaus, S., Gerdes, R., Karcher, M., and Kauker, F.: Sensitivities and uncertainties in a coupled regional atmosphere-ocean-ice model with respect to the simulation of Arctic sea ice, J. Geophys. Res., 112, D10118, doi:10.1029/2006jd007814, 2007.

Dorn, W., Dethloff, K., and Rinke, A.: Improved simulation of feedbacks between atmosphere and sea ice over the Arctic Ocean in a coupled regional climate model, Ocean Modelling, 29, 103-114, doi:10.1016/j.ocemod.2009.03.010, 2009.

Döscher, R., Vihma, T., and Maksimovich, E.: Recent Advances in understanding the Arctic Climate System State and Change from a Sea Ice Perspective: a Review, Atmos. Chem. Phys. Discuss., 14, 10929-10999, doi:10.5194/acpd-14-10929-2014, 2014.

Dudko, Y. V., Schmidt, H., von der Heydt, K., and Scheer, E. K.: Edge wave observation using remote seismoacoustic sensing of ice events in the Arctic, J. Geophys. Res., 103, 21775-21781, 1998.

Dutra, E., Viterbo, P., Miranda, P. M. A., and Balsamo, G.: Complexity of Snow Schemes in a Climate Model and Its Impact on
Surface Energy and Hydrology, J. Hydrometeorol., 13, 521-538, doi:10.1175/jhm-d-11-072.1, 2012.

Eastman, R. and Warren, S. G.: Interannual Variations of Arctic Cloud Types in Relation to Sea Ice, J. Clim., 23, 4216-4232, doi:10.1175/2010jcli3492.1, 2010.

Ebner, L., Schröder, D., and Heinemann, G.: Impact of Laptev Sea flaw polynyas on the atmospheric boundary layer and ice production using idealized mesoscale simulations, Polar Res., 30, 7210, doi:10.3402/polar.v30i0.7210, 2011.

ECMWF, IFS documentation CY38r1,(last access date: 29 August 2014), 2012.

Ehn, J. K., Mundy, C. J., and Barber, D. G.: Bio-optical and structural properties inferred from irradiance measurements within the bottommost layers in an Arctic landfast sea ice cover, J. Geophys. Res., 113, C09024, doi:10.1029/2007jc004194, 2008a.

Ehn, J. K., Papakyriakou, T. N., and Barber, D. G.: Inference of optical properties from radiation profiles within melting landfast sea ice, J. Geophys. Res., 113, C03S03, doi10.1029/2007jc004656, 2008 b.

Ehn, J. K., Mundy, C. J., Barber, D. G., Hop, H., Rossnagel, A., and Stewart, J.: Impact of horizontal spreading on light propagation in melt pond covered seasonal sea ice in the Canadian Arctic, J. Geophys. Res., 116, C00G02, doi:10.1029/2010jc006908, 2011.

Eisenman, I. and Wettlaufer, J. S.: Nonlinear threshold behavior during the loss of Arctic sea ice, Proc. Nat. Acad. Sci., 106, 28 32, doi:10.1073/pnas.0806887106, 2009.

Esau, I. and Zilitinkevich, S.: On the role of the planetary boundary layer depth in climate system, Adv. Sci. Res., 4, 63-69, 2010.

Esau, I., Davy, R., and Outten, S.: Complementary explanation of temperature response in the lower atmosphere. Environ. Res. Lett., 7, 044026, doi:10.1088/1748-9326/7/4/044026, 2012.

Esau, I. N.: Amplification of turbulent exchange over wide Arctic leads: large-eddy simulation study, J. Geophys. Res., 112, D08109, doi:10.1029/2006JD007225, 2007.

Essery, R., Morin, S., Lejeune, Y., and B Ménard, C.: A comparison of 1701 snow models using observations from an alpine site, Adv. Water Res., 55, 131-148, doi:10.1016/j.advwatres.2012.07.013, 2012.

Feltham, D. L., Untersteiner, N., Wettlaufer, J. S., and Worster, M. G.: Sea ice is a mushy layer, Geophys. Res. Lett., 33, L14501, doi:10.1029/2006GL026290, 2006.

Fer, I.: Weak vertical diffusion allows maintenance of cold halocline in the central Arctic, Atmos. Ocean. Sci. Lett., 2, 148-152, 2009.

Fer, I.: Near-inertia-1 mixing in the central Arctic Ocean, J. Phys. Oceanogr., 44, 2031-2049, doi:10.1175/JPO-D-13-0133.1, 2014.

Fer, I. and Sundfjord, A.: Observations of upper ocean boundary layer dynamics in the marginal ice zone, J. Geophys. Res., 112, C04012, doi:10.1029/2005jc003428, 2007.

Fer, I., Skogseth, R., and Geyer, F.: Internal waves and mixing in the Marginal Ice Zone near the Yermak Plateau, J. Phys. Oceanogr., 40, 1613-1630, 2010.

Fer, I., Peterson, A. K., and Ullgren, J. E.: Microstructure measurements from an underwater glider in the turbulent Faroe Bank Channel overflow, J. Atmos. Ocean. Tech., 31, 1128-1150, 2014.

Fiedler, E. K., Lachlan-Cope, T. A., Renfrew, I. A., and King, J. C.: Convective heat transfer over thin ice covered coastal polynyas, J. Geophys. Res., 115, C10051, doi:10.1029/2009JC005797, 2010.

Flanner, M. G.: Arctic climate sensitivity to local black carbon, J. Geophys. Res., 118, 1840-1851, doi:10.1002/jgrd.50176, 2013. 
Flanner, M. G. and Zender, C. S.: Linking snowpack microphysics and albedo evolution, J. Geophys. Res., 111, D12208, doi:10.1029/2005JD006834, 2006.

Flanner, M. G., Zender, C. S., Randerson, J. T., and Rasch, P. J.: Present-day climate forcing and response from black carbon in snow, J. Geophys. Res., 112, doi:10.1029/2006jd008003, 2007.

Flanner, M. G., Zender, C. S., Hess, P. G., Mahowald, N. M., Painter, T. H., Ramanathan, V., and Rasch, P. J.: Springtime warming and reduced snow cover from carbonaceous particles, Atmos. Chem. Phys., 9, 2481-2497, doi:10.5194/acp-9-24812009, 2009.

Flanner, M. G., Shell, K. M., Barlage, M., Perovich, D. K., and Tschudi, M. A.: Radiative forcing and albedo feedback from the Northern Hemisphere cryosphere between 1979 and 2008, Nature Geosci, 4, 151-155, http://www.nature.com/ngeo/journal/ v4/n3/abs/ngeo1062.html\#supplementary-information (last access: 29 August 2014), 2011.

Flocco, D. and Feltham, D. L.: A continuum model of melt pond evolution on Arctic sea ice, J. Geophys. Res., 112, C08016, doi:10.1029/2006JC003836, 2007.

Flocco, D., Felthman, D. L., and Turner, A. K.: Incorporation of a physically based melt pond scheme into the sea ice component of a climate model, J. Geophys. Res., 115, C08012, doi:10.1029/2009JC005568, 2010.

Flocco, D., Schröder, D., Feltham, D. L., and Hunke, E. C.: Impact of melt ponds on Arctic sea ice simulations from 1990 to 2007, J. Geophys. Res., 117, C09032, oi:10.1029/2012JC008195, 2012.

Føre, I. and Nordeng, T. E.: A polar low observed over the Norwegian Sea on 3-4 March 2008: high-resolution numerical experiments, Q. J. Roy. Meteor. Soc., 138, 1983-1998, 2012.

Føre, I., Kristjánsson, J. E., Saetra, Ø, Breivik, Ø., Røsting, B., and Shapiro, M.: The full life cycle of a polar low over the Norwegian Sea observed by three research aircraft flights, Q. J. Roy. Meteor. Soc., 137, 1659-1673, 2011.

Forsström, S., Ström, J., Pedersen, C. A., Isaksson, E., and Gerland, S.: Elemental carbon distribution in Svalbard snow, J. Geophys. Res., 114, D19112, doi:10.1029/2008JD011480, 2009.

Forsström, S., Isaksson, E., Skeie, R. B., Ström, J., Pedersen, C. A., Hudson, S. R., Berntsen, T. K., Lihavainen, H., Godtliebsen, F., and Gerland, S.: Elemental carbon measurements in European Arctic snow packs, J. Geophys. Res., 118, 13614-13627, doi:10.1002/2013JD019886, 2013.

Forster, P., Ramaswamy, V., Artaxo, P., Berntsen, T., Betts, R., Fahey, D. W., Haywood, J., Lean, J., Lowe, D. C., Myhre, G., Nganga, J., Prinn, R., Raga, G., Schulz, M., and Van Dorland, R.: Changes in Atmospheric Constituents and in Radiative Forcing, in: Climate Change 2007: The Physical Science Basis. Contribution of Working Group I to the Fourth Assessment Report of the Intergovernmental Panel on Climate Change, edited by: Solomon, S., Qin, D., Manning, M., Chen, Z., Marquis, M., Averyt, K. B., Tignor, M., and Miller, H. L., Cambridge University Press, Cambridge, UK, and New York, USA, 2007.

Fox-Kemper, B., Danabasoglu, G., Ferrari, R., Griffies, S. M., Hallberg, R. W., Holland, M. M., Maltrud, M. E., Peacock, S., and Samuels, B. L.: Parameterization of mixed layer eddies. III: Implementation and impact in global ocean climate simulations, Ocean Modell., 39, 61-78, 2011.

Francis, J. A., Chan, W., Leathers, D. J., Miller, J. R., and Veron, D. E.: Winter Northern Hemisphere weather patterns remember summer Arctic sea-ice extent, Geophys. Res. Lett., 36, L07503, doi:10.1029/2009GL037274, 2009.

Frey, K. E., Perovich, D. K., and Light, B.: The spatial distribution of solar radiation under a melting Arctic sea ice cover, Geophys. Res. Lett., 38, L22501, doi:10.1029/2011GL049421, 2011.

Fridlind, A. M., Van Diederhoven, B., Ackerman, A. S., Avramov, A., Mrowiec, A., Morrison, H., Zuidema, P., and Shupe, M. D., A FIRE-ACE/SHEBA Case Study of Mixed-Phase Arctic Boundary Layer Clouds: Entrainment Rate Limitations on Rapid Primary Ice Nucleation Processes, J. Atmos. Sci., 69, 365-389, doi:10.1175/JAS-D-11-052.1, 2012.

Gallet, J.-C, Domine, F., Zender, C. S., and Picard, G.: Measurement of the specific surface area of snow using infrared reflectance in an integrating sphere at 1310 and $1550 \mathrm{~nm}$, The Cryosphere, 3, 167-182, doi:10.5194/tc-3-167-2009, 2009.

Galperin, B., Sukoriansky, S., and Anderson, P. S.: On the critical Richardson number in stably stratified turbulence. Atmosph. Sci. Lett., 8, 65-69, doi:10.1002/as1.153, 2007.

Gardner, A. S. and Sharp, M. J.: A review of snow and ice albedo and the development of a new physically based broadband albedo parameterization, J. Geophys. Res., 115, F01009, doi:10.1029/2009jf001444, 2010.

Garrett, T. J. and Zhao, C.: Increased Arctic cloud longwave emissivity associated with pollution from mid-latitudes, Nature, 440 , 787-789, doi:10.1038/nature04636, 2006.

Gascard, J.-C., Watson, A. J., Messias, M.-J., Olsson, K. A., Johannessen, T., and Simonsen, K.: Long-lived vortices as a mode of deep ventilation in the Greenland Sea, Nature, 416, 525-527, 2002.

Gascard, J. C., Festy, J., le Gogg, H., Weber, M., Bruemmer, B., Offermann, M., Doble, M., Wadhams, P., Forsberg, R., Hanson, S., Skourup, H., Gerland, S., Nicolaus, M., Metaxin, J. P., Grangeon, J., Haapala, J., Rinne, E., Haas, C., Heygster, G., Jakobson, E., Palo, T., Wilkinson, J., Kaleschke, L., Claffey, K., Elder, B., and Bottenheim, J.: Exploring Arctic Transpolar Drift During Dramatic Sea Ice Retreat, EOS Trans., 89, 21-28, 2008.

Gent, P. R., Danabasoglu, G., Donner, L. J., Holland, M. M., Hunke, E. C., Jayne, S. R., Lawrence, D. M., Neale, R. B., Rasch, P. J., Vertenstein, M., Worley, P. H., Yang, Z.-L., and Zhang, M.: The Community Climate System Model Version 4, J. Clim., 24, 4973-4991, doi:10.1175/2011jcli4083.1, 2011.

Gimbert, F., Marsan, D., Weiss, J., Jourdain, N. C. and Barnier, B.: Sea ice inertial oscillations in the Arctic Basin, The Cryosphere, 6, 1187-1201, 2012a, http://www.the-cryosphere-discuss.net/6/1187/2012/.

Gimbert, F., Jourdain, N. C., Marsan, D., Weiss, J., and Barnier, B.: Recent mechanical weakening of the Arctic sea ice cover as revealed from larger inertial oscillations, J. Geophys. Res., 117, C00J12, 2012b.

Goldenson, N., Doherty, S. J., Bitz, C. M., Holland, M. M., Light, B., and Conley, A. J.: Arctic climate response to forcing from light-absorbing particles in snow and sea ice in CESM, Atmos. Chem. Phys., 12, 7903-7920, doi:10.5194/acp-12-7903-2012, 2012.

Goosse, H., Arzel, O., Bitz, C. M., de Montety, A., and Vancoppenolle, M.: Increased variability of the Arctic summer ice extent in a warmer climate, Geophys. Res. Lett., 36, doi:10.1029/2009g1040546, 2009. 
Gorodetskaya, I. V., Tremblay, L. B., Liepert, B., Cane, M. A., and Cullather, R. I.: The influence of cloud and surface properties on the Arctic Ocean shortwave radiation budget in coupled models, J. Climate, 21, 866-882, 2008.

Grachev, A. A., Andreas, E. L., Fairall, C. W., Guest, P. S., and Persson, P. O. G.: SHEBA flux-profile relationships in the stable atmospheric boundary layer, Bound.-Layer Meteorol., 124, 315333, 2007a.

Grachev, A. A., Andreas, E. L., Fairall, C. W., Guest, P. S., and Persson, P. O. G.: On the turbulent Prandtl number in the stable atmospheric boundary layer, Bound.-Layer Meteorol., 125, 329341, 2007b.

Grachev, A. A., Andreas, E. L., Fairall, C. W., Guest, P. S., and Persson, P. O. G.: Outlier problem in evaluating similarity functions in the stable atmospheric boundary layer, Bound.-Layer Meteorol., 144, 137-155, 2012.

Graversen, R. G. and Wang, M.: Polar amplification in a coupled climate model with locked albedo, Clim. Dynam., 33, 629-643, doi:10.1007/s00382-009-0535-6, 2009.

Graversen, R. G., Mauritsen, T., Tjernström, M., Källen, E., and Svensson, G.: Vertical structure of recent Arctic warming, Nature, 451, 53-56, doi:10.1038/nature06502, 2008.

Graversen, R. G., Mauritsen, T., Drijfhout, S., Tjernström, M., and Mårtensson, S.: Warm winds from the Pacific caused extensive Arctic sea-ice melt in summer 2007, Clim. Dynam., 36, 21032112, doi:10.1007/s00382-010-0809-z, 2011.

Griewank, P. J. and Notz, D.: Insights into brine dynamics and sea ice desalination from a 1-D model study of gravity drainage, J. Geophys. Res. Oceans, 118, 3370-3386, doi:10.1002/jgrc.20247, 2013.

Gryschka, M., Drüe, C., Etling, D., Raasch, S.: On the influence of sea-ice inhomogeneities onto roll convection in cold-air outbreaks, Geophys. Res. Lett., 35, L23804, doi:10.1029/2008GL035845, 2008.

Guthrie, J., Morison, J., and Fer, I.: Revisiting Internal Waves and Mixing in the Arctic Ocean, J. Geophys. Res., 118, 3966-3977, doi:10.1002/jgrc.20294, 2013.

Haas, C., Le Goff, H., Audrain, S., Perovich, D., and Haapala, J.: Comparison of seasonal sea-ice thickness change in the Transpolar Drift observed by local ice mass-balance observations and floe-scale EM surveys, Ann. Glaciol., 52, 97-102, 2011.

Hadley, O. L. and Kirchstetter, T. W.: Black-carbon reduction of snow albedo, Nature Climate Change, 2, 437-440, doi:10.1038/nclimate143310.1038/NCLIMATE1433, 2012.

Haine, T. W. N., Zhang, S., Moore, G. W. K., and Renfrew, I. A.: On the impact of high-resolution, high frequency meteorological forcing on Denmark-Strait ocean circulation, Q. J. Roy. Meteor. Soc., 135, 2067-2085, 2009.

Hakkinen, S., Proshutinsky, A., and Ashik, I.: Sea ice drift in the Arctic since the 1950s, Geophys. Res. Lett., 35, L19704, doi:10.1029/2008GL034791, 2008.

Hansen, J., Sato, M., Ruedy, R., Nazarenko, L., Lacis, A., Schmidt, G. A., Russell, G., Aleinov, I., Bauer, M., Bauer, S., Bell, N., Cairns, B., Canuto, V., Chandler, M., Cheng, Y., Del Genio, A., Faluvegi, G., Fleming, E., Friend, A., Hall, T., Jackman, C., Kelley, M., Kiang, N., Koch, D., Lean, J., Lerner, J., Lo, K., Menon, S., Miller, R., Minnis, P., Novakov, T., Oinas, V., Perlwitz, J., Perlwitz, J., Rind, D., Romanou, A., Shindell, D., Stone, P., Sun, S., Tausnev, N., Thresher, D., Wielicki, B., Wong, T., Yao, M., and Zhang, S.: Efficacy of climate forcings, J. Geophys. Res., 110, D18104, doi:10.1029/2005jd005776, 2005.

Harden, B. E. and Renfrew, I. A.: On the spatial distribution of high winds off southeast Greenland, Geophys. Res. Lett., 39, L14806, doi:10.1029/2012GL052245, 2012.

Harden, B. E., Renfrew, I. A., and Petersen, G. N.: A climatology of wintertime barrier winds off southeast Greenland, J. Clim., 24, 4701-4717, 2011.

Harpaintner J., Gascard, J.-C., and Haugan, P.: Ice production and brine formation in Storfjorden, Svalbard, J. Geophys. Res., 106, 14001-14013, 2001.

Harrington, J. Y., Reisin, T., Cotton, W. R., and Kreidenweis, S. M.: Cloud resolving simulations of Arctic stratus. Part II: Transitionseason clouds, Atmos. Res., 45-75, 1999.

Hawkins, E. and Sutton, R.: The potential to narrow uncertainty in regional climate predictions, B. Am. Meteor. Soc., 90, 1095, doi:10.1175/2009BAMS2607.1, 2009.

Hebbinghaus, H., Schlünzen, H., and Dierer, S.: Sensitivity studies on vortex development over a polynyas, Theor. Appl. Climatol., 88, 1-16, doi:10.1007/s00704-006-0233-9, 2006.

Heinemann, G.: The polar regions: a natural laboratory for boundary layer meteorology - a review, Meteorol. Zeitschr., 17, 589601, 2008.

Heygster, G., Alexandrov, V., Dybkjær, G., von HoyningenHuene, W., Girard-Ardhuin, F., Katsev, I. L., Kokhanovsky, A., Lavergne, T., Malinka, A. V., Melsheimer, C., Toudal Pedersen, L., Prikhach, A. S., Saldo, R., Tonboe, R., Wiebe, H., and Zege, E. P.: Remote sensing of sea ice: advances during the DAMOCLES project, The Cryosphere, 6, 1411-1434, doi:10.5194/tc-61411-2012, 2012.

Hines, K. M. and Bromwich, D. H.: Development and Testing of Polar WRF. Part I. Greenland Ice Sheet Meteorology, Mon. Weather Rev., 136, 1971-1989, doi:10.1175/2007MWR2112.1, 2008.

Holland, M. M., Bailey, D. A., Briegleb, B. P., Light, B., and Hunke, E.: Improved Sea Ice Shortwave Radiation Physics in CCSM4: The Impact of Melt Ponds and Aerosols on Arctic Sea Ice, J. Clim., 25, 1413-1430, doi:10.1175/jcli-d-11-00078.1, 2012.

Holloway, G. and Proshutinsky, A.: Role of tides in Arctic ocean/ice climate, J. Geophys. Res., 112, C04S06, doi:10.1029/2006JC003643, 2007.

Hudson, S. R.: Estimating the global radiative impact of the sea icealbedo feedback in the Arctic, J. Geophys. Res., 116, D16102, doi:10.1029/2011jd015804, 2011.

Hudson, S. R., Granskog, M. A., Karlsen, T. I., and Fossan, K.: An integrated platform for observing the radiation budget of sea ice at different spatial scales, Cold Reg. Sci. Technol., 82, 14-20, doi:10.1016/j.coldregions.2012.05.002, 2012.

Hudson, S. R., Granskog, M. A., Sundfjord, A., Randelhoff, A., Renner, A. H. H., and Divine, D. V.: Energy budget of first-year Arctic sea ice in advanced stages of melt, Geophys. Res. Lett., 40, 2679-2683, doi:10.1002/grl.50517, 2013.

Hunke, E. C. and Lipscomb, W. H.: CICE: the Los Alamos Sea Ice Model Documentation and Software User's Manual Version 4.1, Los Alamos National Laboratory, Los Alamos, NM, 1-115, 2010.

Hunke, E. C., Notz, D., Turner, A. K., and Vancoppenolle, M.: The multiphase physics of sea ice: a review for model developers, The Cryosphere, 5, 989-1009, doi:10.5194/tc-5-989-2011, 2011. 
Inoue, J., Curry, J. A., and Maslanik, J. A.: Application of Aerosondes to melt-pond observations over Arctic sea ice, J. Atmos. Ocean. Technol., 25, 327-334, doi:10.1175/2007JTECHA955.1, 2008.

Inoue, J., Enomoto, T., Miyoshi, T., and Yamane S.: Impact of observations from Arctic drifting buoys on the reanalysis of surface fields, Geophys. Res. Lett., 36, L08501, doi:10.1029/2009GL037380, 2009.

Intrieri, J. M., Shupe, M. D., Uttal, T., and McCarty, B. J.: An annual cycle of Arctic cloud characteristics observed by radar and lidar at SHEBA, J. Geophys. Res., 107, 8030, doi:10.1029/2000JC000423, 2002.

IPCC: Climate Change 2007: The Physical Science Basis. Contribution of Working Group I to the Fourth Assessment Report of the Intergovernmental Panel on Climate Change, edited by: Solomon, S., Qin, D., Manning, M., Chen, Z., Marquis, M., Averyt, K. B., Tignor, M., and Miller, H. L., Cambridge University Press, Cambridge, UK, and New York, USA, 996 pp., 2007.

Irvine, E. A., Gray, S. L., and Methven, J.: Targeted observations of a polar low in the Norwegian Sea, Q. J. Roy. Meteor. Soc., 137, 1688-1699, 2011.

Itoh, M., Inoue, J., Shimada, K., Zimmermann, S., Kikuchi, T., Hutchings, J., McLaughlin, F., and Carmack, E.: Acceleration of sea-ice melting due to transmission of solar radiation through ponded ice area in the Arctic Ocean: results of in situ observations from icebreakers in 2006 and 2007, Ann. Glaciol., 52, 249260, 2011.

Jaiser, R., Dethloff, K., Handorf, D., Rinke, A., and Cohen, J.: Impact of sea ice cover changes on the Northern Hemisphere atmospheric winter circulation, Tellus A., 64, 11595, doi:10.3402/tellusaV64i0.11595, 2012.

Jakobson, E., Vihma, T., Palo, T., Jakobson, L., Keernik, H., and Jaagus, J.: Validation of atmospheric reanalyzes over the central Arctic Ocean, Geophys. Res. Lett. 39, L10802, doi:10.1029/2012GL051591, 2012.

Jakobson, L., Vihma, T., Jakobson, E., Palo, T., Männik, A., and Jaagus, J.: Low-level jet characteristics over the Arctic Ocean in spring and summer. Atmos. Chem. Phys., 13, 11089-11099, doi:10.5194/acp-13-11089-2013, 2013.

Jung, T. and Leutbecher, M.: Performance of the ECMWF forecasting system in the Arctic during winter, Q. J. Roy. Meteor. Soc., 133, 1327-1340, 2007.

Kaempfer, T. U., Hopkins, M. A., and Perovich, D. K.: A three-dimensional microstructure-based photon-tracking model of radiative transfer in snow, J. Geophys. Res., 112, D24113, doi:10.1029/2006JD008239, 2007.

Kagan, B. A., Sofina, E. V., and Timofeev, A. A.: Modeling of the $\mathrm{M}_{2}$ surface and internal tides and their seasonal variability in the Arctic Ocean: Dynamics, energetics and tidally induced diapycnal diffusion, J. Mar. Res., 69, 245-276, 2011.

Kahl, J. D.: Characteristics of the low-level temperature inversion along the Alaskan Arctic coast, Int. J. Climatol., 10, 537-548, 1990.

Kapsch, M.-L., Graversen, R. G., and Tjernström, M.: Springtime atmospheric energy transport and the control of Arctic summer sea-ice extent, Nature Climate Change, 3, 744-748, doi:10.1038/nclimate1884, 2013.

Karlsson, J. and Svensson, G.: The simulation of Arctic clouds and their influence on the winter surface temperature in present-day climate in the CMIP3 multi-model dataset, Clim. Dynam., 36, 623-635, doi:10.1007/s00382-010-0758-6, 2011.

Kay, J. E. and Gettelman, A.: Cloud influence on and response to seasonal Arctic sea ice loss, J. Geophys. Res., 114, D18204, doi:10.1029/2009jd011773, 2009.

Kay, J. E., Raeder, K., Gettelman, A., and Anderson, J: The boundary layer response to recent Arctic sea ice loss and implications for high-latitude climate feedbacks, J. Climate, 24, 428447, doi:10.1175/2010JCLI3651.1, 2011.

Kelley, D. E., Fernando, H. J. S., Gargett, A. E., Tanny, J., and Ozsoy, E.: The diffusive regime of double diffusive convection, Prog. Oceanogr., 56, 461-481, 2003.

Kilpeläinen, T. and Sjöblom, A.: Momentum and sensible heat exchange in an ice-free Arctic fjord. Bound.-Layer Meterol., 134, 109-130, doi:10.1007/s10546-009-9435-x, 2010.

Kilpeläinen, T., Vihma, T., and Olafsson, H.: Modelling of spatial variability and topographic effects over Arctic fjords in Svalbard, Tellus, 63A, 223-237, doi:10.1111/j.1600-0870.2010.00481.x, 2011.

Kilpeläinen, T., Vihma, T., Manninen, M., Sjöblom, A., Jakobson, E., Palo, T., and Maturilli, M.: Modelling the vertical structure of the atmospheric boundary layer over Arctic fjords in Svalbard, Q. J. Roy. Meteor. Soc., 138, 1867-1883, doi:10.1002/qj.1914, 2012.

Koch, D., Menon, S., Del Genio, A., Ruedy, R., Alienov, I., and Schmidt, G. A.: Distinguishing Aerosol Impacts on Climate over the Past Century, J. Clim., 22, 2659-2677, 2009.

Koch, D., Bauer, S. E., Del Genio, A., Faluvegi, G., McConnell, J. R., Menon, S., Miller, R. L., Rind, D., Ruedy, R., Schmidt, G. A., and Shindell, D.: Coupled Aerosol-Chemistry-Climate Twentieth-Century Transient Model Investigation: Trends in Short-Lived Species and Climate Responses, J. Clim., 24, 2693 2714, 2011.

Kolstad, E. W. and Bracegirdle, T. J.: Marine cold-air outbreaks in the future: an assessment of IPCC AR4 model results for the Northern Hemisphere, Clim. Dynam., 30, 871-885, 2008.

Kolstad, E. W., Bracegirdle, T. J., and Seierstad, I. A.: Marine coldair outbreaks in the North Atlantic: Temporal distribution and associations with large-scale atmospheric circulation, Clim. Dynam., 33, 187-197, 2009.

Køltzow, M.: The effect of a new snow and sea ice albedo scheme on regional climate model simulations, J. Geophys. Res., 112, D07110, doi:10.1029/2006jd007693, 2007.

Kral, S. T., Sjb̈lom, A., and Nygård, T.: Observations of summer turbulent surface fluxes in a High Arctic fjord. Q.J.Roy. Meteorol Soc., 140, 666-675, doi:10.1002/qj.2167, 2014.

Krasnopolsky, V. M., Fox-Rabinovitz, M. S., and Belochitski, A. A.: Using ensemble of neural networks to learn stochastic convection parameterizations for climate and numerical weather prediction models from data simulated by a cloud resolving model, Adv. Artif. Neural Syst., 485913, 13 pp., doi:10.1155/2013/485913, 2013.

Kristiansen, J., Sørland, S. L., Iversen, T., Bjørge, D., and Køltzow, M. Ø.: High-resolution ensemble prediction of a polar low development, Tellus A, 63, 585-604, 2011.

Kristjansson, J. E., Barstad, I., Aspelien, T., Føre, I., Godøy, Ø. A., Hov, Ø., Irvine, E., Iversen,T., Kolstad, E. W., Nordeng, T. E., McInnes, H., Randriamampianina, R., Reuder, J., Sætra, Ø., Shapiro, M. A., Spengler, T., and Ólafsson, H.: The Norwegian 
IPY-THORPEX. Polar Lows and Arctic Fronts during the 2008 Andøya Campaign, Bull. Amer. Meteor. Soc., 92 1443-1466, doi:10.1175/2011BAMS2901.1, 2011.

Lammert, A., Brummer, B., and Kaleschke, L.: Observation of cyclone-induced inertial sea-ice oscillation in Fram Strait, Geophys. Res. Lett., 36, L10503, doi:10.1029/2009GL037197, 2009.

Lammert, A., Brümmer, B., Haller, M., Müller, G., and Schyberg, H.: Comparison of three weather prediction models with buoy and aircraft measurements under cyclone conditions in Fram Strait, Tellus A, 62, 361-376, doi:10.1111/j.16000870.2010.00460.x, 2010.

Lampert, A., Maturilli, M., Ritter, C., Hoffmann, A., Stock, M., Herber, A., Birnbaum, G., Neuber, R., Dethloff, K., Orgis, T., Stone, R., Brauner, R., Kässbohrer, J., Haas, C., Makshtas, A., Sokolov., V., and Liu, P.: The spring-time boundary layer in the central Arctic observed during PAMARCMiP 2009, Atmosphere, 3, 320-351, doi:10.3390/atmos3030320, 2012.

Lance, S., Shupe, M. D., Feingold, G., Brock, C. A., Cozic, J., Holloway, J. S., Moore, R. H., Nenes, A., Schwarz, J. P., Spackman, J. R., Froyd, K. D., Murphy, D. M., Brioude, J., Cooper, O. R., Stohl, A., and Burkhart, J. F.: Cloud condensation nuclei as a modulator of ice processes in Arctic mixed-phase clouds, Atmos. Chem. Phys., 11, 8003-8015, doi:10.5194/acp-11-80032011, 2011.

Langen, P. L., Graversen, R. G., and Mauritsen, T.: Separation of contributions from radiative feedbacks to polar amplification on an aquaplanet. J. Clim., 25, 3010-3024, 2012.

Láska, K., Witoszová, D., and Prošek, P.: Weather patterns of the coastal zone of Petuniabukta, central Spitsbergen in the period 2008-2010, Polish Polar Res., 33, 297-318, doi:10.2478/v10183-012-0025-0, 2012.

Lawrence, D., Oleson, K. W., Flanner, M. G., Thorton, P. E., Swenson, S. C., Lawrence, P. J., Zeng, X., Yang, Z.-L., Levis, S., Skaguchi, K., Bonan, G. B., and Slater, A. G.: Parameterization Improvements and Functional and Structural Advances in Version 4 of the Community Land Model, J. Adv. Modeling Earth Systems, 3, 27 pp., doi:10.1029/2011ms000045, 2011.

Lecomte, O., Fichefet, T., Vancoppenolle, M., and Nicolaus, M.: A new snow thermodynamic scheme for large-scale sea-ice models, Ann. Glaciol., 52, 337-346, 2011. v Lenn, Y.-D., Rippeth, T. P., Old, C. P., Bacon, S., Polyakov, I., Ivanov, V., and Hölemann, J.: Intermittent intense turbulent mixing under Ice in the Laptev Sea continental shelf, J. Phys. Oceanogr., 41, 531-547, doi:10.1175/2010JPO4425.1, 2011.

Levine, M. D., Paulson, C. A., and Morison, J. H.: Internal waves in the Arctic Ocean: Comparison with lower-latitude observations, J. Phys. Oceanogr., 15, 800-809, 1985.

Light, B., Grenfell, T. C., and Perovich, D. K.: Transmission and absorption of solar radiation by Arctic sea ice during the melt season, J. Geophys. Res., 113, C03023, doi:10.1029/2006jc003977, 2008.

Linders, T. and Saetra, O.: Can CAPE maintain polar lows?, J. Atmos. Sci., 67, 2559-2571, 2010.

Lique, C. and Steele, M.: Where can we find a seasonal cycle of the Atlantic water temperature within the Arctic Basin?, J. Geophys. Res., 117, C03026, doi:10.1029/2011jc007612, 2012.

Liu, A., Moore, G., Tsuboki, K., and Renfrew, I.: The Effect of the Sea-ice Zone on the Development of Boundary-layer Roll Clouds
During Cold Air Outbreaks, Bound.-Layer Meteorol., 118, 557581, doi:10.1007/s10546-005-6434-4, 2006.

Liu, J., Zhang, Z., Inoue, J., and Horton, R. M.: Evaluation of snow/ice albedo parameterizations and their impacts on sea ice simulations, Int. J. Climatol., 27, 81-91, doi:10.1002/joc.1373, 2007.

Liu, Y., Key, J. R., Ackerman, S. A., Mace, G. C., and Zhang, Q.: Arctic cloud macrophysical characteristics from CloudSat and CALIPSO, Remote Sensing Environ., 124, 159-173, doi:10.1016/j.rse.2012.05.006, 2012.

Lu, P., Li, Z., Cheng, B., and Leppäranta, M.: A parameterization of the ice-ocean drag coefficient, J. Geophys. Res., 116, C07019, 2011.

Lubin, D. and Vogelmann, A. M.: A climatologically significant aerosol longwave indirect effect in the Arctic, Nature, 439, 453456, doi:10.1038/nature04449, 2006.

Lüpkes, C., Vihma, T., Birnbaum, G., and Wacker, U.: Influence of leads in sea ice on the temperature of the atmospheric boundary layer during polar night, Geophys. Res. Lett., 35, L03805, doi:10.1029/2007GL032461, 2008a.

Lüpkes, C., Gryanik, V. M., Witha, B., Gryschka, M., Raasch, S., and Gollnik, T.: Modeling convection over arctic leads with LES and a non-eddy-resolving microscale model, J. Geophys. Res., 113, C09028, doi:10.1029/2007JC004099, 2008b.

Lüpkes, C., Vihma, T., Jakobson, E., König-Langlo, G., and Tetzlaff, A.: Meteorological observations from ship cruises during summer to the central Arctic: A comparison with reanalysis data, Geophys. Res. Lett., 37, L09810, doi:10.1029/2010GL042724, 2010.

Lüpkes, C., Gryanik, V. M., Hartmann, J., and Andreas, E. L.: A parametrization, based on sea ice morphology, of the neutral atmospheric drag coefficients for weather prediction and climate models, J. Geophys. Res., 117, D13112, doi:10.1029/2012JD017630, 2012a.

Lüpkes, C., Vihma, T., Birnbaum, G., Dierer, S., Garbrecht, T., Gryanik, V., Gryschka, M., Hartmann, J., Heinemann, G., Kaleschke, L., Raasch, S., Savijärvi, H., Schlünzen, K., and Wacker, U.: Mesoscale modelling of the Arctic atmospheric boundary layer and its interaction with sea ice, Chapter 7 in: ARCTIC climate change - The ACSYS decade and beyond, Lemke, P. and Jacobi, H.-W., Springer, Atmospheric and Oceanographic Sciences Library, 43, 279-324, doi:10.1007/97894-007-2027-5, 2012b.

Lüpkes, C., Gryanik, V. M., Rösel, A., Birnbaum, G., and Kaleschke, L.: Effect of sea ice morphology during Arctic summer on atmospheric drag coefficients used in climate models, Geophys. Res. Lett., 40, 446-451, doi:10.1002/grl.50081, 2013.

Mäkiranta, E., Vihma, T., Sjöblom, A., and Tastula, E.-M.: Observations and modelling of the atmospheric boundary layer over sea ice in a Svalbard fjord, Bound.-Layer Meteorol., 140, 105-123, doi:10.1007/s10546-011-9609-1, 2011.

Maksimovich, E. and Vihma, T.: The effect of surface heat fluxes on interannual variability in the spring onset of snow melt in the central Arctic Ocean, J. Geophys. Res., 117, C07012, doi:10.1029/2011JC007220, 2012.

Marcq, S. and Weiss, J.: Influence of sea ice lead-width distribution on turbulent heat transfer between the ocean and the atmosphere, The Cryopshere, 6, 143-156, doi:10.5194/tc-6-143-2012, 2012. 
Marsan, D., Weiss, J., Metaxian, J. P., Grangeon, J., Roux, P. F., and Haapala, J.: Low-frequency bursts of horizontally polarized waves in the Arctic sea-ice cover, J. Glaciol., 57, 231-237, 2011.

Marsan, D., Weiss, J., Larose, E., and Metaxian, J. P.: Sea-ice thickness measurement based on the dispersion of ice swell, J. Acoustic. Soc. Am., 131, 80-91, 2012.

Massonnet, F., Fichefet, T., Goosse, H., Bitz, C. M., PhilipponBerthier, G., Holland, M. M., and Barriat, P.-Y.: Constraining projections of summer Arctic sea ice, The Cryosphere, 6, 13831394, doi:10.5194/tc-6-1383-2012, 2012.

Mauldin, A., Schlosser, P., Newton, R., Smethie Jr., W. M., Bayer, R., Rhein, M., and Jones, E. P.: The velocity and mixing time scale of the Arctic Ocean Boundary Current estimated with transient tracers, J. Geophys. Res., 115, C08002, doi:10.1029/2009JC005965, 2010.

Mauritsen, T. and Svensson, G.: Observations of Stably Stratified Shear-Driven Atmospheric Turbulence at Low and High Richardson Numbers, J. Atmos. Sci., 64, 645-655, 2007.

Mauritsen, T., Svensson, G., Zilitinkevich, S., Esau, I., Enger, L., and Grisogono, B.: A total turbulent energy closure model for neutrally and stably stratified atmospheric boundary layers, J. Atmos. Sci., 64, 4113-4126, 2007.

Mauritsen, T., Sedlar, J., Tjernström, M., Leck, C., Martin, M., Shupe, M., Sjogren, S., Sierau, B., Persson, P. O. G., Brooks, I. M., and Swietlicki, E.: An Arctic CCN-limited cloud-aerosol regime, Atmos. Chem. Phys., 11, 165-173, doi:10.5194/acp-11165-2011, 2011.

Mauritsen, T., Graversen, R. G., Klocke, D., Langen, P. L., Stevens, B., and Tomassini, L.: Climate feedback efficiency and synergy. Clim. Dynam., 41, 2539-2554, doi:10.1007/s00382-013-1808-7, 2013.

Maykut, G. A. and Untersteiner, N.: Some results from a timedependent, thermodynamic model of sea ice, J. Geophys. Res., 76, 1550-1575, 1971.

McFarquhar, G. M., Zhang, G., Poellot, M. R., Kok, G. L., McCoy, R., Tooman, T., Fridlind, A., and Heymsfield, A. J.: Ice properties of single-layer stratocumulus during the Mixed-Phase Arctic Cloud Experiment: 1. Observations, J. Geophys. Res., 112, D24201, doi:10.1029/2007JD008633, 2007.

McInnes, H., Kristiansen, J., Kristjánsson, J. E., Schyberg, H.: The role of horizontal resolution for polar low simulations, Q. J. Roy. Meteor. Soc., 137, 1674-1687, 2011.

McPhee, M.: Air-Ice-Ocean Interaction: Turbulent Ocean Boundary Layer Ex- change Processes, Springer Verlag, 215 pp., 2008.

McPhee, M. G., Maykut, G. A., and Morison, J. H.: Dynamics and thermodynamics of the ice/upper ocean system in the marginal ice zone of the Greenland Sea, J. Geophys. Res., 92, 7017-7031, 1987.

McPhee, M. G., Kottmeier, C., and Morrison, J. H.: Ocean heat ux in the central Weddell Sea in winter, J. Phys. Oceanogr., 29, 11661179, 1999.

Meehl, G., Washington, W., Arblaster, J., Hu, A., Teng, H., Kay, J., Gettelman, A., Lawrence, D., Sanderson, B., and Strand, W.: Climate change projections in CESM1(CAM5) compared to CCSM4, J. Clim., 26, 6287-6308, doi:10.1175/JCLI-D-1200572.1, 2013.

Medeiros, B., Deser, C., Tomas, R. A., and Kay, J. E.: Arctic Inversion Strength in Climate Models. J. Clim., 24, 4733-4740, doi:10.1175/2011jcli3968.1, 2011.
Meier, W. N., Hovelsrud, G. K., van Oort, B. E. H., Key, J. R., Kovacs, K. M., Michel, C., Haas, C., Granskog, M. A., Gerland, S., Perovich, D. K., Makshtas, A., and Reist, J. D.: Arctic sea ice in transformation: A review of recent observed changes and impacts on biology and human activity, Rev. Geophys., 15, doi:10.1002/2013RG000431, 2014.

Middag, R., de Baar, H. J. W., Laan, P., and Bakker, K.: Dissolved aluminium and the silicon cycle in the Arctic Ocean, Marine Chem., 115, 176-195, doi:10.1016/j.marchem.2009.08.002, 2009.

Molteni, F., Stockdale, T., Balmaseda, M., Balsamo, G., Buizza, R., Ferranti, L., Magnusson, L., Mogensen, K., Palmer, T., and Vitart, F.: The new ECMWF seasonal forecast system (System 4), European Centre for Medium Range Weather Forecasts, Reading, England, 2011.

Moore, G. W. K.: A new look at Greenland flow distortion and its impact on barrier flow, tip jets and coastal oceanography, Geophys. Res. Lett., 39, L22806, doi:10.1029/2012GL054017, 2012.

Moore, G. W. K. and Pickart, R. S.: Northern Bering Sea tip jets, Geophys. Res. Lett., 39, L08807, doi:10.1029/2012GL051537, 2012.

Morrison, H., de Boer, G., Feingold, G., Harrington, J., Shupe, M. D., and Sulia, K.: Resilience of persistent Arctic mixed-phase clouds, Nature Geosci., 5, 11-17, doi:10.1038/NGE01332, 2012.

Müller-Stoffels, M. and Wackerbauer, R.: Albedo parametrization and reversibility of sea ice decay, Nonlin. Proc. Geophys., 19, 81-94, doi:10.5194/npg-19-81-2012, 2012.

Mundy, C. J., Ehn, J. K., Barber, D. G., and Michel, C.: Influence of snow cover and algae on the spectral dependence of transmitted irradiance through Arctic landfast first-year sea ice, J. Geophys. Res., 112, C03007, doi:10.1029/2006JC003683, 2007.

Nicolaus, M., Haas, C., and Bareiss, J.: Observations of superimposed ice formation at melt-onset on fast ice on Kongsfjorden, Svalbard, Phys. Chem. Earth, 28, 1241-1248, 2003.

Nicolaus, M., Gerland, S., Hudson, S. R., Hanson, S., Haapala, J., and Perovich, D. K.: Seasonality of spectral albedo and transmittance as observed in the Arctic Transpolar Drift in 2007, J. Geophys. Res., 115, C11011, doi:10.1029/2009JC006074, 2010a.

Nicolaus, M., Hudson, S. R., Gerland, S., and Munderloh, K.: A modern concept for autonomous and continuous measurements of spectral albedo and transmittance of sea ice, Cold Reg. Sci. Technol. 62, 14-28, 2010b.

Nicolaus, M., Petrich, C., Hudson, S. R., and Granskog, M. A.: Variability of light transmission through Arctic land-fast sea ice during spring, The Cryosphere, 7, 977-986, doi:10.5194/tc-7-9772013, 2013.

Nordeng, T. E., Brunet, G., and Caughey, J.: Improvement of weather forecasts in polar regions, WMO Bulletin 56, 2007.

Notz, D.: Challenges in simulating sea ice in Earth System Models, WIREs, Clim. Change, 3, 509-526, doi:10.1002/wcc.189, 2012.

Notz, D. and Worster, M. G.: Desalination processes of sea ice revisited, J. Geophys. Res., 114, C05006, doi:10.1029/2008JC004885, 2009.

Notz, D., McPhee, M. G., Worster, M. G., Maykut, G., Schlünzen, K. H., and Eicken, H.: Impact of underwater-ice evolution on Arctic summer sea ice, J. Geophys. Res., 108, 3223, doi:10.1029/2001JC001173, 2003.

Nygård, T., Valkonen, T., and Vihma, T.: Characteristics of Arctic low-tropospheric humidity inversions based on radio soundings, 
Atmos. Chem. Phys., 14, 1959-1971, doi:10.5194/acp-14-19592014, 2014.

Outten, S. D., Renfrew, I. A., and Petersen, G. N.: An easterly tip jet off Cape Farewell, Greenland. Part II: Simulations and dynamics, Q. J. Roy. Meteor. Soc., 135, 1934-1949, 2009.

Outten, S. D., Renfrew, I. A., and Petersen, G. N.: Erratum to "An easterly tip jet off Cape Farewell, Greenland. II: Simulations and dynamics", Q. J. Roy. Meteor. Soc., 136, 1099-1101, 2010.

Overland, J. E., McNutt, S. L., Groves, J., Salo, S., Andreas, E. L., and Persson, P. O. G.: Regional sensible and radiative heat flux estimates for the winter Arctic during the Surface Heat Budget of the Arctic Ocean (SHEBA) experiment, J. Geophys. Res., 105, 14093-14102, 2000.

Overland, J. E., Wang, M., and Salo, S.: The recent Arctic warm period, Tellus, Ser. A, 60, 589-597, doi:10.1111/j.1600-0870-2008, 2008.

Overland, J. E., Wang, M., Walsh, J. E., Christensen, J. H., Kattsov, V. M., and Champan, W. L.: Chapter 3: Climate model projections for the Arctic. In Snow, Water, Ice and Permafrost in the Arctic (SWIPA), Oslo, Arctic Monitoring and Assessment Programme (AMAP), 2011.

Padman, L.: Small-Scale Physical Processes in the Arctic Ocean, Arctic Oceanography, Marginal Ice Zones and Continental Shelves, 97-129, 1995.

Palmer, T. and Williams, P.: Stochastic Physics and Climate Modelling, Cambridge University Press, Cambridge, UK, 480 pp., 2010.

Pavelsky, T. M., Boe, J., Hall, A., and Fetzer, E. J.: Atmospheric inversion strength over polar oceans in winter regulated by sea ice, Clim. Dynam., 36, 945-955, doi:10.1007/s00382-010-07568, 2011.

Pedersen, C. A., Roeckner, E., Lüthje, M., and Winther, J.-G.: A new sea ice albedo scheme including melt ponds for ECHAM5 general circulation model, J. Geophys. Res., 114, D08101, doi:10.1029/2008JD010440, 2009.

Peltoniemi, J. I.: Spectropolarised ray-tracing simulations in densely packed particulate medium, J. Quant. Spectrosc. Radiat. Transf., 108, 180-196, doi:10.1016/j.jqsrt.2007.05.009, 2007.

Perovich, D. K.: Light reflection and transmission by a temperate snow cover, J. Glaciol., 53, 201-210, 2007.

Perovich, D. K. and Polashenski, C.: Albedo evolution of seasonal Arctic sea ice, Geophys. Res. Lett., 39, L08501, doi:10.1029/2012g1051432, 2012.

Perovich, D. K., Nghiem, S. V., Markus, T., and Schweiger, A.: Seasonal evolution and interannual variability of the local solar energy absorbed by the Arctic sea ice-ocean system, J. Geophys. Res., 112, C03005, doi:10.1029/2006jc003558, 2007a.

Perovich, D. K., Light, B., Eicken, H., Jones, K. F., Runciman, K., and Nghiem, S. V.: Increasing solar heating of the Arctic Ocean and adjacent seas, 1979-2005: Attribution and role in the ice-albedo feedback, Geophys. Res. Lett., 34, L19505, doi:10.1029/2007GL031480, 2007b.

Perovich, D. K., Grenfell, T. C., Light, B., Elder, B. C., Harbeck, J., Polashenski, C., Tucker, W. B., and Stelmach, C.: Transpolar observations of the morphological properties of Arctic sea ice, J. Geophys. Res., 114, doi:10.1029/2008JC004892, 2009.

Persson, P. O. G.: Onset and end of the summer melt season over sea ice: thermal structure and surface energy perspective from SHEBA, Clim. Dynam. 39, 1349-1371, 2012.
Persson, P. O. G., Fairall, C. W., Andreas, E. L., Guest, P. G., and Perovich, D. K.: Measurements near the Atmospheric Surface Flux Group tower at SHEBA: Near-surface conditions and surface energy budget, J. Geophys. Res., 107, 8045, doi:10.1029/2000JC000705, 2002.

Petersen, G. N. and Renfrew, I. A.: Aircraft-based observations of air-sea fluxes over Denmark Strait and the Irminger Sea during high wind speed conditions, Q. J. Roy. Meteor. Soc., 135, 2030 2045, doi:10.1002/qj.355, 2009.

Petersen, G. N., Renfrew, I. A., and Moore, G. W. K.: An overview of barrier winds off southeastern Greenland during GFDex, Q. J. Roy. Meteor. Soc., 135, 1950-1967, 2009.

Pirazzini, R. and Räisänen, P.: A method to account for surface albedo heterogeneity in single-column radiative transfer calculations under overcast conditions, J. Geophys. Res., 113, C03005, doi:10.1029/2008jd009815, 2008.

Pithan, F. and Mautitsen, T.: Arctic amplification dominated by temperature feedbacks in contemporary climate models, Nature Geosci., 7, 181-184, doi:10.1038/ngeo2071, 2014.

Polashenski, C., Perovich, D., and Courville, Z.: The mechanisms of sea ice melt pond formation and evolution, J. Geophys. Res., 117, C01001, doi:10.1029/2011JC007231, 2012.

Polyakov, I. V., Timokhov, L. A., Alexeev,V. A., Bacon, S., Dmitrenko, I. A., Fortier, L., Frolov, I. E., Gascard, J.-C., Hansen, E., Ivanov, V. V., Laxon, S., Mauritzen, C., Perovich, D., Shimada, K., Simmons, H. L., Sokolov, V. T., Steele, M., Toole, J.: Arctic Ocean warming contributes to reduced polar ice cap, J. Phys. Oceanogr., 40, 2743-2756, doi:10.1175/2010JPO4339.1, 2010.

Polyakov I.V., Pnyushkov, A., Rember, R., Ivanov, V. V., Lenn, Y.D., Padman, L., and Carmack, E. C.: Mooring-based observations of double-diffusive staircases over the Laptev Sea slope, J. Phys. Oceanogr., 42, 95-109, doi:10.1175/2011JPO4606.1, 2012.

Porter, D. F., Cassano, J. J., and Serreze, M. C.: Analysis of the Arctic atmospheric energy budget in WRF: A comparison with reanalyses and satellite observations, J. Geophys. Res., 116, D22108, doi:10.1029/2011jd016622, 2011.

Postlethwaite, C. F., Morales Maqueda, M. A., le Fouest, V., Tattersall, G. R., Holt, J., and Willmott, A. J.: The effect of tides on dense water formation in Arctic shelf seas, Ocean Sci., 7, 203217, doi:10.5194/os-7-203-2011, 2011.

Prenni, A. J., Harrington, J. Y., Tjernström, M., DeMott, P. J., Avramov, A., Long, C. N., Kreidenweis, S. M., Olsson, P. Q., and Verlinde, J.: Can Ice-Nucleating Aerosols Affect Arctic Seasonal Climate, B. Am. Meteorol. Soc., 88, 541-550, doi:10.1175/BAMS-88-4-541, 2007.

Pringle, D. J., Eicken, H., Trodahl, H. J., and Backstrom, L. G. E.: Thermal conductivity of landfast Antarctic and Arctic sea ice, J. Geophys. Res., 112, C04017, doi:10.1029/2006JC003641, 2007.

Quinn, P. K., Bates, T. S., Baum, E., Doubleday, N., Fiore, A. M., Flanner, M., Fridlind, A., Garrett, T. J., Koch, D., Menon, S., Shindell, D., Stohl, A., and Warren, S. G.: Short-lived pollutants in the Arctic: their climate impact and possible mitigation strategies. Atmos. Chem. Phys., 8, 1723-1735, doi:10.5194/acp8-1723-2008, 2008.

Raddatz, R. L., Asplin, M. G., Candlish, L., and Barber, D. G.: General Characteristics of the Atmospheric Boundary Layer Over a 
Flaw Lead Polynya Region in Winter and Spring. Bound.-Layer Meterol., 138, 321-335, doi:10.1007/s10546-010-9557-1, 2011.

Rainville, L. and Winsor, P.: Mixing across the Arctic Ocean: Microstructure observations during the Beringia 2005 Expedition, Geophys. Res. Lett., 35, L08606, doi:10.1029/2008GL033532, 2008.

Rainville, L. and Woodgate, R. A.: Observations of internal wave generation in the seasonally ice-free Arctic, Geophys. Res. Lett., 36, L23604, doi:10.1029/2009GL041291, 2009.

Rainville, L., Lee, C. M., and Woodgate, R. A.: Impact of WindDriven Mixing in the Arctic Ocean, Oceanography, 24, 136-145, 2011.

Rampal, P., Weiss, J., and Marsan, D.: Positive trend in the mean speed and deformation rate of Arctic sea ice: 1979-2007, J. Geophys. Res., 114, C05013, 2009.

Rampal, P., Weiss, J., Dubois, C., and Campin, J. M.: IPCC climate models do not capture Arctic sea ice drift acceleration: Consequences in terms of projected sea ice thinning and decline, J. Geophys. Res., 116, C00D07, 2011.

Rasmussen, E. A. and Turner, J.: Polar lows: mesoscale weather systems in the polar regions, xi, 612 p. pp., Cambridge University Press, Cambridge, UK, New York, 2003.

Renfrew, I. A.: Polar lows, The Encyclopedia of the Atmospheric Sciences, 3, 1761-1768, edited by: Holton, J. R., Pylem J., and Curry, J. A., Academic Press, 2003.

Renfrew, I. A., Moore, G. W. K., Kristjansson, J. E., Olafsson, H., Gray, S. L., Petersen, G. N., Bovis, K., Brown, P. R. A., Føre, I, Haine, T, Hay, C, Irvine, E. A., Lawrence, A., Ohigashi, T., Outten, S., Pickart, R. S., Shapiro, M., Sproson, D., Swinbank, R., Woolley, A., Zhang, S.: The Greenland Flow Distortion experiment, B. Am. Meteorol. Soc., 89, 1307-1324, 2008.

Renfrew, I. A., Outten, S. D., and Moore, G. W. K.: An easterly tip jet off Cape Farewell, Greenland. Part I: Aircraft observations, Q. J. Roy. Meteor. Soc., 135, 1919-1933, 2009a.

Renfrew, I. A., Petersen, G. N., Sproson, D. A. J., Moore, G. W. K., Adiwidjaja, H., Zhang, S., and North, R.: A comparison of aircraft-based surface-layer observations over Denmark Strait and the Irminger Sea with meteorological analyses and QuikSCAT winds, Q. J. Roy. Meteor. Soc., 135, 2046-2066, doi:10.1002/qj.444, 2009b.

Rees Jones, D. W. and Worster, M. G.: Fluxes through steady chimneys in a mushy layer during binary alloy solidification. J. Fluid Mech., 714, 127-151, 2013a.

Rees Jones, D. W. and Worster, M. G.: A simple dynamical model for gravity drainage of brine from growing sea ice. Geophys. Res. Lett., 40(2), 307-311, doi:10.1029/2012GL054301, 2013b.

Reeve, M. A. and Kolstad, E. W.: The Spitsbergen South Cape tip jet. Q. J. Roy. Meteor. Soc., 137, 1739-1748, 2011.

Reuder, J., Jonassen, M., and Olafsson, H.: The Small Unmanned Meteorological Observer SUMO: Recent developments and applications of a micro-UAS for atmospheric boundary layer research, Acta Geophys., 60, 1454-1473, doi:10.2478/s11600012-0042-8, 2012.

Revelle, D. O. and Nilsson, E. D.: Summertime low-level jets over the high-latitude Arctic Ocean, J. Appl. Meteorol. Clim., 47, 1770-1784, doi:10.1175/2007JAMC1637.1, 2008.

Riihelä, A., Manninen, T., Laine, V., Andersson, K., and Kaspar, F.: CLARA-SAL: a global 28 yr timeseries of Earth's black-sky surface albedo, Atmos. Chem. Phys., 13, 3743-3762, doi:10.5194/acp-13-3743-2013, 2013.

Rösel, A., Kaleschke, L., and Birnbaum, G.: Melt ponds on Arctic sea ice determined from MODIS satellite data using an artificial neural network, The Cryosphere, 6, 431-446, doi:10.5194/tc-6431-2012, 2012.

Rudels, B., Anderson, L. G., and Jones, E. P.: Formation and evolution of the surface mixed layer and halocline of the Arctic Ocean, J. Geophys. Res., 101, 8807-8822, 1996.

Rudels, B., Björk, G., Muench, R. D., and Schauer, U.: Doublediffusive layering in the Eurasian Basin of the Arctic Ocean, J Mar. Sys., 21, 3-27, 1999.

Rudels, B., Schauer, U., Björk, G., Korhonen, M., Pisarev, S., Rabe, B., and Wisotzki, A.: Observations of water masses and circulation with focus on the Eurasian Basin of the Arctic Ocean from the 1990 s to the late 2000s, Ocean Sci., 9, 147-169, doi:10.5194/os-9-147-2013, 2013.

Saetra, O., Linders, T., and Deberbard, J. B.: Can polar lows lead to a warming of the ocean surface?, Tellus A, 60, 141-153, 2008.

Sankelo, P., Haapala, J., Heiler, I., and Rinne, E.: Melt pond formation and temporal evolution at the drifting station Tara during summer 2007, Polar Res., 29, 311-321, doi:10.1111/j.17518369.2010.00161.x, 2010.

Screen, J. A. and Simmonds, I.: Increasing fall-winter energy loss from the Arctic Ocean and its role in Arctic temperature amplification, Geophys. Res. Lett., 37, L16707, doi:10.1029/2010GL044136, 2010a.

Screen, J. A. and Simmonds, I.: The central role of diminishing sea ice in recent Arctic temperature amplification, Nature, 464, 1334-1337, 2010b.

Screen, J. A., and Simmonds, I.: Declining summer snowfall in the Arctic: causes, impacts and feedbacks, Clim. Dynam., 38, 2243 2256, doi:10.1007/s00382-011-1105-2, 2012.

Scott, F. and Feltham, D. L.: A model of the three-dimensional evolution of Arctic melt ponds on first-year and multiyear sea ice, J. Geophys. Res., 115, C12064, doi:10.1029/2010JC006156, 2010.

Sedlar, J. and Devasthale, A.: Clear-sky thermodynamic and radiative anomalies over a sea ice sensitive region of the Arctic, J Geophy. Res., 117, D19111, doi:10.1029/2012JD017754, 2012.

Sedlar, J. and Shupe, M. D.: Characteristic nature of vertical motions observed in Arctic mixed-phase stratocumulus, Atmos. Chem. Phys., 14, 3461-3478, doi:10.5194/acp-14-3461-2014, 2014.

Sedlar, J. and Tjernström, M.: Stratiform Cloud-Inversion Characterization During the Arctic Melt Season, Bound.-Layer Meterol., 132, 455—474, doi:10.1007/s10546-009-9407-1, 2009.

Sedlar, J., Tjernström, M., Mauritsen, T., Shupe, M., Brooks, I., Persson, P. O., Birch, C., Leck, C., Sirevaag, A., and Nicolaus, M.: A transitioning Arctic surface energy budget: the impacts of solar zenith angle, surface albedo and cloud radiative forcing, Clim. Dynam., 37, 1643-1660, doi:10.1007/s00382-010-0937-5, 2011.

Sedlar, J., Shupe, M. D., and Tjernström, M.: On the Relationship between thermodynamic structure and cloud top, and its climate significance in the Arctic. J. Climate, 25, 2374-2393, doi:10.1175/jcli-d-11-00186.1, 2012.

Semmler, T., Cheng, B., Yang, Y., and Rontu, L.: Snow and ice on Bear Lake (Alaska) - sensitivity experiments 
with two lake ice models, Tellus A 2012, 64, 17339, doi:10.3402/tellusa.v64i0.17339, 2012.

Send, U. and Marshall, J.: Integral effects of deep convection, J. Phys. Oceanogr., 25, 855-872, 1995.

Serreze, M. C. and Barry, R. G.: Processes and impacts of Arctic amplification: A research synthesis, Global Planet. Change, 77, 85-96, doi:10.1016/j.gloplacha.2011.03.004, 2011.

Serreze, M. C., Kahl, J. D. W., and Schnell, R. C.: Low-level temperature inversions of the Eurasian Arctic 5 and comparisons with Soviet drifting stations, J. Climate, 8, 719-731, 1992.

Serreze, M. C., Barrett, A. P., and Cassano, J. J.: Circulation and surface controls on the lower tropospheric temperature field of the Arctic, J. Geophys. Res., 116, D07104, doi:10.1029/2010JD015127, 2011.

Serreze, M. C., Barrett, A. P., and Stroeve, J.: Recent changes in tropospheric water vapor over the Arctic as assessed from radiosondes and atmospheric reanalyses, J. Geophys. Res., 117, D10104, doi:10.1029/2011jd017421, 2012.

Shaw, G. E.: Vertical distribution of tropospheric aerosols at Barrow, Alaska, Tellus, 27, 39-50, 1975.

Shaw, W. J., Stanton, T. P., McPhee, M. G., Morison, J. H., and Martinson, D. G.: Role of the upper ocean in the energy budget of arctic sea ice during SHEBA, J. Geophys. Res., 114, C06012, doi:10.1029/2008JC004991, 2009.

Shertzer, R. H. and Adams, E. E.: Anisotropic thermal conductivity model for dry snow, Cold Reg. Sci. Technol., 69, 122-128, doi:10.1016/j.coldregions.2011.09.005, 2011.

Shindell, D. and Faluvegi, G.: Climate response to regional radiative forcing during the twentieth century, Nature Geosci., 2, 294-300, doi:10.1038/ngeo473 10.1038/NGEO473, 2009.

Shupe, M. D.: Clouds at Arctic Observatories. Part II: Thermodynamic Phase Characteristics, J. Appl. Meteorol. Climatol., 50, 645-661, doi:10.1175/2010JAMC2468.1, 2011.

Shupe, M. D. and Intrieri, J. M.: Cloud radiative forcing of the Arctic surface: the influence of cloud properties, surface albedo, and solar zenith angle, J. Clim., 17, 616-628, 2004.

Shupe, M. D., Kollias, P., Persson, P. O. G., and McFarquhar, G. M.: Vertical Motions in Arctic Mixed-Phase Stratiform Clouds, J. Atmos. Sci., 65, 1304-1322, doi:10.1175/2007JAS2479.1, 2008.

Shupe, M. D., Walden, V. P., Eloranta, E., Uttal, T., Campbell, J. R., Starkweather, S. M., and Shiobara, M.: Clouds at Arctic atmospheric observatories. Part I: occurrence and macrophysical properties, J. Appl. Meteorol. Climatol., 50, 626-644, doi:10.1175/2010JAMC2467.1, 2011.

Shupe, M. D., Brooks, I. M., and Canut, G.: Evaluation of turbulent dissipation rate retrievals from Doppler Cloud Radar, Atmos. Meas. Tech., 5, 1375-1385, doi:10.5194/amt-5-1375-2012, 2012.

Shupe, M. D., Persson, P. O. G., Brooks, I. M., Tjernström, M., Sedlar, J., Mauritsen, T., Sjogren, S., and Leck, C.: Cloud and boundary layer interactions over the Arctic sea ice in late summer, Atmos. Chem. Phys., 13, 9379-9400, doi:10.5194/acp-139379-2013, 2013.

Sirevaag, A.: Turbulent exchange coefficients for the ice/ocean interface in case of rapid melting, Geophys. Res. Lett., 36, L04606, doi:10.1029/2008GL036587, 2009.

Sirevaag, A. and Fer, I.: Early spring oceanic heat fluxes and mixing observed from drift stations north of Svalbard, J. Phys. Oceanogr., 39, 3049-3069, 2009.
Sirevaag, A. and Fer, I.: Vertical heat transfer in the Arctic Ocean: The role of double-diffusive mixing, J. Geophys. Res., 117, C07010, doi:10.1029/2012jc007910, 2012.

Sirevaag, A., de la Rosa, S., Fer, I., Nicolaus, M., Tjernström, M., and McPhee, M. G.: Mixing, heat fluxes and heat content evolution of the Arctic Ocean mixed layer, Ocean Sci., 7, 335-349, doi:10.5194/os-7-335-2011, 2011.

Skyllingstad, E. D., Paulson, C. A., and Perovich, D. K.: Simulation of melt pond evolution on level ice, J. Geophys. Res., 114, C12019, doi:10.1029/2009JC005363, 2009.

Solomon, A., Shupe, M. D., Persson, P. O. G., and Morrison, H.: Moisture and dynamical interactions maintaining decoupled Arctic mixed-phase stratocumulus in the presence of a humidity inversion, Atmos. Chem. Phys., 11, 10127-10148, doi:10.5194/acp-11-10127-2011, 2011.

Sorbjan, Z. and Grachev, A. A.: An evaluation of the flux-gradient relationship in the stable boundary layer, Bound.-Layer Meteorol., 135, 385-405, 2010.

Sotiropoulou, G., Sedlar, J., Tjernström, M., Shupe, M. D., Brooks, I. M., and Persson, P. O. G.: The thermodynamic structure of summer Arctic stratocumulus and the dynamic coupling to the surface, Atmos. Chem. Phys. Discuss., 14, 3815-3874, doi:10.5194/acpd-14-3815-2014, 2014.

Spreen, G., Kwok, R., and Menemenlis, D.: Trends in Arctic sea ice drift and role of wind forcing: 1992-2009, Geophys. Res. Lett., 38, L19501, doi:10.1029/2011GL048970, 2011.

Sproson, D. A. J., Renfrew, I. A., and Heywood, K. J.: Atmospheric conditions associated with oceanic convection in the south-east Labrador Sea, Geophys. Res. Lett., 35, L06601, doi:10.1029/2007GL032971, 2008.

Sproson, D. A. J., Renfrew, I. A., and Heywood, K. J.: A Parameterization of Greenland's tip jets suitable for ocean or coupled climate models, J. Geophys. Res., 115, C08022, doi:10.1029/2009JC006002, 2010.

Steele, M., Zhang, J., and Ermold, W.: Mechanisms of summertime upper Arctic Ocean warming and the effect on sea ice melt, J. Geophys. Res., 115, C11004, doi:10.1029/2009jc005849, 2010.

Steeneveld, G. J., Wokke, M. J. J., Groot Zwaaftink, C. D., Pijlman, S., Heusinkveld, B. G., Jacobs, A. F. G., and Holtslag, A. A. M.: Observations of the radiation divergence in the surface layer and its implication for its parametrization in numerical weather prediction models, J. Geophys. Res., 115, D06107, doi:10.1029/2009JD013074, 2010.

Sterk, H. A. M., Steeneveld, G. J., and Holtslag, A. A. M.: The role of snow-surface coupling, radiation, and turbulent mixing in modeling a stable boundary layer over Arctic sea ice, J. Geophys. Res., 118, 1199-1217, doi:10.1002/jgrd.50158, 2013.

Straneo, F., Hamilton, G. S., Sutherland, D. A., Stearns, L. A., Davidson, F., Hammill, M. O., Stenson, G. B., and RosingAsvid, A.: Rapid circulation of warm subtropical waters in a major glacial fjord in East Greenland, Nature Geosci., 3, 182-186, 2010.

Stranne, C. and Björk, G.: On the Arctic Ocean ice thickness response to changes in the external forcing, Clim. Dynam., 39, 3007-3018, doi:10.1007/s00382-011-1275-y, 2011.

Stroeve, J. C., Kattsov, V., Barrett, A., Serreze, M., Pavlova, T., Holland, M., and Meier, W. N.: Trends in Arctic sea ice extent from CMIP5, CMIP3 and observations, Geophys. Res. Lett., 39, L16502, doi:10.1029/2012GL052676, 2012. 
Sukoriansky, S., Galperin, B., and Perov, V.: Application of a new spectral theory of stably stratified turbulence to the atmospheric boundary layer over ice. Bound.-Layer Meteorol., 117, 231-257, 2005.

Svensson, G. and Holtslag, A. A. M.: Analysis of model results for the turning of the wind and the related momentum fluxes and depth of the stable boundary layer, Bound.-Layer Meteorol., 132, 261-277, doi:10.1007/s10546-009-9395-1, 2009.

Taylor, P. C., Cai, M., Hu, A., Meehl, J., Washington, W., and Zhang, G. J.: A decomposition of feedback contributions to polar warming amplification, J. Clim. 26, 7023-7043, 2013.

Tetzlaff, A., Kaleschke, L., Lüpkes, C., Ament, F., and Vihma, T.: The impact of heterogeneous surface temperatures on the 2-m air temperature over the Arctic Ocean in spring, The Cryosphere, 7, 153-166, doi:10.5194/tc-7-153-2013, 2013.

Thorpe, A. J. and Guymer, T. H.: The nocturnal jet, Q. J. Roy. Meteor. Soc., 103, 633-653, 1977.

Tietsche, S., Notz, D., Jungclaus, J. H., and Marotzke, J.: Recovery mechanisms of Arctic summer sea ice, Geophys. Res. Lett., 38, doi:10.1029/2010GL045698, 2011.

Timmermans, M.-L., Toole, J., Krishfield, R. A., and Winsor, P.: Ice-tethered profiler observations of the double-diffusive staricase in the Canada Basin thermocline, J. Geophys. Res., 113, C00A02, doi:10.1029/2008JC004829, 2008.

Timmermans, M.-L., Cole, S. T., and Toole, J. M.: Horizontal density structure and restratification in the Arctic Ocean surface layer, J. Phys. Oceanogr., 42, 659-668, 2012.

Tisler, P., Vihma, T., Müller, G., and Brümmer, B.: Modelling of warm-air advection over Arctic sea ice, Tellus, 60A, 775-788, 2008.

Tjernström, M.: Is there a diurnal cycle in the summer cloudcapped arctic boundary layer?, J. Atmos. Sci., 64, 3970-3986, doi:10.1175/2007jas2257.1, 2007.

Tjernström, M. and Graversen, R. G.: The vertical structure of the lower Arctic troposphere analysed from observations and the ERA-40 reanalysis, Q. J. Roy. Meteor. Soc., 135, 431-443, doi:10.1002/qj.380, 2009.

Tjernström, M., Leck, C., Persson, P. O. G., Jensen, M. L., Oncley, S. P., and Targino, A.: The Summertime Arctic Atmosphere: Meteorological Measurements during the Arctic Ocean Experiment 2001, Bull. Amer. Meteorol. Soc., 85, 1305-1321, doi:10.1175/BAMS-85-9-1305, 2004.

Tjernström, M., Zagar, M., Svensson, G., Cassano, J. J., Pfeifer, S., Rinke, A., Wyser, K., Dethloff, K., Jones, C., Semmler, T., and Shaw M.: Modelling the Arctic boundary layer: an evaluation of six ARCMIP regional-scale models using data from the SHEBA project, Bound.-Layer Meteorol., 117, 337-381, 2005.

Tjernström, M., Sedlar, J., and Shupe, M. D.: How well do regional climate models reproduce radiation and clouds in the Arctic? An evaluation of ARCMIP simulations. J. Appl. Meteorol. Climatol., 47, 2405-2422, 2008.

Tjernström, M., Birch, C. E., Brooks, I. M., Shupe, M. D., Persson, P. O. G., Sedlar, J., Mauritsen, T., Leck, C., Paatero, J., Szczodrak, M., and Wheeler, C. R.: Meteorological conditions in the central Arctic summer during the Arctic Summer Cloud Ocean Study (ASCOS), Atmos. Chem. Phys., 12, 6863-6889, doi:10.5194/acp-12-6863-2012, 2012.

Tjernström, M., Leck, C., Birch, C. E., Bottenheim, J. W., Brooks, B. J., Brooks, I. M., Bäcklin, L., Chang, R. Y.-W., de Leeuw, G.,
Di Liberto, L., de la Rosa, S., Granath, E., Graus, M., Hansel, A., Heintzenberg, J., Held, A., Hind, A., Johnston, P., Knulst, J., Martin, M., Matrai, P. A., Mauritsen, T., Müller, M., Norris, S. J., Orellana, M. V., Orsini, D. A., Paatero, J., Persson, P. O. G., Gao, Q., Rauschenberg, C., Ristovski, Z., Sedlar, J., Shupe, M. D., Sierau, B., Sirevaag, A., Sjogren, S., Stetzer, O., Swietlicki, E., Szczodrak, M., Vaattovaara, P., Wahlberg, N., Westberg, M., and Wheeler, C. R.: The Arctic Summer Cloud Ocean Study (ASCOS): overview and experimental design, Atmos. Chem. Phys., 14, 2823-2869, doi:10.5194/acp-14-2823-2014, 2014.

Toole, J. M., Timmermans, M. L., Perovich, D. K., Krishfield, R. A., Proshutinsky, A., and Richter-Menge, J. A.: Influences of the ocean surface mixed layer and thermohaline stratification on Arctic Sea ice in the central Canada Basin, J. Geophys. Res., 115, C10018, doi:10.1029/2009jc005660, 2010.

Tsai, V. C. and McNamara, D. E.: Quantifying the influence of sea ice on ocean microseism using observations from the Bering Sea, Alaska, Geophys. Res. Lett., 38, L22502, doi:10.1029/2011GL049791, 2011.

Turner, A. K., Hunke, E. C., and Bitz, C. M.: Two modes of sea-ice gravity drainage: A parameterization for large-scale modeling, J. Geophys. Res., 118, 2279-2294, 2013.

Turner, J. S.: The melting of ice in the Arctic Ocean: the influence of double-diffusive transport of heat from below, J. Phys. Oceanogr., 40, 249-256, doi:10.1175/2009jpo4279.1, 2010.

Uotila, P., Holland, P. R., Vihma, T., Marsland, S. J., and Kimura, N.: Is realistic Antarctic sea ice extent in climate models the result of excessive ice drift?, Ocean Model., 79, 33-42, doi:10.1016/j.ocemod.2014.04.004, 2014.

Våge, K., Pickart, R. S., Moore, G. W. K., and Ribergaard, M. H.: Winter mixed layer development in the central Irminger Sea: The effect of strong, intermittent wind events, J. Phys. Oceanogr., 38, 541-565, 2008.

Valkonen, T., Vihma, T., and Doble, M.: Mesoscale modelling of the atmospheric boundary layer over the Antarctic sea ice: a late autumn case study, Mon. Weather Rev., 136, 1457-1474, 2008.

Vavrus, S., Walsh, J. E., Chapman, W. L., and Portis, D.: Behavior of extreme cold air outbreaks under greenhouse warming, Int. J. Climatol., 26, 1133-1147, 2006.

Vihma, T.: Effects of Arctic sea ice decline on weather and climate: A review. Surv. Geophys., DOI 10.1007/s10712-014-9284$0,2014$.

Vihma, T., Jaagus, J., Jakobson, E., and Palo, T.: Meteorological conditions in the Arctic Ocean in spring and summer 2007 as recorded on the drifting ice station Tara, Gephys. Res. Lett., 35, L18706, doi:10.1029/2008GL034681, 2008.

Vihma, T., Kilpeläinen, T., Manninen, M., Sjöblom, A., Jakobson, E., Palo, T., Jaagus, J., and Maturilli, M.: Characteristics of temperature and humidity inversions and low-level jets over Svalbard fjords in spring, Adv. Meteorol., 2011, 486807, doi:10.1155/2011/486807, 2011.

Vihma, T., Tisler, P., and Uotila, P.: Atmospheric forcing on the drift of Arctic sea ice in 1989-2009, Geophys. Res. Lett., 39, L02501, doi:10.1029/2011GL050118, 2012.

Voss, P. B., Hole, L. R., Helbling, E. F., Roberts, T. J.: Continuous In-Situ Soundings in the Arctic Boundary Layer: A New Atmospheric Measurement Technique Using Controlled Meteorological Balloons, J. Intell. Robot Syst., 70, 609-617, doi:10.1007/s10846-012-9758-6, 2013. 
Wagner, J. S., Gohm, A., Dörnbrack, A., and Schäfler, A.: The mesoscale structure of a polar low: airborne lidar measurements and simulations, Q. J. Roy. Meteor. Soc., 137, 1516-1531, 2011.

Walsh, D. and Carmack, E.: The nested structure of Arctic thermohaline intrusions, Ocean Model., 5, 267-289, 2003.

Walsh, J. E.: Intensified warming of the Arctic: causes and impacts on middle latitudes, Glob. Planet. Change, 117, 52-63, doi:10.1016/j.gloplacha.2014.03.003, 2014.

Wang, C., Granskog, M. A., Gerland, S., Hudson, S. R., Perovich, D. K., Nicolaus, M., Karlsen, T. I., Fossan, K., and Bratrein, M.: Autonomous observations of solar energy partitioning in firstyear sea ice in the Arctic Basin. J. Geophys. Res., 119, 20662080, doi:10.1002/2013JC009459, 2014.

Wang, Q., Jacob, D. J., Fisher, J. A., Mao, J., Leibensperger, E. M., Carouge, C. C., Le Sager, P., Kondo, Y., Jimenez, J. L., Cubison, M. J., and Doherty, S. J.: Sources of carbonaceous aerosols and deposited black carbon in the Arctic in winter-spring: implications for radiative forcing, Atmos. Chem. Phys., 11, 1245312473, doi:10.5194/acp-11-12453-2011, 2011.

Wang, S., Trishchenko, A. P., Khlopenkov, K. V., and Davidson, A.: Comparison of International Panel on Climate Change Fourth Assessment Report climate model simulations of surface albedo with satellite products over northern latitudes, J. Geophys. Res., 111, D21108, doi:10.1029/2005jd006728, 2006.

Weiss, J., Schulson, E. M., and Stern, H. L.: Sea ice rheology from in-situ, satellite and laboratory observations: Fracture and friction, Earth Planet. Sci. Lett., 255, 1-8, 2007.

Wells, A. J., Wettlaufer, J. S., and Orszag, S. A.: Brine fluxes from growing sea ice, Geophys. Res. Lett., 38, L04501, doi:10.1029/2010GL046288, 2011.

Wesslén, C., Tjernström, M., Bromwich, D. H., de Boer, G., Ekman, A. M. L., Bai, L.-S., and Wang, S.-H.: The Arctic summer atmosphere: an evaluation of reanalyses using ASCOS data, Atmos. Chem. Phys., 14, 2605-2624, doi:10.5194/acp-14-26052014, 2014.

Wetzel, C. and Brummer, B.: An Arctic inversion climatology based on the European Centre Reanalysis ERA-40. Meteorol. Zeitschr., 20, 589-600, doi:10.1127/0941-2948/2011/0295, 2011.
Widell, K., Fer, I., and Haugan, P. M.: Salt release from warming sea ice, Geophys. Res. Lett., 33, L12501, doi:10.1029/2006GL026262, 2006.

Wilson, A. B., Bromwich, D. H., and Hines, K. M.: Evaluation of Polar WRF forecasts on the Arctic System Reanalysis domain: Surface and upper air analysis, J. Geophys. Res., 116, D11112, doi:10.1029/2010JD015013, 2011.

Wyser, K., Jones, C. G., Du, P., Girard, E., Willén, U., Cassano, J., Christensen, J. H., Curry, J. A., Dethloff, K., Haugen, J. E., Jacob, D., Køltzow, M., Laprise, R., Lynch, A., Pfeifer, S., Rinke, A., Serreze, M., Shaw, M. J., Tjernström, M., and Zagar, M.: An evaluation of Arctic cloud and radiation processes during the SHEBA year: simulation results from eight Arctic regional climate models, Clim. Dynam., 30, 203-223, doi:10.1007/s00382007-0286-1, 2008.

Yasunari, T. J., Koster, R. D., Lau, K. M., Aoki, T., Sud, Y. C., Yamazaki, T., Motoyoshi, H., and Kodama, Y.: Influence of dust and black carbon on the snow albedo in the NASA Goddard Earth Observing System version 5 land surface model, J. Geophys. Res., 116, D02210, doi:10.1029/2010JD014861, 2011.

Zahn, M. and von Storch, H.: Decreased frequency of North Atlantic polar lows associated with future climate warming. Nature, 467, 309-312, 2010.

Zhang, Y., Seidel, D. J., Golaz, J. C., Deser, C., and Tomas, R. A.: Climatological characteristics of Arctic and Antarctic Surface-Based Inversions, J. Clim., 24, 5167-5186, doi:10.1175/2011JCLI4004.1, 2011.

Zilitinkevich, S. S. and Esau, I. N.: Resistance and heat-transfer laws for stable and neutral planetary boundary layers: old theory advanced and re-evaluated, Q. J. Roy. Meteorol. Soc., 131, 1863-1892, 2005.

Zilitinkevich, S. S., Elperin, T., Kleeorin, N., Rogachevskii, I., and Esau, I.: A Hierarchy of Energy- and Flux-Budget (EFB) Turbulence Closure Models for Stably-Stratified Geophysical Flows, Bound.-Layer Meteorol., 146, 341-373, doi:10.1007/s10546012-9768-8, 2013. 